\title{
SITUAÇÕES CRÍTICAS NO PROJETO DE EDIFÍCIOS DE CONCRETO ARMADO SUBMETIDOS A AÇÕES DE CONSTRUÇÃO
}

\author{
Dissertação apresentada à Escola de \\ Engenharia de São Carlos da Universidade \\ de São Paulo, como parte dos requisitos \\ para a obtenção do Título de Mestre em \\ Engenharia de Estruturas.
}

Orientador: Prof. Dr. Márcio Roberto Silva Corrêa

\section{São Carlos}

2004 
Ofereço este trabalho aos meus pais,

Francisco e Ermelinda, meus grandes mestres.

"A vocês, que me deram a vida e me ensinaram a vivê-la com dignidade, não bastaria um obrigado. A vocês que me iluminaram os caminhos obscuros com afeto e dedicação, para que eu trilhasse sem medo e cheio de esperança, não bastaria um obrigado.

A vocês que se doaram inteiros e renunciaram aos seus sonhos, para que, muitas vezes, eu pudesse realizar o meu sonho, não bastaria um muito obrigado.

A vocês pais por natureza por opção e por amor não bastaria dizer que não tenho palavras para agradecer tudo isso.

Mas é o que me acontece agora, quando procuro sofregamente uma forma verbal de exprimir uma emoção ímpar. Uma emoção que palavras dificilmente traduziriam." 


\section{AGRADECIMENTOS}

A Deus - que é Pai, Filho e Espírito Santo - de quem procedem todas as bênçãos de minha vida.

Ao competente trabalho de orientação prestado pelo prof. Dr. Márcio Roberto Silva Corrêa, e, acima de tudo, pela amizade nestes anos de trabalho conjunto.

Aos funcionários do Departamento de Estruturas da EESC/USP, em especial à Maria Nadir Minatel pela sua dedicação e boa vontade.

À Coordenadoria de Aperfeiçoamento de Pessoal de Nível Superior - CAPES, pela bolsa de estudos fornecida.

Às minhas irmãs: Imalda, Maria Bernadete, Sirlei e ao meu irmão Miguel.

Aos amigos: Flávio e Marina Ciaco, Fábio, Fernanda, Alessandro, como também Alexandre Buttler e Glauco Pimenta pelo apoio e horas de descontração que passamos juntos.

E principalmente um obrigado especial à minha companheira Fabiana, que em todos os momentos ofereceu-me apoio, dedicação e muito amor. 


\section{RESUMO}

FREITAS, A. A. (2004). Situações críticas no projeto de edifícios de concreto armado submetidos a ações de construção. São Carlos, 2004. 103p. Dissertação (Mestrado) Escola de Engenharia de São Carlos, Universidade de São Paulo, 2004.

O presente trabalho consiste no estudo das ações construtivas e seus efeitos em edifícios de concreto armado. Para a avaliação desses efeitos é aplicado o Método das Estruturas Primárias em pavimentos de edifícios, verificando-se os Estados Limites durante a sua construção. São considerados edifícios com diferentes subsistemas horizontais, alterando-se o sistema de escoramento e o ciclo de construção. As condições de construção são comparadas com aquelas usualmente empregadas no projeto estrutural que considera o edifício submetido às ações finais $e$ com resistência do concreto aos 28 dias, buscando evidenciar as que são críticas. A partir dos resultados obtidos na pesquisa conclui-se que a situação usual de projeto está a favor da segurança para sistemas estruturais semelhantes aos apresentados e nas situações construtivas adotadas.

Palavras-chave: Ações construtivas, edifícios em concreto, estruturas primárias, sistemas de escoramentos, situações críticas. 


\section{ABSTRACT}

FREITAS, A. A. (2004). Critical situations in reinforced concrete building design subjected to construction loads. São Carlos, 2004. 103p. Dissertação (Mestrado) Escola de Engenharia de São Carlos, Universidade de São Paulo, 2004.

The present work deals with the structural effects of construction loads on reinforced concrete buildings. The evaluation of those effects is carried out on building floors with the Method of the Primary Structures, including the verification of all limit states during the construction phase. Alternative structural systems are considered for buildings, varying the formwork and the construction cycle. The usual structural design, which considers the building subjected to the total loads and concrete with the age of 28 days, is compared with the design base on the construction conditions, searching for the critical ones. From the results it is apparent that the usual structural design is safe for structural systems and construction conditions similar to those considered in this work.

Keywords: Construction loads; concrete buildings; primary structures; formwork; critical situations. 


\section{LISTA DE FIGURAS}

Figura 2.1 - Processo construtivo convencional com sistema temporário de apoio $(2+1)$

Figura 2.2 - Processo construtivo racionalizado com sistema temporário de apoio $(2+1)$.

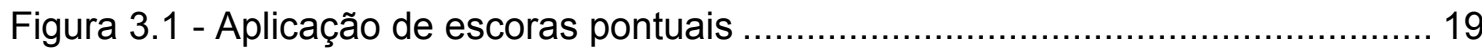

Figura 3.2 - Detalhe de ajuste de altura de escoras metálicas ................................. 20

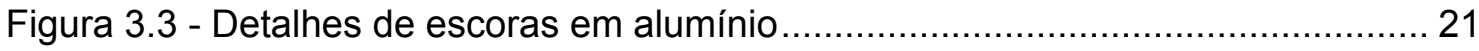

Figura 3.4 - Etapas construtivas e respectivas porcentagens para os colapsos de cimbramentos.

Figura 3.5 - Posição inadequada do reescoramento................................................. 25

Figura 4.1 - Etapa de concretagem de um pavimento - EP1 .................................. 32

Figura 4.2 - Etapa de retirada total de escoras ou reescoras - EP2 …...................... 32

Figura 4.3 - Etapa construtiva quando não há escoras ligadas à fundação rígida - EP3.

Figura 4.4 - Etapa com alteração de rigidez relativa escoramento/pavimento com reescoras ligadas à fundação - EP4

Figura 4.5 - Etapa com alteração de rigidez relativa escoramento/pavimento sem reescoras ligadas à fundação - EP5

Figura 5.1 - Desenho esquemático de uma longarina.

Figura 5.2 - Seqüência de montagem dos painéis de fôrmas no processo construtivo racionalizado.

Figura 5.3 - Desmontagem dos painéis de fôrmas no processo construtivo racionalizado.

Figura 5.4 - Tela de entrada de geometria do STRAP - versão 9.0 .......................... 44

Figura 6.1 - Planta de formas de meio pavimento tipo $(\mathrm{cm})$ - Laje Plana. ................... 53

Figura 6.2 - Distribuição das escoras pelo pavimento para o processo construtivo convencional $(\mathrm{cm})$ - Laje Plana

Figura 6.3 - Aspecto do pavimento tipo para o processo construtivo convencional (etapa construtiva) - Laje Plana

Figura 6.4 - Distribuição das escoras pelo pavimento para o processo construtivo racionalizado $(\mathrm{cm})$ - Laje Plana.

Figura 6.5 - Distribuição das reescoras com pré-carga pelo pavimento para o processo construtivo racionalizado $(\mathrm{cm})$ - Laje Plana

Figura 6.6 a - Caminhamento das cargas por pavimentos e escoramentos - Laje Plana

Figura 6.7 - Pontos do pavimento para verificação da segurança e da deformação excessiva - Laje Plana. 
Figura 6.8 - Arranjo arquitetônico de meio pavimento tipo $(\mathrm{cm})$ - Laje / Paredes de Alvenaria.

Figura 6.9 - Distribuição dos escoramentos para o processo construtivo convencional (cm) - Laje / Paredes de Alvenaria.....

Figura 6.10 - Aspecto do pavimento tipo para o processo construtivo convencional (etapa construtiva) - Laje / Paredes de Alvenaria. 71

Figura 6.11 - Pontos do pavimento para verificação da segurança e da deformação excessiva - Laje / Paredes de Alvenaria. 72

Figura 6.12 - Planta de formas de meio pavimento tipo $(\mathrm{cm})$ - Laje/Viga/Pilar. 77

Figura 6.13 - Aspecto do pavimento tipo para o processo construtivo convencional (etapa construtiva) - Laje/Viga/Pilar.

Figura 6.14 - Distribuição dos escoramentos para o processo construtivo convencional (cm) - Laje/Viga/Pilar.. 79

Figura 6.15 - Distribuição das escoras para o processo construtivo racionalizado $(\mathrm{cm})$ - Laje/Viga/Pilar..... 80

Figura 6.16 - Distribuição das reescoras com pré-carga para o processo construtivo racionalizado $(\mathrm{cm})$ - Laje/Viga/Pilar.

Figura 6.17 - Pontos do pavimento para verificação da segurança e da deformação excessiva - Laje/Viga/Pilar. 83 


\section{LISTA DE TABELAS}

Tabela 2.1 - Análises das variáveis que possivelmente influenciam nos fatores de carga (k).

Tabela 5.1 - Pesos específicos dos materiais. 39

Tabela 5.2 - Variáveis e opções.

Tabela 5.3 - Situações construtivas adotadas.

Tabela 5.4 - Dimensões de painéis de fôrmas - processo construtivo racionalizado. . 42

Tabela 6.1 - Quantitativos e medidas para meio pavimento tipo - Laje Plana. 53

Tabela 6.2 - Proporções de absorção de carga - Laje Plana e $\mathrm{f}_{\mathrm{ck}}=30 \mathrm{MPa}$. 56

Tabela 6.3 - Proporções de absorção de carga - Laje Plana e $\mathrm{f}_{\mathrm{ck}}=20 \mathrm{MPa}$. 56

Tabela 6.4 - $A_{s e}$ para pontos de laje - Laje Plana e $\mathrm{f}_{\mathrm{ck}}=20 \mathrm{MPa}$. 64

Tabela 6.5 - $A_{\text {sn }}$ para os pontos PL1 e PL2 - Laje Plana e $f_{c k}=20 M P a$. 64

Tabela 6.6 - Comparação entre armaduras - Laje Plana e $\mathrm{f}_{\mathrm{ck}}=20 \mathrm{MPa}$. 64

Tabela 6.7 - $\mathrm{A}_{\mathrm{se}}$ para os pontos PL1 e PL2 - Laje Plana e $\mathrm{f}_{\mathrm{ck}}=30 \mathrm{MPa}$. ..................... 65

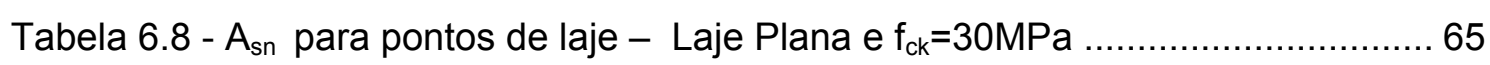

Tabela 6.9 - Comparação entre armaduras - Laje Plana e $f_{c k}=30 M P a \ldots \ldots \ldots \ldots \ldots \ldots \ldots . . . . . . . . .65$

Tabela 6.10 - Deslocamento limite total no ponto PL1 - Laje Plana............................ 66

Tabela 6.11 - Deslocamento usual no ponto PL1 - Laje Plana e $\mathrm{f}_{\mathrm{ck}}=20 \mathrm{MPa}$............... 66

Tabela 6.12 - Deslocamentos finais no ponto PL1 - Laje Plana e $\mathrm{f}_{\mathrm{ck}}=20 \mathrm{Mpa}$. .............66

Tabela 6.13 - Deslocamento usual no ponto PL1 - Laje Plana e $\mathrm{f}_{\mathrm{ck}}=30 \mathrm{MPa}$.............. 68

Tabela 6.14 - Deslocamentos finais no ponto PL1 - Laje Plana e $\mathrm{f}_{\mathrm{ck}}=30 \mathrm{MPa}$............. 68

Tabela 6.15 - Quantitativos e medidas para meio pavimento tipo - Laje / Paredes de Alvenaria.

Tabela 6.16 - Proporções de absorção de carga - Laje / Paredes de Alvenaria e

$\mathrm{f}_{\mathrm{ck}}=20 \mathrm{MPa}$.

Tabela 6.17 - Proporções de absorção de carga - Laje / Paredes de Alvenaria e $\mathrm{f}_{\mathrm{ck}}=30 \mathrm{MPa}$. 72

Tabela 6.18 - $A_{\text {se }}$ para pontos de laje - Laje / Paredes de Alvenaria e $f_{c k}=20 M P a . \ldots . .73$

Tabela 6.19 - $A_{s n}$ para os pontos PL e PA - Laje / Paredes de Alvenaria e $f_{c k}=20 M P a$.

Tabela 6.20 - Comparação entre armaduras - Laje / Paredes de Alvenaria e $\mathrm{f}_{\mathrm{ck}}=20 \mathrm{MPa}$. .73

Tabela 6.21 - $A_{\text {se }}$ para pontos de laje - Laje / Paredes de Alvenaria e $f_{c k}=30 M P a$.... 74

Tabela 6.22 - $A_{s n}$ para pontos de laje - Laje / Paredes de Alvenaria e $f_{c k}=30 M P a . . . . .74$

Tabela 6.23 - Comparação entre armaduras - Laje / Paredes de Alvenaria e $\mathrm{f}_{\mathrm{ck}}=30 \mathrm{MPa}$. 
Tabela 6.24 - Deslocamento limite total no ponto PL - Laje / Paredes de Alvenaria... 75

Tabela 6.25 - Deslocamento usual no ponto PL - Laje / Paredes de Alvenaria e

$\mathrm{f}_{\mathrm{ck}}=20 \mathrm{MPa}$.

Tabela 6.26 - Deslocamentos finais no ponto PL - Laje / Paredes de Alvenaria e $\mathrm{f}_{\mathrm{ck}}=20 \mathrm{MPa}$.

Tabela 6.27 - Deslocamento usual no ponto PL - Laje / Paredes de Alvenaria e

$\mathrm{f}_{\mathrm{ck}}=30 \mathrm{MPa}$.

Tabela 6.28 - Deslocamento final no ponto PL - Laje / Paredes de Alvenaria e

$\mathrm{f}_{\mathrm{ck}}=30 \mathrm{MPa}$.

Tabela 6.29 - Quantitativos e medidas para meio pavimento tipo - Laje/Viga/Pilar. ... 78

Tabela 6.30 - Proporções de absorção de carga - Laje/Viga/Pilar e $f_{c k}=20 M P a$......... 82

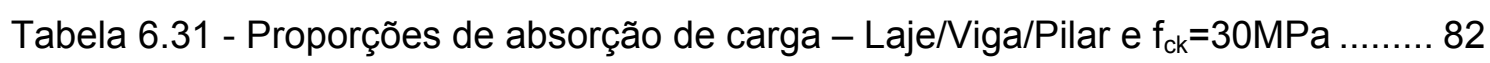

Tabela 6.32 - $\mathrm{A}_{\text {se }}$ para pontos de laje - Laje/Viga/Pilar e $\mathrm{f}_{\mathrm{ck}}=20 \mathrm{MPa}$......................... 83

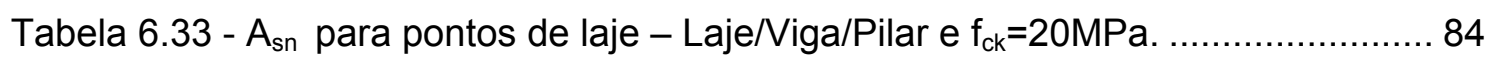

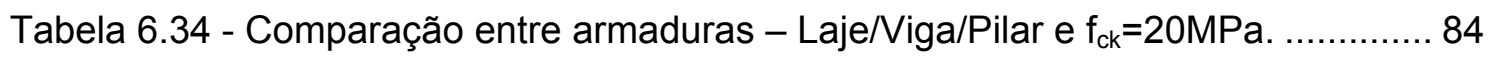

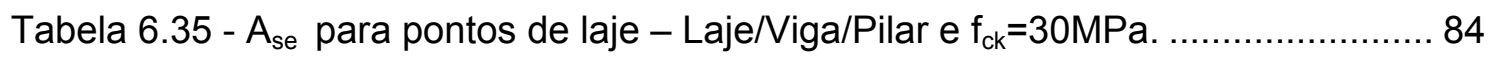

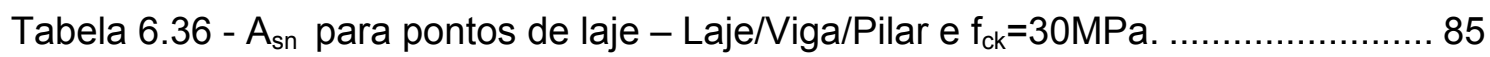

Tabela 6.37 - Comparação entre armaduras - Laje/Viga/Pilar e $\mathrm{f}_{\mathrm{ck}}=30 \mathrm{MPa}$. ............. 85

Tabela 6.38 - $A_{\text {se }}$ e $A_{\text {swe }}$ para pontos de viga - Laje/Viga/Pilar e $f_{c k}=20 M P a \ldots \ldots \ldots \ldots \ldots . . . . .85$

Tabela 6.39 - $A_{s n}$ e $A_{s w n}$ para pontos de viga - Laje/Viga/Pilar e $f_{c k}=20 M P a \ldots \ldots \ldots \ldots . . . . .86$

Tabela 6.40 - Comparação entre armaduras longitudinais - Laje/Viga/Pilar e

$\mathrm{f}_{\mathrm{ck}}=20 \mathrm{MPa}$.

Tabela 6.41 - Comparação entre armaduras transversais - Laje/Viga/Pilar e

$\mathrm{f}_{\mathrm{ck}}=20 \mathrm{MPa}$.

Tabela 6.42 - $A_{\text {se }}$ e $A_{\text {swe }}$ para pontos de viga - Laje/Viga/Pilar e $f_{c k}=30 M P a \ldots \ldots \ldots \ldots \ldots . . . . .87$

Tabela 6.43 - $A_{s n}$ e $A_{\text {swn }}$ para pontos de viga - Laje/Viga/Pilar e $f_{c k}=30 M P a \ldots \ldots \ldots \ldots \ldots . . . . .87$

Tabela 6.44 - Comparação entre armaduras longitudinais - Laje/Viga/Pilar e

$\mathrm{f}_{\mathrm{ck}}=30 \mathrm{MPa}$.

Tabela 6.45 - Comparação entre armaduras transversais - Laje/Viga/Pilar e

$\mathrm{f}_{\mathrm{ck}}=30 \mathrm{MPa}$.

Tabela 6.46 - Deslocamento limite total no ponto PL2 - Laje/Viga/Pilar...................... 88

Tabela 6.47 - Deslocamento usual no ponto PL2 - Laje/Viga/Pilar e $\mathrm{f}_{\mathrm{ck}}=20 \mathrm{MPa} \ldots \ldots . . .88$

Tabela 6.48 - Deslocamentos finais no ponto PL2 - Laje/Viga/Pilar e $f_{c k}=20 M P a \ldots . . .89$

Tabela 6.49 - Deslocamento usual no ponto PL2 - Laje/Viga/Pilar e $\mathrm{f}_{\mathrm{ck}}=30 \mathrm{MPa}$. ....... 89

Tabela 6.50 - Deslocamentos finais no ponto PL2 - Laje/Viga/Pilar e $f_{c k}=30 M P a \ldots . . .90$

Tabela 6.51 - Deslocamento limite total no ponto PL3 - Laje/Viga/Pilar..................... 90

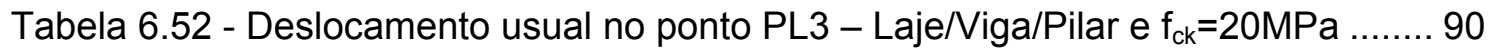

Tabela 6.53 - Deslocamentos finais no ponto PL3 - Laje/Viga/Pilar e $f_{c k}=20 M P a \ldots \ldots . .91$ 
Tabela 6.54 - Deslocamento usual no ponto PL3 - Laje/Viga/Pilar e $\mathrm{f}_{\mathrm{ck}}=30 \mathrm{MPa}$. 92

Tabela 6.55 - Deslocamentos finais no ponto PL3 - Laje/Viga/Pilar e $f_{c k}=30 M P a \ldots \ldots . .92$

Tabela 6.56 - Deslocamento limite total no ponto PV2 - Laje/Viga/Pilar. 93

Tabela 6.57 - Deslocamento usual no ponto PV2 - Laje/Viga/Pilar e $\mathrm{f}_{\mathrm{ck}}=20 \mathrm{Mpa}$. ...... 93

Tabela 6.58 - Deslocamentos finais no ponto PV2 - Laje/Viga/Pilar e $f_{c k}=20$ MPa. .... 94

Tabela 6.59 - Deslocamento usual no ponto PV2 - Laje/Viga/Pilar e $\mathrm{f}_{\mathrm{ck}}=30 \mathrm{MPa} \ldots \ldots . .95$

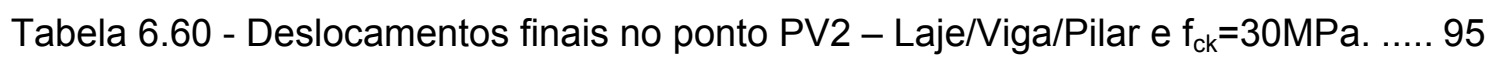




\section{LISTA DE ABREVIATURAS E SIGLAS}

$\begin{array}{ll}\text { ABNT } & \text { - Associação Brasileira de Normas Técnicas } \\ \text { ACI } & \text { - American Concrete Institute } \\ \text { ANSI } & \text { - American National Standards Institute } \\ \text { ASCE } & \text { - American Society of Civil Engineers } \\ \text { CAPES } & \text {-Coordenadoria de Aperfeiçoamento de Pessoal de Nível Superior } \\ \text { EESC } & \text { - Escola de Engenharia de São Carlos } \\ \text { EMBRAMEM } & \text {-Encontro Brasileiro em Madeiras e em Estruturas de Madeira } \\ \text { IBRACON } & - \text { Instituto Brasileiro do Concreto } \\ \text { NBR } & - \text { Norma Brasileira Registrada } \\ \text { PUC } & \text { - Pontifícia Universidade Católica } \\ \text { SET } & - \text { Departamento de Engenharia de Estruturas } \\ \text { STRAP } & - \text { Structural Analisys Program } \\ \text { UFMG } & - \text { Universidade Federal de Minas Gerais } \\ \text { USP } & - \text { Universidade de São Paulo }\end{array}$




\section{LISTA DE SIMBOLOS}

g - ação do peso próprio do pavimento por $\mathrm{m}^{2}$

k $\quad$ - fator de carga construtiva

$\mathrm{f}_{\mathrm{ck}} \quad$ - resistência característica à compressão do concreto

$\gamma_{g} \quad$ - coeficiente de ponderação das ações características verticais permanentes

$\gamma_{q} \quad$ - coeficiente de ponderação das ações características verticais variáveis

$\gamma_{c} \quad$ - coeficiente de minoração da resistência do concreto

$\gamma_{s} \quad$ - coeficiente de minoração da resistência da armadura

$\psi_{2} \quad$ - fator de redução para as ações variáveis

$\Delta_{\mathrm{e}} \quad$ - deslocamento elástico

$\Delta_{\mathrm{i}} \quad$ - deslocamento imediato

$\Delta_{l} \quad$ - deslocamento correspondente à deformação lenta

$\Delta_{r} \quad$ - deslocamento correspondente à deformação por retração

$\Delta_{f} \quad$ - deslocamento final correspondente à situação construtiva de projeto

$\Delta_{\mathrm{u}} \quad$ - deslocamento calculado de forma usual

$\Delta_{\mathrm{t}} \quad$ - deslocamento limite total incluindo contra flecha

$M_{a} \quad-\quad$ momento fletor atuante

$M_{r} \quad$ - momento de fissuração

Ie $\quad-$ momento de inércia efetivo

Ig - momento de inércia da seção bruta

L - vão entre apoios do elemento estrutural

$\mathrm{CP} \quad$ - cimento portland 
$v_{c} \quad-\quad$ coeficiente de Poisson do concreto

$\mathrm{A}_{\mathrm{sn}} \quad$ - armadura longitudinal necessária

$\mathrm{A}_{\mathrm{se}} \quad$ - armadura longitudinal existente

$A_{\text {swn }} \quad$ - armadura transversal necessária

$\mathrm{A}_{\text {swe }} \quad-$ armadura transversal existente

$V_{\mathrm{Rd} 2} \quad$ - força cortante resistente de cálculo

$V_{S d} \quad$ - força cortante solicitante de cálculo 


\section{SUMÁRIO}

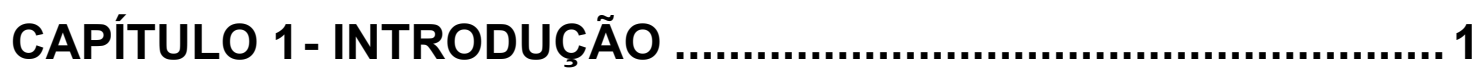

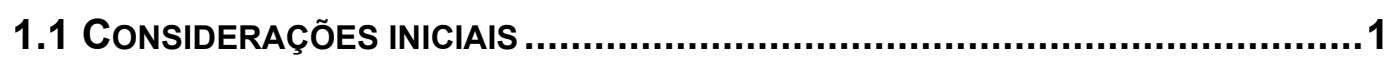

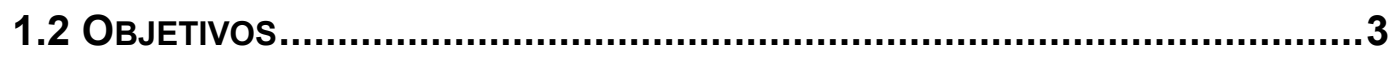

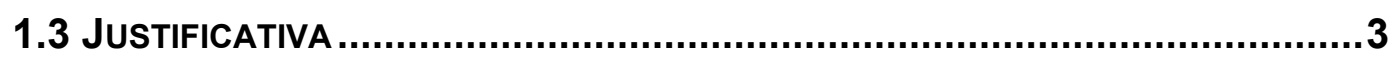

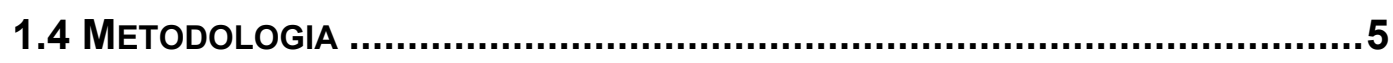

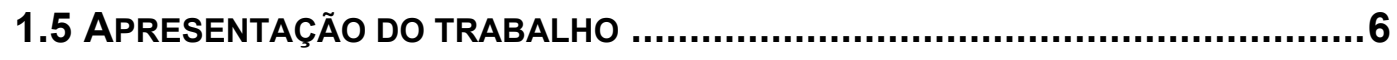

CAPÍTULO 2- AÇÕES DE CONSTRUÇÃO ................................... 7

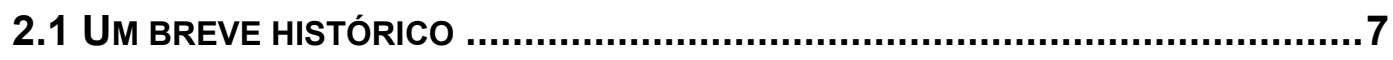

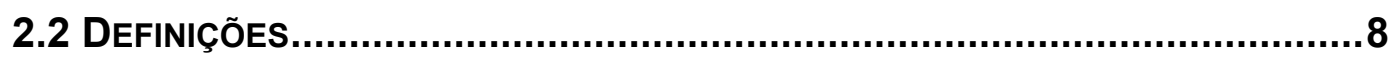

2.3 PROCESSOS CONSTRUTIVOS DAS ESTRUTURAS DE CONCRETO ....................9

2.3.1 PROCESSO CONSTRUTIVO CONVENCIONAL ...................................

2.3.2 PROCESSO CONSTRUTIVO RACIONALIZADO ………........................ 10

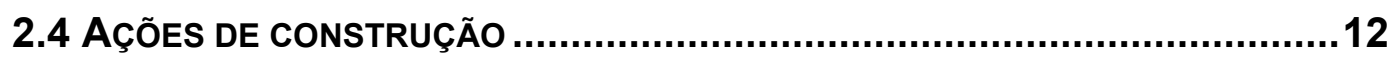

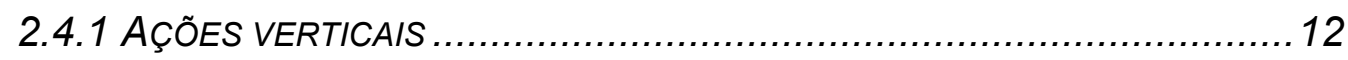

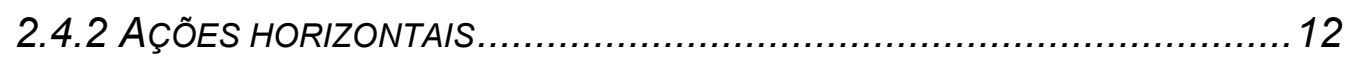

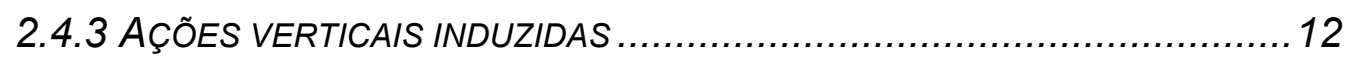

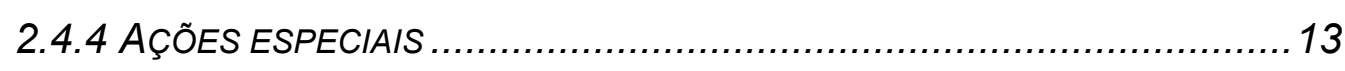

2.5 DISPOSIÇÕES NORMATIVAS RELACIONADAS ÀS ETAPAS CONSTRUTIVAS ....13

2.6 FATORES QUE INFLUENCIAM A DISTRIBUIÇÃO DAS AÇÕES DE CONSTRUÇÃO. 14

2.7 EVOLUÇÃO DOS CARREGAMENTOS DE CONSTRUÇÃO ...............................15

2.8 Probabilidade de ColaPSo eStRUtURAL........................................16

\section{CAPÍTULO 3- SISTEMAS DE ESCORAMENTOS PARA} EDIFÍCIOS............................................................................ 18

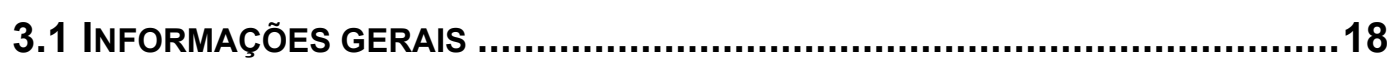

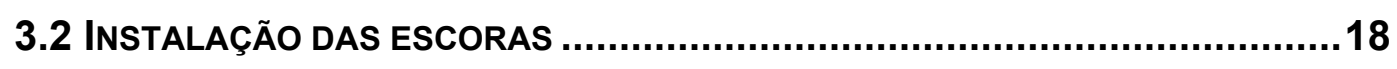

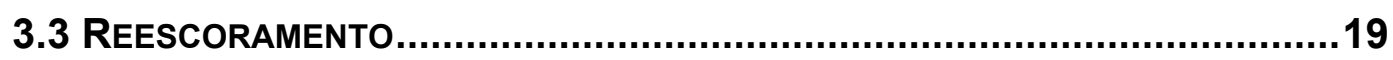

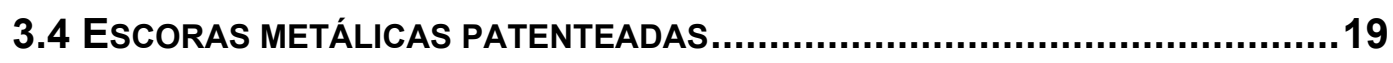


3.4.1 DETALHE DE ESCORA METÁLICA EXTENSIVIEL 20

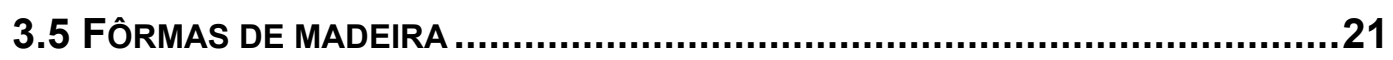

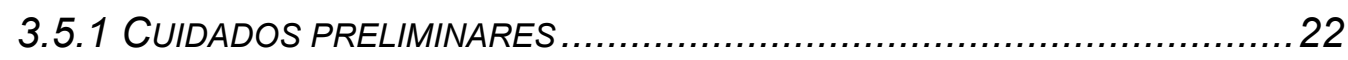

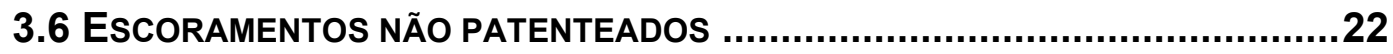

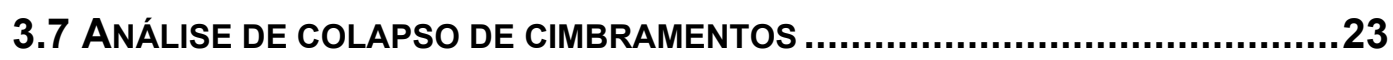

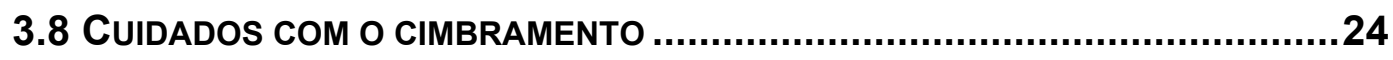

CAPÍTULO 4- MÉTODO DAS ESTRUTURAS PRIMÁRIAS E FUNDAMENTOS DA MODELAGEM.......................................... 27

4.1 UM BREVE HISTÓRICO .......................................................................27

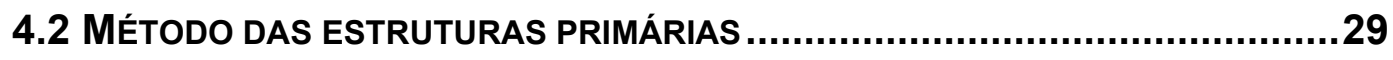

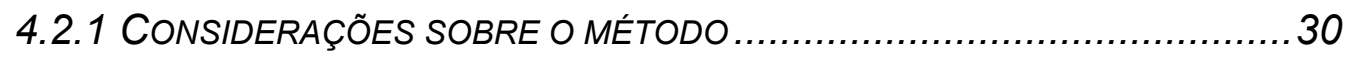

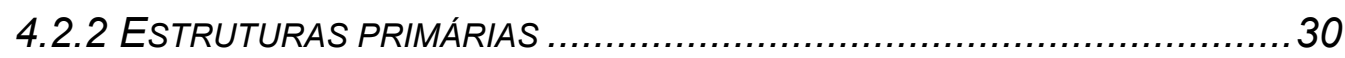

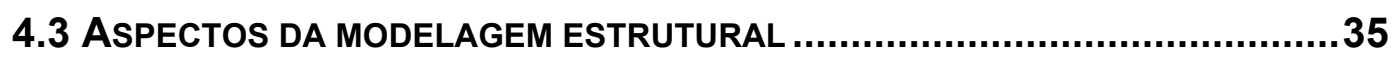

4.3.1 SUBDIVISÕES DO SISTEMA ESTRUTURAL: ELEMENTOS ESTRUTURAIS

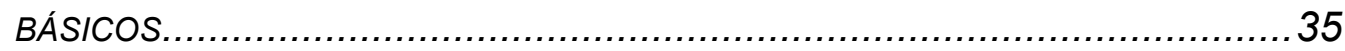

4.3.2 MÉTODOS NUMÉRICOS: MÉTODO DOS ELEMENTOS FINITOS.................36

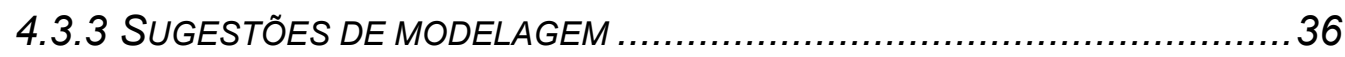

CAPÍTULO 5- CARACTERÍSTICAS DO TRABALHO................... 38

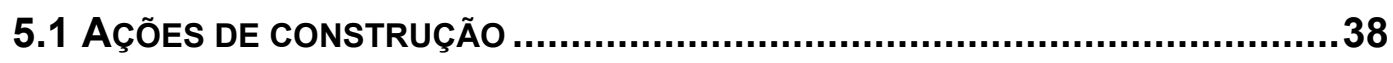

5.2 SitUAÇÕES CONSTRUTIVAS ADOTADAS .................................................39

5.3 ESCORAMENTO NÃO PATENTEADO ......................................................41

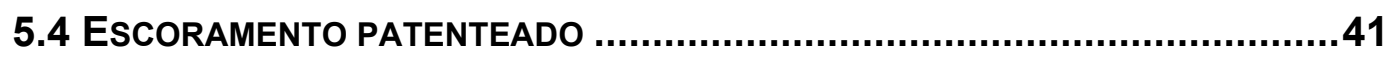

5.5 ESPAÇAMENTO ENTRE ESCORAS NOS PROCESSOS CONSTRUTIVOS ............43

5.6 ESCOLHA DO PROGRAMA COMPUTACIONAL E ASPECTOS DA MODELAGEM .44

5.7 CONSIDERAÇÕES SOBRE AS VERIFICAÇÕES DOS ESTADOS LIMITES .............45

5.7.1 METODOLOGIA PARA VERIFICAÇÃO DOS ESTADOS LIMITES DURANTE AS

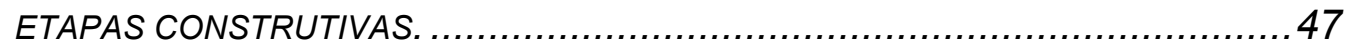

5.8 IDADES PARA AS ENTRADAS DOS CARREGAMENTOS .............................48

5.9 Características Do Concreto Jovem.............................................49

CAPÍTULO 6- ESTUDO DE CASOS E ANÁLISES ...................... 50 
6.1 DEFINIÇÕES E CONSIDERAÇÕES INICIAIS 50

6.2 LAJE PLANA APOIADA EM PILARES . 52

6.2.1 SISTEMAS DE ESCORAMENTOS E PONTOS PARA VERIFICAÇÃO DOS ESTADOS LIMITES. 53

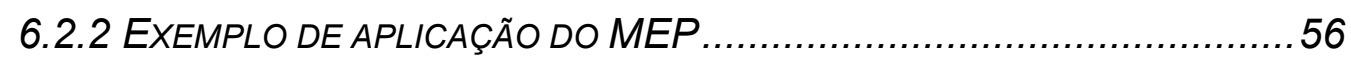

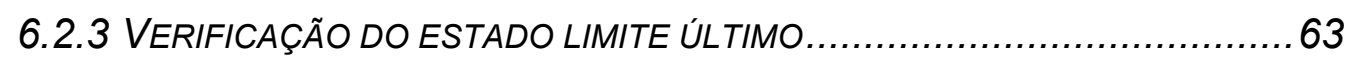

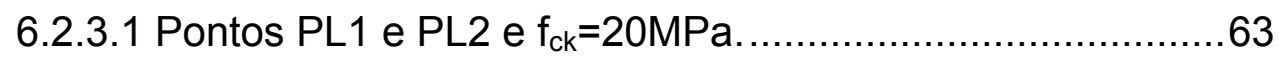

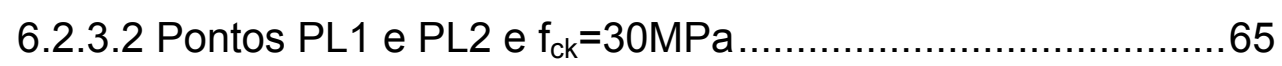

6.2.4 VERIFICAÇÃO DO ESTADO LIMITE DE SERVIÇO ..................................6

6.2.4.1 Deslocamento limite total para o ponto PL1 …..................66

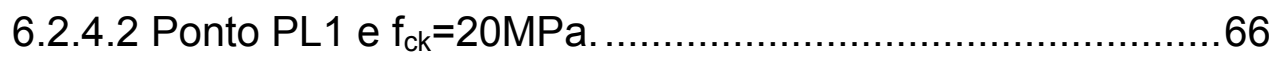

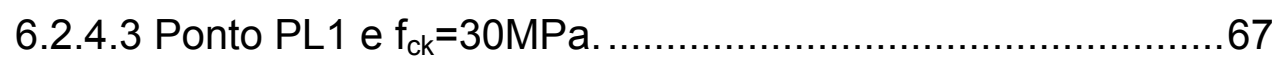

6.3 LAJES APOIADAS EM PAREDES DE ALVENARIA ESTRUTURAL.....................69

6.3.1 SISTEMAS DE ESCORAMENTOS E PONTOS PARA VERIFICAÇÃO DOS

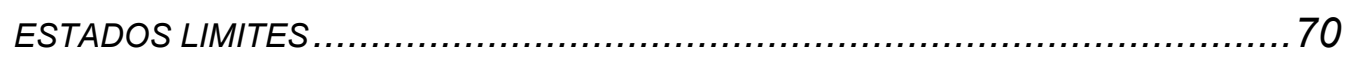

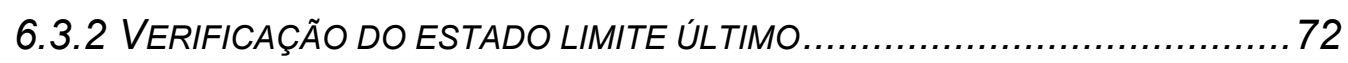

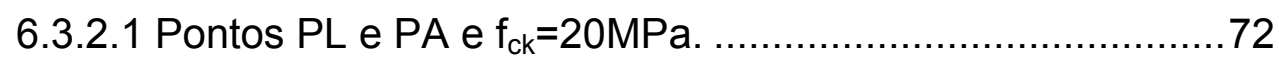

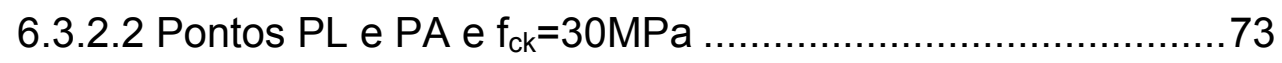

6.3.3 VERIFICAÇÃO DO ESTADO LIMITE DE SERVIÇO................................. 74

6.3.3.1 Deslocamento limite total para o ponto PL........................74

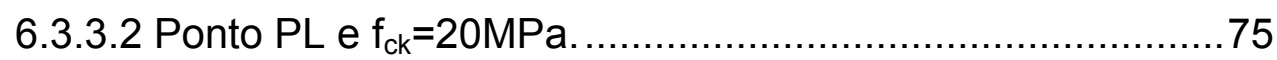

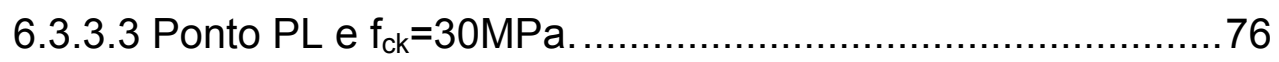

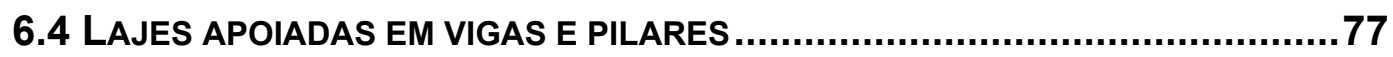

6.4.1 SISTEMAS DE ESCORAMENTOS E PONTOS PARA VERIFICAÇÃO DOS

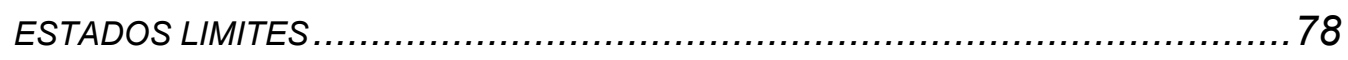

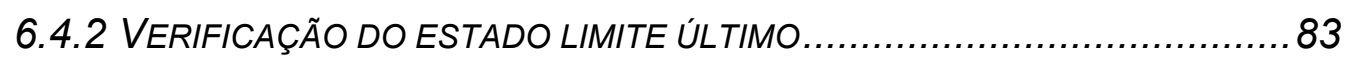

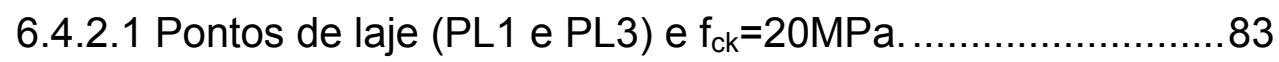

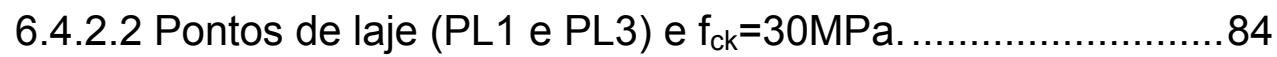

6.4.2.3 Pontos de viga (PV1, PV2 e PV3) e $\mathrm{f}_{\mathrm{ck}}=20 \mathrm{MPa}$................85

6.4.2.4 Pontos de viga (PV1, PV2 e PV3) e $\mathrm{f}_{\mathrm{ck}}=30 \mathrm{MPa}$................86

6.4.3 VERIFICAÇÃO DO ESTADO LIMITE DE SERVIÇO ................................. 88

6.4.3.1 Deslocamento limite total para o ponto PL2 .................... 88

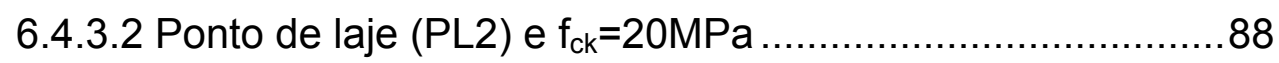

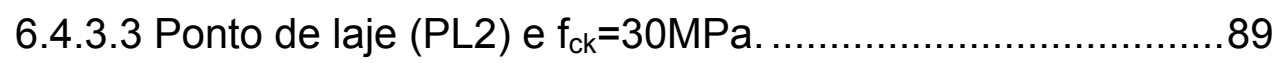

6.4.3.4 Deslocamento limite total para o ponto PL3 .....................90

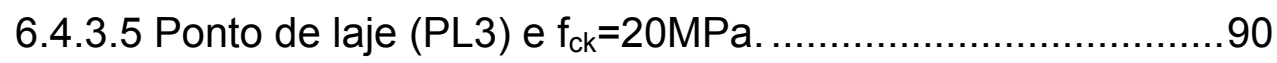

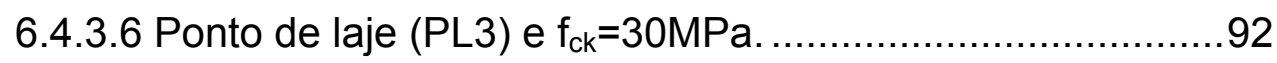


6.4.3.7 Deslocamento limite total para o ponto PV2 - Viga V12:

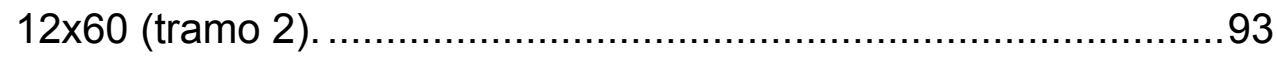

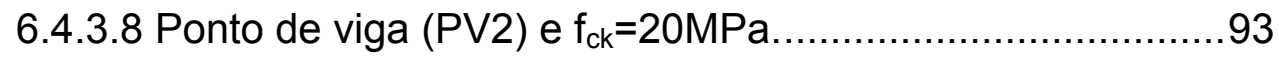

6.4.3.9 Ponto de viga (PV2) e $\mathrm{f}_{\mathrm{ck}}=30 \mathrm{MPa}$...................................95

CAPÍTULO 7- CONCLUSÕES ...................................................... 96

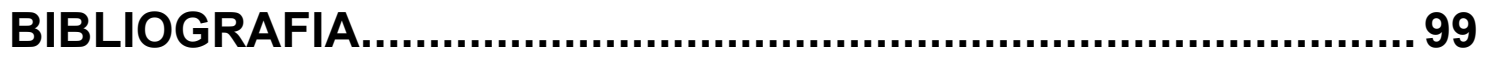




\section{CAPÍTULO 1 - INTRODUÇÃO}

\subsection{CONSIDERAÇÕES INICIAIS}

A estrutura de um edifício de concreto armado é normalmente projetada para resistir apenas às ações atuantes finais, correspondentes à fase de ocupação do mesmo e considerando-se a resistência do concreto aos 28 dias. Entretanto, durante as etapas construtivas, a composição das ações a que a estrutura está submetida é bem diferente daquela inicialmente prevista.

Durante a construção de edifícios por processos convencionais, um pavimento recém concretado é temporariamente suportado por outros pavimentos, previamente executados (suportados por escoras e reescoras), até que o mesmo adquira resistência suficiente para absorver as cargas que nele incidem.

Conforme PRADO (1999), as ações que atuam nos pavimentos durante a construção podem ultrapassar as ações em serviço previstas usualmente no projeto. Além disso, as ações de construção solicitam o concreto antes que o mesmo tenha atingido as condições de resistência e deformabilidade previstas aos 28 dias. Tal situação é ainda agravada em edifícios residenciais e comerciais onde a ação variável de projeto é pequena comparada ao peso próprio da estrutura, ficando a mesma submetida a uma parcela bastante significativa da carga total de projeto já nas etapas iniciais de construção. Além do mais, a situação torna-se um pouco mais grave se for considerado que a tentativa de industrialização das atividades da construção civil, nos dias atuais, tem conduzido a uma tendência de aceleração na construção dos edifícios.

A distribuição das ações de construção entre os pavimentos interligados pelo sistema de escoramento depende de vários fatores. A cada nova etapa construtiva 
realizada, uma nova parcela de ação é absorvida pelo conjunto de lajes, curadas ou parcialmente curadas. Assim, ao longo da construção, a estrutura é submetida a esforços solicitantes que devem ser comparados aos esforços resistentes. Desta forma, a estrutura poderá apresentar em uma dada etapa de construção, razão entre esforço resistente e solicitante inferior àquela considerada no projeto, podendo com isso causar o aparecimento de fissuras, deformações excessivas, ou ainda colapso parcial ou total da estrutura. Nesse contexto, é oportuno lembrar que toda estrutura deve satisfazer às exigências de segurança e deformação adequadas aos limites normativos em qualquer idade, inclusive durante a construção. Assim, é imprescindível que o processo construtivo das estruturas de concreto seja estudado com a mesma atenção dada ao projeto estrutural, garantindo que as condições últimas e de serviço sejam admissíveis.

Além da diminuição do ciclo de construção utilizado para a execução de pavimentos em concreto armado, escoras, reescoras e lajes de concreto são muitas vezes solicitados com carregamentos de construção além dos previstos em projeto. Desta maneira, observa-se que a consideração das ações de construção nas estruturas de concreto é de suma importância para a garantia de segurança de uma obra.

O conhecimento das propriedades do concreto jovem, das ações ocorridas durante a construção e das deformações impostas por essas ações são relevantes para a verificação dos estados limites último e de serviço de uma estrutura.

A análise estrutural considerando as etapas construtivas, além de fornecer maior segurança ao longo da construção, pode oferecer subsídios para:

- Racionalizar os trabalhos de escoramento e reescoramento, considerando as idades corretas de instalação e remoção do sistema de escoramento;

- Otimizar o tempo de mobilização dos equipamentos sem comprometer a segurança estrutural;

- Adotar de forma correta o número necessário de pavimentos interligados simultaneamente, evitando a utilização desnecessária de pavimentos escorados ou reescorados;

- Reduzir a influência das ações de construção nas deformações da estrutura, etc. 


\subsection{OBJETIVOS}

O objetivo principal do trabalho consiste na análise comparativa entre as condições usualmente empregadas em projetos de edifícios de concreto armado e aquelas provenientes das ações de construção, com o emprego do Método das Estruturas Primárias desenvolvido por PRADO (1999). Objetiva-se realizar as análises apenas para lajes e vigas dos pavimentos, pois CORRÊA e RAMALHO (1993) já fizeram o estudo dos pilares e concluíram que, utilizando processos convencionais, não há qualquer tipo de problema com a segurança dos pilares durante as etapas construtivas.

Como objetivos específicos têm-se:

- Levantar os sistemas usuais de escoramento para diferentes tipos de subsistemas de pisos de edifícios, a saber: lajes de concreto apoiadas sobre paredes de alvenaria estrutural, lajes sobre vigas e pilares, lajes planas apoiadas em pilares;

- Verificar a influência de algumas variáveis nas ações de construção que ocorrem nos pavimentos interligados pelo sistema de escoramento;

- E finalmente, fazer uma avaliação das situações construtivas críticas no projeto do edifício.

\subsection{JUSTIFICATIVA}

De acordo com LEE et al. (1991) 70\% dos colapsos de estruturas de concreto armado têm sua origem em problemas construtivos (segundo estudos realizados na antiga União Soviética). Dentre esses problemas incluem-se a aplicação de ações não previstas sobre escoras, reescoras, lajes de apoio e principalmente remoção prematura do sistema de escoramento.

Nos últimos 25 anos ocorreram mais de 85 colapsos em estruturas de concreto durante a construção só nos Estados Unidos. Segundo STIVAROS e KAMINETZKY ${ }^{1}$ (1994) apud PRADO (1999), esses colapsos tiveram como causas a ruptura das escoras ou a ruptura do concreto, em virtude de ações de construção não previstas ou por causa da insuficiente resistência do concreto.

\footnotetext{
${ }^{1}$ STIVAROS, P.C.; KAMINETZKY, D. (1994). Early-age concrete: construction loads, behavior and failures. Concrete International, Vol. 16, No 1, Janeiro, pp. 58-63.
} 
Segundo CARINO² et al. (1983) apud RODRIGUES JÚNIOR (1996), um caso de desastre durante a etapa construtiva foi o do colapso parcial do edifício residencial Skyline Plaza, em 1973 nos Estados Unidos. Segundo os técnicos do National Bureal of Standards (NBS) encarregados de investigarem o acidente, o colapso teve como causa a remoção prematura do escoramento do vigésimo terceiro pavimento e a insuficiente resistência do concreto na data da remoção.

HADIPRIONO (1985) observou colapsos ocorridos em estruturas de edifícios de pequeno porte (até quatro pavimentos) e de grande porte (múltiplos pavimentos) cujas causas foram problemas ocorridos durante a construção e/ou projetos mal elaborados. Os colapsos durante a construção tiveram como causas deficiências nos trabalhos de escoramentos e operações de concretagem. Segundo esse mesmo autor, dos 57 casos estudados de colapsos em estruturas de pequeno porte foi observado que um terço desses tiveram como causa tais deficiências durante a construção. Com relação aos edifícios de múltiplos pavimentos foram estudados 13 colapsos de estruturas, dos quais quatro delas (31\%), também foram deficiências durante a construção.

No Brasil dois colapsos de edifícios de concreto armado ocorreram durante as etapas construtivas e deixaram vitimas fatais. O primeiro incidente ocorreu no anexo do Hotel Intercontinental em 1993 no Rio de Janeiro, causando a morte de duas pessoas e deixando onze feridos. O segundo refere-se a um prédio na zona norte da cidade de São Paulo em 1994, o qual ocorreu após a remoção das escoras do segundo pavimento e resultou na morte de três pessoas.

No ano de 2003 ocorreu o colapso de um edifício durante a construção na cidade de Cascavel (PR). Autoridades julgaram que o incidente foi causado por um sistema de escoramento mal posicionado no piso do primeiro pavimento e pela insuficiente resistência do concreto. Neste desabamento não houve vítima fatal, mas dois operários ficaram feridos por causa da queda que sofreram de uma altura de 10 metros (DESABAMENTO..., 2003).

Problemas como os citados anteriormente ocorrem freqüentemente, uma vez que as etapas construtivas são definidas normalmente com base na experiência do construtor e na urgência de finalização da obra, ocorrendo muitas vezes falta de fiscalização adequada da obra e de planejamento do projeto ligado às etapas construtivas. Dificilmente a construção de um edifício é fruto de uma análise mais

${ }^{2}$ CARINO, N. J., WOODWARD, K. a, LEYENDECKER, E. V., AND FATTAL, S. G., A review of the Skyline Plaza collapse, Concrete International: Design e Construction, Vol. 5, No. 7, Julho, 1983, pp.35-42 
detalhada que envolva o conhecimento das características do concreto na etapa de retirada do sistema de escoramento e dos esforços solicitantes que ocorrem nas estruturas, bem como suas conseqüências nas verificações dos estados limites.

Muitos engenheiros tornaram-se "puros analistas" pois não se preocupam com o fato de que as ações de construção passam a ser significantes e decisivas para as verificações ligadas aos critérios de segurança contra a ruína de uma estrutura e, também, para satisfazer as suas condições de utilização. Tal situação é ainda agravada pela falta de informações mais detalhadas por parte das normas brasileiras relacionadas ao projeto da produção de estruturas, aos métodos de análise estrutural que não consideram as etapas construtivas necessárias às verificações dos estados limites e ao fato da maioria das estruturas serem projetadas apenas com base nas ações em serviço.

O advento de industrialização da construção civil aliado à utilização de novos materiais e diferentes concepções estruturais freqüentemente requer novas técnicas de construção. Dessa forma, engenheiros projetistas devem conhecer melhor o processo construtivo das estruturas e engenheiros de obras entender a interação entre projeto e execução, a fim de garantir a segurança durante as etapas construtivas.

Como justificativa final deste trabalho nota-se a existência de pouca pesquisa no Brasil sobre ações de construção como, também, verifica-se que as mesmas não tratam o assunto com a objetividade necessária.

\subsection{Metodologia}

Inicialmente o trabalho envolveu a familiarização com o Método das Estruturas Primárias desenvolvido por PRADO (1999), evidenciando a técnica utilizada para a modelagem dos pavimentos durante as etapas construtivas e a transferência das ações de construção entre os pavimentos interconectados pelo sistema de escoramento.

Posteriormente escolheu-se o "software" em elementos finitos que permitisse a modelagem tridimensional das estruturas necessárias à aplicação do método da estruturas primárias utilizado.

Visando melhor conhecimento das características do sistema de escoramento de lajes de concreto, foram feitos contatos com construtores de edifícios, produtores e fornecedores de escoramentos para a obtenção de informações sobre as condições de construção atualmente empregadas no Brasil. 
Projetos de edifícios com subsistemas estruturais diferentes foram escolhidos junto a projetistas de estruturas para a realização das análises propostas, buscando selecionar os de maior freqüência de utilização nos centros urbanos.

Na seqüência foi feita a modelagem estrutural das etapas construtivas segundo o método das estruturas primárias, utilizando o "software" previamente escolhido. Foi feito estudo paramétrico, procurando sempre confrontar as condições usuais de projeto com as geradas nas etapas construtivas. Foram considerados tanto os estados limites últimos como os de serviço.

Com base no estudo realizado, a pesquisa foi concluída com as observações mais importantes obtidas das análises desenvolvidas pelo trabalho.

\subsection{APRESENTAÇÃo do TRABALHO}

Uma vez exposto o problema a ser estudado e estabelecida uma metodologia de modo a dar indicações que servirão de base para que se alcance os objetivos deste trabalho, no Capítulo 2, serão descritos os aspectos relevantes ligados às ações de construção e aos fatores que influenciam a sua distribuição. Também serão identificados os processos construtivos das estruturas de concreto caracterizados pela seqüência de operações realizadas.

Algumas particularidades relacionadas aos sistemas de escoramentos, tais como detalhes de escoras e classificação do sistema de escoramento serão mostrados no Capítulo 3. Nesse mesmo capítulo serão apresentados alguns aspectos de segurança ligados ao cimbramento.

Os conceitos do método das estruturas primárias necessários para se determinar a distribuição das ações de construção por pavimentos interconectados pelos escoramentos serão mostrados no quarto capítulo. Também serão expostos aspectos importantes relacionados à modelagem estrutural.

O Capítulo 5 abordará as características tratadas nos capítulos anteriores e que serão adotadas por este trabalho.

A aplicação do método das estruturas primárias, verificação dos estados limites e as análises dos resultados serão realizados no Capítulo 6.

Finalmente, no Capítulo 7, serão apresentadas as conclusões obtidas a partir do estudo proposto. 


\section{CAPÍTULO 2 - AÇÕES DE CONSTRUÇÃO}

\subsection{UM BREVE HISTÓRICO}

Em 1937 Forslind e Ödma verificaram o estado limite de serviço relacionado a deformações excessivas em lajes armadas em duas direções durante a construção de edifícios de concreto. Os autores concluíram que para se obter uma análise satisfatória sobre as causas das deformações seria necessário determinar as ações as quais as lajes de concreto estariam submetidas durante o processo construtivo. Tal avaliação era justificada por não ter o concreto, durante este período, atingido sua resistência completa e por apresentar baixo módulo de elasticidade.

Como resultado da conclusão de investigação das deformações de lajes, desenvolvido por Forslind e Ödma, NIELSEN (1952) ${ }^{1}$ apud RODRIGUES JÚNIOR (1996) propôs o primeiro estudo relacionado ao cálculo das ações nas lajes e escoras durante a construção. Desse estudo, Nielsen publicou um trabalho com o título "Loads on Reinforced Concrete Floor Slabs and Their Deformations During Construction" e, a partir desta publicação, outros trabalhos têm sido desenvolvidos. Tais trabalhos incluem a consideração de métodos simplificados e refinados de cálculo para as ações de construção, desenvolvimento de procedimentos construtivos visando reduzir o valor das ações de construção e análises experimentais de processos construtivos.

\footnotetext{
${ }^{1}$ NIELSEN, K. E. C.(1952), Loads on Reinforced Concrete Floor Slabs and Their Deformations During Construction, Proc. No. 15, Swedish Cement and Concrete Research Institute, Royal Institute of Technology, Stockholm.
} 


\subsection{DEFINIÇÕES}

Para melhor entendimento do assunto serão feitas algumas definições importantes a seguir.

- Cimbramento: corresponde ao conjunto de construções provisórias, em geral constituídas por peças acopladas e depois desmontadas, destinadas a suportar ações permanentes e variáveis que ocorrem durante a execução das estruturas de concreto. O cimbramento deve transferir com segurança todas as solicitações atuantes para o solo ou para outra estrutura de apoio, como também, ser utilizado até que a estrutura se torne autoportante.

Os principais elementos do cimbramento são:

- Fôrmas: superfícies onde o concreto é lançado para moldar os elementos;

- Escoras ou pontaletes: elementos unidirecionais constituídos por diversos materiais utilizados para apoiar fôrmas de lajes e/ou vigas;

- Reescoras: elementos unidirecionais constituídos por diversos materiais utilizados para apoiar lajes parcialmente curadas após a remoção de fôrmas e escoras. Quando as reescoras são instaladas após completa remoção de escoras e fôrmas, permitindo a deformação das lajes, diz-se que as mesmas foram instaladas sem pré-carga, ou seja, sob tensão nula. Porém, quando algumas escoras permanecem na posição em que foram instaladas inicialmente, não permitindo a deformação das lajes depois de retirada parcial do escoramento, passam a ser chamadas de reescoras instaladas com pré-carga (sob tensão não nula).

Outras definições:

- Sistema temporário de apoio: conjunto de lajes curadas ou parcialmente curadas interligadas por escoras e/ou reescoras instaladas com ou sem pré-carga.

- Ciclo de construção: intervalo de tempo entre a concretagem de dois pavimentos consecutivos;

- Fator de carga construtiva: representação das ações de construção atuantes no sistema temporário de apoio em termos de peso próprio do pavimento por $\mathrm{m}^{2}(\mathrm{~g})$. Nas etapas de cálculo o peso próprio do pavimento será tomado como referência. Ao longo deste trabalho os fatores de carga serão expressos por $\mathbf{k}$. 


$$
k=\frac{\text { açẫo atuante no pavimento ou no pontalete }}{\text { peso próprio do pavimento }}
$$

\subsection{PROCEssos CONSTRUtivos dAS ESTRUTURAS DE CONCRETO}

As ações atuantes durante as etapas construtivas de uma estrutura são introduzidas pelo processo construtivo adotado, que, por sua vez, é caracterizado por uma seqüência repetida de operações. O processo construtivo das estruturas de concreto será definido pelas etapas de instalação e retirada dos elementos que constituem o cimbramento. Atualmente pode-se identificar dois processos construtivos das estruturas de concreto: processo construtivo convencional e processo construtivo racionalizado.

As características de cada processo construtivo serão apresentadas seguir.

\subsubsection{PROCEsso CONStRUtivo CONVENCIONAL}

O processo construtivo convencional caracteriza-se pela remoção total de escoras e fôrmas para a realização do reescoramento, ou seja, as reescoras são instaladas sem pré-carga. Este processo é utilizado principalmente em cimbramentos que fazem uso de escoras de madeira, embora escoras metálicas também possam ser utilizadas de maneira semelhante.

De forma geral este processo se realiza por uma seqüência repetida de operações. Normalmente existem cinco operações básicas de construção, em um sistema temporário de apoio que pode ter um número variado de níveis escorados e reescorados. Essas operações constituem-se em:

1. Remoção de reescoras do nível mais baixo;

2. Remoção total de escoras e fôrmas do nível mais baixo;

3. Instalação das reescoras no nível do pavimento onde as escoras e fôrmas foram removidas;

4. Instalação das escoras e fôrmas para a concretagem do próximo pavimento;

5. Concretagem. 
Caso o processo construtivo não utilize reescoras, as operações 1 e 3 serão eliminadas.

Como referência ao sistema temporário de apoio constituído de dois níveis de pavimentos escorados e um nível reescorado será utilizada a seguinte convenção: $(2+1)$. Da mesma forma, será utilizada a convenção: $(1+1)$ para o sistema temporário de apoio constituído por um nível escorado e um nível reescorado.

Como ilustração pode-se verificar na figura 2.1 as operações básicas de construção para o processo construtivo convencional com sistema temporário de apoio $(2+1)$.

\section{Convenções}

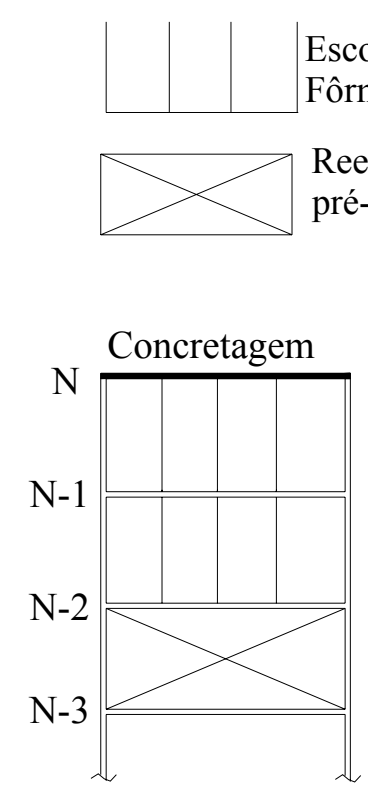

Etapa E

Escora /

Fôrma

Reescora sem pré-carga

Figura 2.1 - Processo construtivo convencional com sistema temporário de apoio $(2+1)$.

\subsubsection{PROCESSO CONSTRUTIVO RACIONALIZADO}

Nos últimos anos, em virtude da tendência de industrialização da construção civil, novos materiais como o aço e o alumínio passaram a ser utilizados na execução das escoras. Esses materiais viabilizaram o desenvolvimento de escoras extensíveis e permitiram a utilização de novas técnicas no processo construtivo. Dessa forma, o processo construtivo que faz uso dessas novas técnicas pode ser classificado como racionalizado, pois introduz vantagens comparadas ao processo convencional. 
A principal característica do processo construtivo racionalizado refere-se à possibilidade de retirada parcial das escoras e retirada das fôrmas, ou seja, algumas escoras permanecem na posição em que foram instaladas inicialmente (passando a ser chamadas de reescoras) e as restantes são retiradas. Dessa maneira, as reescoras estarão submetidas a compressão não nula e serão classificadas neste processo como reescoras com pré-carga.

No processo construtivo racionalizado normalmente existirão quatro operações básicas de construção com número variado de níveis escorados e reescorados. Essas operações constituem-se em:

1. Remoção do nível mais baixo de reescoras;

2. Remoção parcial do nível mais baixo de escoras e fôrmas (escoras não retiradas serão classificadas como reescoras);

3. Instalação das escoras e fôrmas para a concretagem do próximo pavimento;

4. Concretagem.

Como ilustração, nota-se na figura 2.2 as operações básicas para o processo construtivo racionalizado com sistema temporário de apoio $(2+1)$.

\section{Convenções}

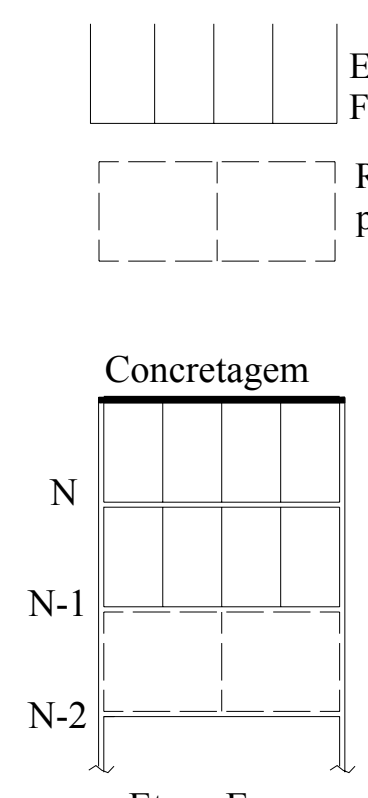

Etapa E

\section{Escora / \\ Fôrma \\ Reescora com pré-carga}

Figura 2.2 - Processo construtivo racionalizado com sistema temporário
Instalação de escoras e fôrmas

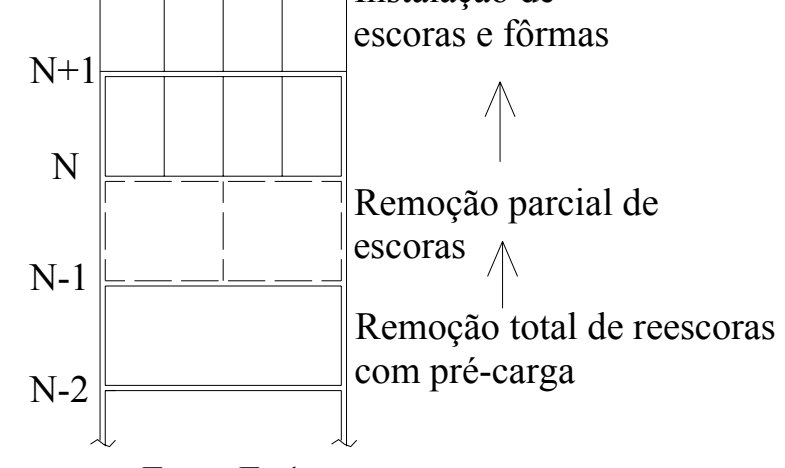

Etapa E+1

$$
\text { de apoio }(2+1) \text {. }
$$


A principal diferença dos processos construtivos apresentados anteriormente refere-se à etapa de instalação do reescoramento, que, no processo construtivo convencional é realizada sem pré-carga e no processo construtivo racionalizado com pré-carga. Como conseqüência direta dessa situação, tanto os esforços solicitantes como as flechas que ocorrem nos elementos estruturais, durante as etapas construtivas, serão diferentes.

\subsection{AÇÕES DE CONSTRUÇÃO}

As ações de construção a serem consideradas em projetos podem ser classificadas em:

\subsubsection{AÇÕES VERTICAIS}

As ações verticais são compostas de ações permanentes, do peso próprio do sistema de fôrmas, escoras, e ações variáveis de construção, que são constituídas pelo peso dos operários, equipamentos, material estocado, passarelas de transporte, impacto produzido pelo lançamento do concreto e operação de equipamentos. A ação permanente pode ser estimada com razoável precisão, todavia, a ação variável depende do método construtivo utilizado.

\subsubsection{AÇÕES HORIZONTAIS}

Estas ações são causadas pelo vento, componentes horizontais do impacto do concreto durante o lançamento e pela operação liga/desliga de equipamentos. Segundo o ACl-347 (1988), o sistema fôrma/escora deve ser projetado para suportar uma ação horizontal (aplicada nas bordas do pavimento a ser concretado) de 1,5 kN/m ou $2 \%$ do total da ação vertical de peso próprio do pavimento (a que for maior).

\subsubsection{AÇÕES VERTICAIS INDUZIDAS}

Quando ações horizontais são resistidas por escoras inclinadas, forças axiais são desenvolvidas nas escoras, as quais, por sua vez, induzem ações verticais na estrutura. A magnitude das ações verticais induzidas é dependente do ângulo de inclinação das escoras. 


\subsubsection{AÇÕES ESPECIAIS}

Ações especiais são produzidas por estocagem de material e lançamento assimétrico do concreto. Em geral, estas ações ocorrem em áreas relativamente pequenas, e podem causar deformações que possivelmente ocasionam fissuração na estrutura.

\subsection{DISPOSIÇÕES NORMATIVAS RELACIONADAS ÀS ETAPAS CONSTRUTIVAS}

A NBR 6118:2003 indica que as estruturas de concreto devem atender aos requisitos mínimos de qualidade ligados à capacidade resistente, desempenho em serviço e durabilidade durante as etapas construtivas e ao longo de toda vida útil da estrutura. A mesma norma recomenda que as verificações das etapas construtivas, as quais não tenham sua segurança garantida, estejam incluídas no projeto e que sejam realizadas considerando a parte da estrutura já executada e os cimbramentos com os respectivos pesos próprios, além das ações variáveis de construção. Entretanto, essa norma não cita valores das ações variáveis a serem consideradas durante essas etapas.

Já o ítem 7.2.2.2 da NBR 14931:2003 cita alguns aspectos que devem ser considerados durante as etapas construtivas relacionados ao sistema de escoramento, como pode ser visto a seguir.

- Nenhuma carga deve ser imposta e nenhum escoramento removido de qualquer parte da estrutura enquanto não houver certeza de que os elementos estruturais e o sistema de escoramento têm resistência suficiente para suportar com segurança as ações a que estarão sujeitos;

- Nenhuma ação adicional, não prevista nas especificações de projeto ou na programação da execução da estrutura de concreto, deve ser imposta à estrutura ou ao sistema de escoramento sem que se comprove que o conjunto têm resistência suficiente para suportar com segurança as ações a que estará sujeito;

- A análise estrutural e os dados de deformação e resistência do concreto usados no planejamento para a reestruturação do escoramento devem ser fornecidos pelo responsável pelo projeto estrutural ou pelo responsável pela obra; 
- A verificação de que a estrutura de concreto suporta as ações previstas, considerando a capacidade de suporte do sistema de escoramento e os dados de resistência e a deformabilidade do concreto.

\subsection{FATORES QUE INFLUENCIAM A DISTRIBUIÇÃO DAS AÇÕES DE CONSTRUÇÃO.}

Para garantir a segurança nas etapas construtivas de uma estrutura em concreto armado é necessário, antes de tudo, um bom conhecimento das ações de construção que atuam no sistema temporário de apoio como também dos fatores que influenciam a distribuição dessas ações em escoras, reescoras e lajes.

O estudo das variáveis que possivelmente influenciam a distribuição das ações de construção tem sido realizado para diferentes sistemas estruturais por vários pesquisadores. Pode-se citar os trabalhos de STIVAROS e HALVORSEN (1990) que verificaram a distribuição dos fatores de carga relativos à construção de edifício de concreto com subsistema estrutural laje plana utilizando madeira para o cimbramento e considerando o sistema temporário de apoio (2+1). FANG et al. (2001) pesquisaram a influência de algumas variáveis, tais como: ciclo de construção e número de níveis reescorados na distribuição das ações de construção para o sistema estrutural laje/viga/pilar. Tal pesquisa foi realizada utilizando-se escoras metálicas com transversinas e longarinas de madeira.

A tabela 2.1 apresenta uma análise relacionada à possível influência de algumas variáveis nos fatores de carga que ocorrem no sistema temporário de apoio. 
Tabela 2.1 - Análises das variáveis que possivelmente influenciam nos fatores de carga $(\mathrm{k})$.

VARIÁVEL

\begin{tabular}{|c|c|}
\hline Espessura da laje & $\begin{array}{l}\text { É evidente que a rigidez e o peso da laje mudam quando a } \\
\text { sua espessura se altera. Este fenômeno faz com que a } \\
\text { influência da espessura sobre os fatores de carga seja } \\
\text { complexa e necessite de um maior estudo para um melhor } \\
\text { entendimento da influência desta variável. }\end{array}$ \\
\hline $\begin{array}{l}\text { Número de níveis } \\
\text { escorados e/ou } \\
\text { reescorados }\end{array}$ & $\begin{array}{l}\text { Apresenta influência na distribuição dos fatores de carga no } \\
\text { sistema temporário de apoio. Porém existe um número de } \\
\text { pavimentos interligados a partir do qual a influência se } \\
\text { estabiliza. }\end{array}$ \\
\hline $\begin{array}{l}\text { Rigidez relativa } \\
\text { Escoramento / } \\
\text { Pavimento }\end{array}$ & $\begin{array}{l}\text { Apresenta influência considerável na distribuição dos fatores } \\
\text { de carga no sistema temporário de apoio. Para alterar a } \\
\text { relação entre essas rigidezes pode-se utilizar escoramentos } \\
\text { de diferentes materiais como: madeira, aço, alumínio, etc. } \\
\text { Pode-se, também, adotar diferentes distribuições } \\
\text { (densidades) de escoramentos para o sistema temporário de } \\
\text { apoio, ou seja, aumentar ou diminuir a quantidade de } \\
\text { escoras por metro quadrado na laje. }\end{array}$ \\
\hline
\end{tabular}

Pouco influente nos valores dos fatores de carga no sistema

Ciclo de Construção temporário de apoio. Ciclos maiores favorecem a segurança nas etapas construtivas pelo aumento da resistência do concreto.

Rigidez das fundações Apresenta influência na distribuição dos fatores de carga no das escoras do $1^{\circ}$ nível sistema temporário de apoio. Necessita de maiores estudos.

\subsection{EVOLUÇÃO DOS CARREGAMENTOS DE CONSTRUÇÃO}

Em seu trabalho experimental, FATTAL (1983) descreve a evolução das ações de construção sobre o sistema temporário de apoio de um edifício com seis pavimentos e ciclo de construção de 7 dias.

É considerado na pesquisa um sistema temporário de apoio constituído de um jogo de escoras e três jogos de reescoras, ou seja, sistema temporário de apoio (1+3). São utilizados escoramentos metálicos tipo torre e madeira compensada para as fôrmas das lajes.

As principais conclusões são:

1. A distribuição dos carregamentos de peso próprio das lajes recém concretadas para os escoramentos é influenciada pela configuração de longarinas e transversinas do cimbramento; 
2. A força máxima atuante em uma escora ocorre durante o impacto do lançamento do concreto;

3. A maior parte da ação dinâmica por causa do impacto do concreto é absorvida nas escoras ligadas à laje concretada. Nenhum dos níveis reescorados abaixo mostraram solicitações dinâmicas apreciáveis durante o lançamento do concreto;

4. A combinação das ações das fôrmas, barras de aço e sistema de escoramento são aproximadamente $10 \%$ do peso próprio da laje;

5. Os resultados desse estudo mostram que o máximo carregamento de construção medido está próximo do carregamento de construção especificado pelo ACI 347 STANDARD. Porém, os carregamentos acidentais nas escoras excedem os valores estipulados pelo ANSI A10.9 STANDARD.

Tal estudo indica também que na etapa de concretagem de um pavimento o carregamento total medido em reescoras instaladas sem pré-carga pode exceder 0 carregamento que solicitava anteriormente as escoras. E se, além disso, o efeito não uniforme da distribuição do carregamento sobre as reescoras for considerado, as mesmas poderão ter sua capacidade de carga excedida.

\subsection{PROBABILIDADE DE COLAPSO ESTRUTURAL}

Dentre as possibilidades de se caracterizar o colapso estrutural observa-se que o colapso referente à laje de concreto pode ocorrer com conseqüências desastrosas. CHEN et al. (1993) estudaram a probabilidade do colapso de lajes planas de concreto armado. A probabilidade de colapso é definida por meio de modelos matemáticos que levam em conta variáveis presentes nas etapas construtivas, tais como: resistência à compressão do concreto, ciclo de construção e espaçamento entre escoras. Dentre estas três variáveis o efeito da resistência do concreto é a mais significante para garantir a segurança de um edifício, ou seja, resulta em menores probabilidades de colapso. Variando os espaçamentos entre escoras de 1,0 a 2,0m a probabilidade de colapso varia de no máximo $2 \%$, ou seja, uma vairação pouco significativa. No entanto, especificar concreto com resistência de $41,4 \mathrm{MPa}$ no lugar de $34,5 \mathrm{MPa}$ conduz a uma redução de $20 \%$ na probabilidade de colapso estrutural, o que corresponde um aumento considerável na segurança.

A análise da probabilidade de colapso de estruturas de concreto armado também foi desenvolvida por EPAARACHCHI (2002), que propôs um modelo 
probabilístico de colapso estrutural durante a construção de edifícios de concreto armado com subsistema horizontal laje plana. São analisadas as influências das seguintes variáveis: número de níveis escorados/reescorados, ciclo de construção, trabalhos de concretagem, cura e adensamento do concreto, propriedades dos materiais, variabilidade dos carregamentos acidentais de construção e peso próprio. Os trabalhos de concretagem, cura e adensamento mau executados (que reduzem a resistência à compressão do concreto) são tão importantes quanto diminuir o ciclo de construção ou reduzir o número de pavimentos escorados para aumentar o risco de colapso das estruturas. É verificado, também, que se o projeto estrutural ignorar o carregamento de construção sobre as lajes poderá ocorrer uma perda considerável da segurança estrutural durante as etapas construtivas do edifício. 


\section{CAPÍTULO 3 - SISTEMAS DE ESCORAMENTOS PARA EDIFÍCIOS}

\subsection{INFORMAÇÕES GERAIS}

Os sistemas de escoramentos são utilizados para dar suporte às fôrmas que sustentam o concreto ainda fresco de vigas, lajes, etc. Os escoramentos são utilizados até que os elementos de concreto adquiram resistência suficiente para suportar o peso próprio.

O mercado de escoramentos oferece modelos e materiais variados. Os materiais mais comuns são a madeira, o aço, ou uma combinação desses materiais. No entanto, tem aumentado a utilização de escoramentos de alumínio. Com relação aos modelos podem ser escoramentos pontuais ou tipo torre.

Como o objetivo deste trabalho é a utilização das escoras pontuais, estas serão discutidas a seguir.

\subsection{INSTALAÇÃO DAS ESCORAS}

Em geral as escoras pontuais são instaladas como uma peça única em cada ponto escorado (figura 3.1), mas podem ser instaladas duas ou mais peças juntas em um ou mais pontos de escoramento, fornecendo maior rigidez e capacidade de suporte.

Como as escoras são responsáveis por suportarem forças, no mínimo duas precauções devem ser tomadas:

1. Serem instaladas de modo a impedir o deslocamento no topo ou na base (quando em uso); 
2. Utilizar travamentos horizontais para aumentar a capacidade de suporte do sistema de escoramento.

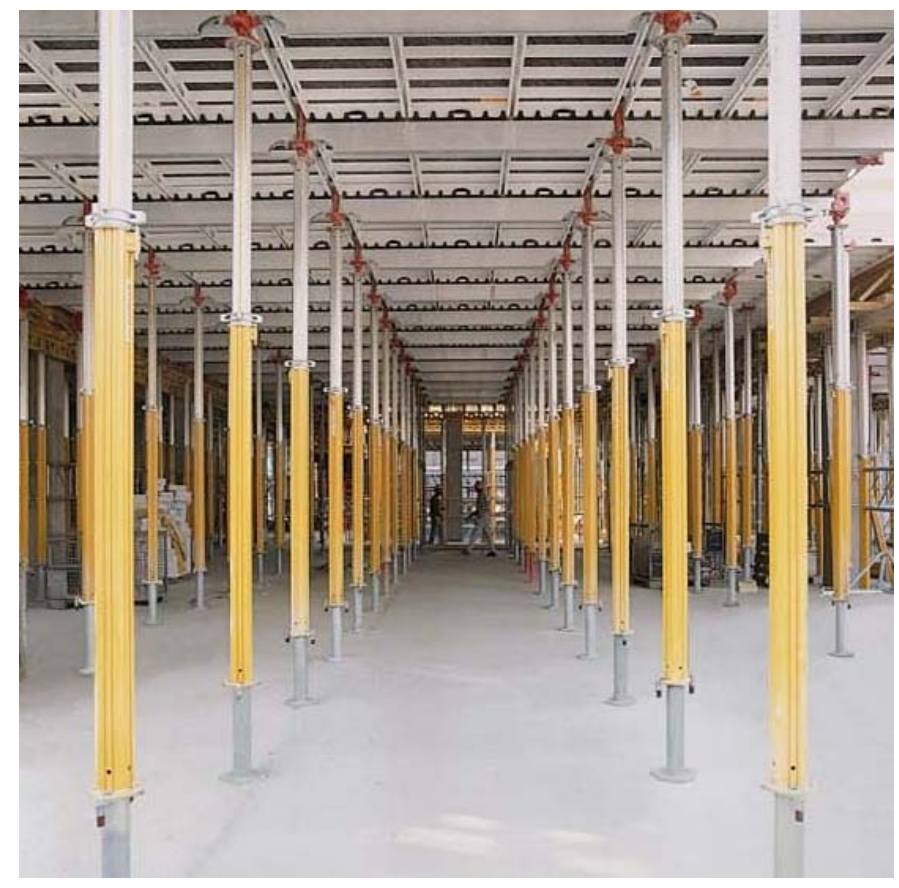

Figura 3.1 - Aplicação de escoras pontuais

Fonte: PERI FÔRMAS E ESCORAMENTOS (2003)

\subsection{REESCORAMENTO}

O reescoramento se faz necessário em pelo menos três casos:

1. Quando a força transmitida à estrutura durante a construção for maior que a sobrecarga de projeto;

2. Quando ainda não foi atingida a resistência total da estrutura, e deseja-se retirar as fôrmas para idades do concreto menores que 28 dias;

3. Quando, antes dos 28 dias, precisa-se deslocar um equipamento sobre a estrutura de ação maior que a sobrecarga de projeto.

\subsection{ESCORAS METÁLICAS PATENTEADAS}

Pelo fato de todas as escoras metálicas serem produzidas por processos industriais e possuírem patente, elas podem ser classificadas como escoras metálicas patenteadas ou simplesmente escoras metálicas.

A partir da década de 70 o escoramento metálico assumiu alto grau de importância que, segundo PFEIL (1989) pode ser atribuído ao fato de permitir maior 
rapidez à construção. No entanto, algumas desvantagens podem ser notadas, como: alto custo na aquisição ou locação e possibilidade de perda de peças, gerando maiores gastos e atraso no cronograma da obra.

\subsubsection{DETALHE DE ESCORA METÁLICA EXTENSÍVEL}

As escoras metálicas extensíveis são compostas por um único elemento de aço ou de alumínio desenvolvidos em vários modelos que permitem ajuste de altura. De uma forma geral a escora é constituída por dois tubos metálicos: um tubo externo que se apóia no pavimento e um tubo interno, mais fino, que se introduz no tubo externo e fornece a regulagem na altura. O peso das escoras varia em função da altura e do material de que são constituídas, permitindo normalmente serem manuseadas por uma única pessoa. As figuras 3.2 e 3.3 mostram respectivamente detalhes das escoras em aço e alumínio.
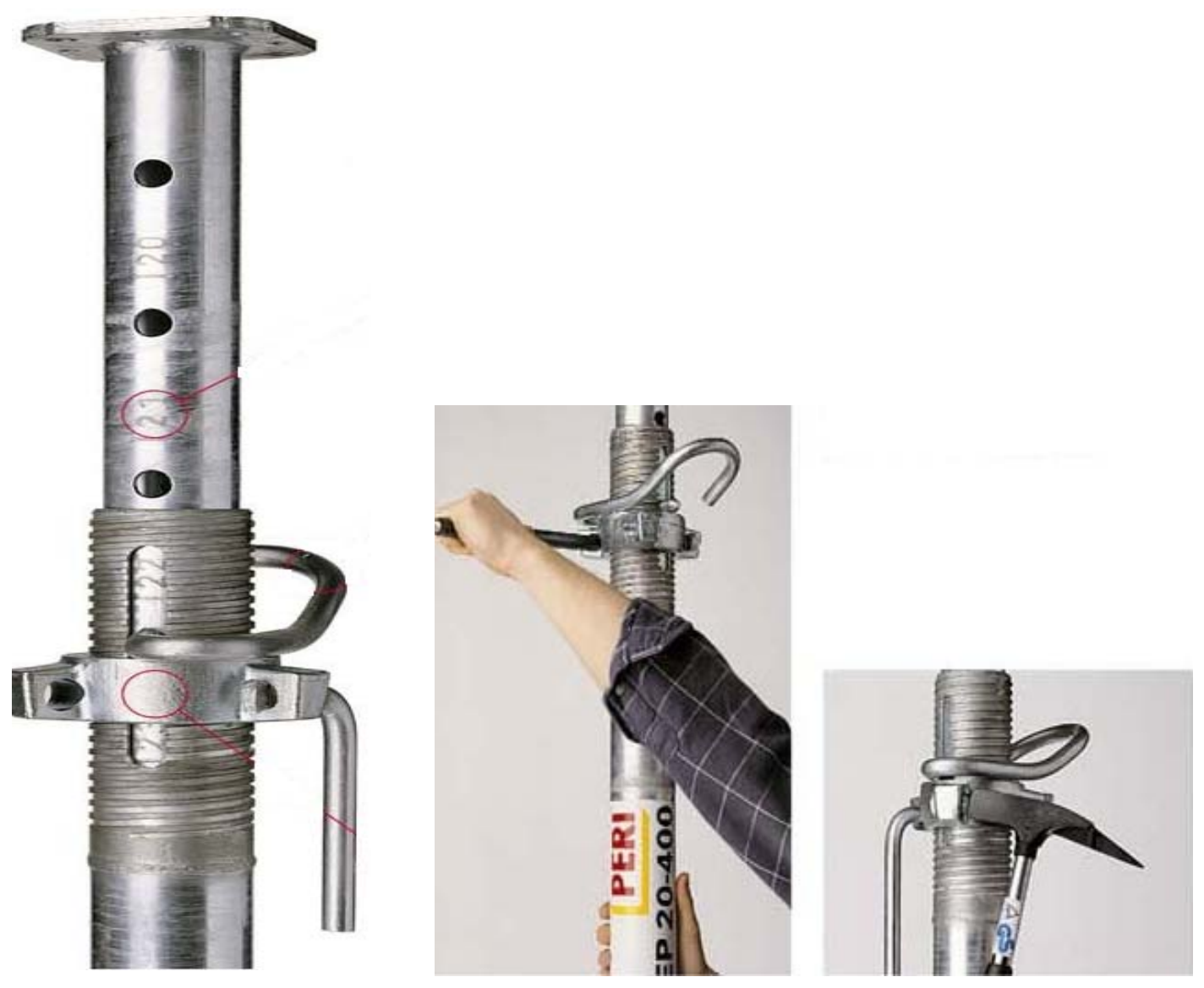

Figura 3.2 - Detalhe de ajuste de altura de escoras metálicas

Fonte: PERI FÔRMAS E ESCORAMENTOS (2003) 

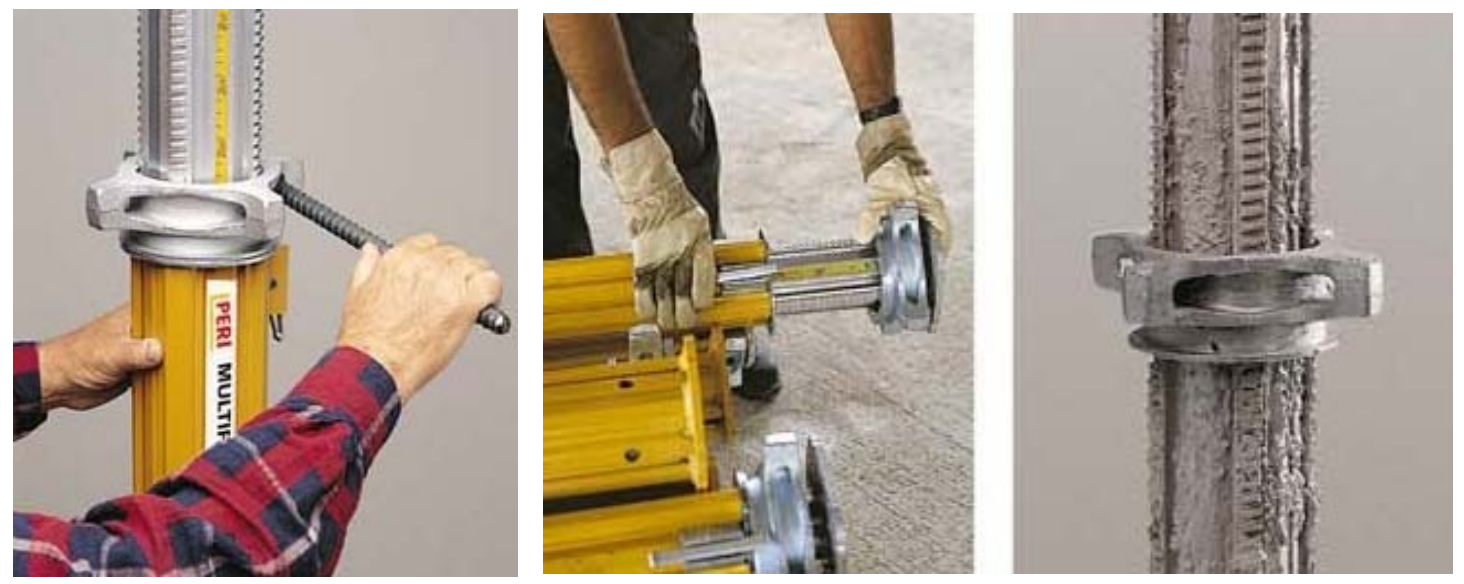

Figura 3.3 - Detalhes de escoras em alumínio

Fonte: PERI FÔRMAS E ESCORAMENTOS (2003)

\subsection{FÔRMAS DE MADEIRA}

As chapas de madeira compensada substituíram as tradicionais tábuas de madeira serrada na construção das fôrmas. As chapas de madeira compensada são constituídas por uma associação de lâminas coladas com adesivos, geralmente obtidas do Pinus Elliotti, totalizando normalmente uma espessura que varia de $10 \mathrm{~mm}$ a $18 \mathrm{~mm}$.

Para a execução das fôrmas, a madeira deve se destacar pelas seguintes qualidades:

- Ter elevado módulo de elasticidade e razoável resistência;

- Exibir bom desempenho quanto à trabalhabilidade, tendo-se em vista a serragem, penetração e extração de pregos;

- Apresentar baixo custo, já que a quantidade de madeira utilizada na construção de edifícios é muito grande;

- Permitir vários reaproveitamentos;

As fôrmas devem adaptar-se ao formato e às dimensões das peças da estrutura projetada, além de serem suficientemente estanques de modo a impedir a perda de pasta de cimento. 


\subsubsection{CUIDADOS PRELIMINARES}

De acordo com a NBR 14931:2003, antes do lançamento do concreto, devem ser conferidas as dimensões e a posição (nivelamento e prumo) das fôrmas, a fim de assegurar que a geometria dos elementos estruturais e da estrutura como um todo estejam de acordo o estabelecido no projeto.

A superfície interna das fôrmas deve ser limpa e deve-se verificar a condição de estanqueidade das juntas, de maneira a evitar a perda de argamassa. Nas fôrmas de paredes, pilares e vigas, devem ser deixadas aberturas provisórias próximas ao fundo, para limpeza.

\subsection{ESCORAMENTOS NÃO PATENTEADOS}

Os escoramentos não patenteados constituem-se de pontaletes de madeira utilizados, geralmente, em uma única obra.

Para as fôrmas de lajes, vigas e pilares utilizam-se as chapas de madeira compensada, como nos escoramentos patenteados.

A madeira normalmente utilizada para pontaletes, transversinas e longarinas é o Pinus Elliotti, uma espécie conífera. Entretanto, como um ótimo substituto para o Pinus Elliotti tem-se destacado o Eucalipto Citriodora. O eucalipto é uma espécie dicotiledônea e apresenta fibras torcidas. Desta maneira, se utilizado serrado ou esquadrejado, como normalmente é feito com o pinus, não há condições de avaliar sua resistência mecânica. Por essa razão é aconselhável utilizá-lo sem interromper a disposição natural de suas fibras, ou seja, como peça roliça.

Se as escoras de madeira forem muito longas para um dado uso, elas podem ser serradas, resultando em custos adicionais de mão-de-obra e desperdício de material. Caso elas sejam muito pequenas, poderão ser unidas, reduzindo sua capacidade de carga. Também o custo da mão-de-obra requerida para fazer tal união pode ser substancial.

O ajuste final na altura é feito por meio de cunhas de madeira posicionadas na parte inferior e em lados opostos da escora.

Os escoramentos não patenteados se destacam pelo baixo custo de aquisição, porém apresentam difícil ajuste na altura, o que eleva o custo da mão-de-obra de instalação. 


\subsection{ANÁLISE DE COLAPSO DE CIMBRAMENTOS}

HADIPRIONO e WANG (1986) estudaram os colapsos de 85 cimbramentos utilizados para estruturas de concreto. Como resultado, notaram que o sistema de escoramento deficiente foi a principal causa desses colapsos, observados em $48 \%$ dos cimbramentos que fazem uso de escoras pontuais e $33 \%$ para os que utilizam escoras tipo torre.

A figura 3.4 identifica as etapas construtivas em que ocorrem os colapsos de cimbramentos e suas respectivas porcentagens, segundo análises de HADIPRIONO e WANG (1986). Constata-se que as etapas de lançamento do concreto nas fôrmas são situações críticas, pois são responsáveis por praticamente metade dos colapsos observados.

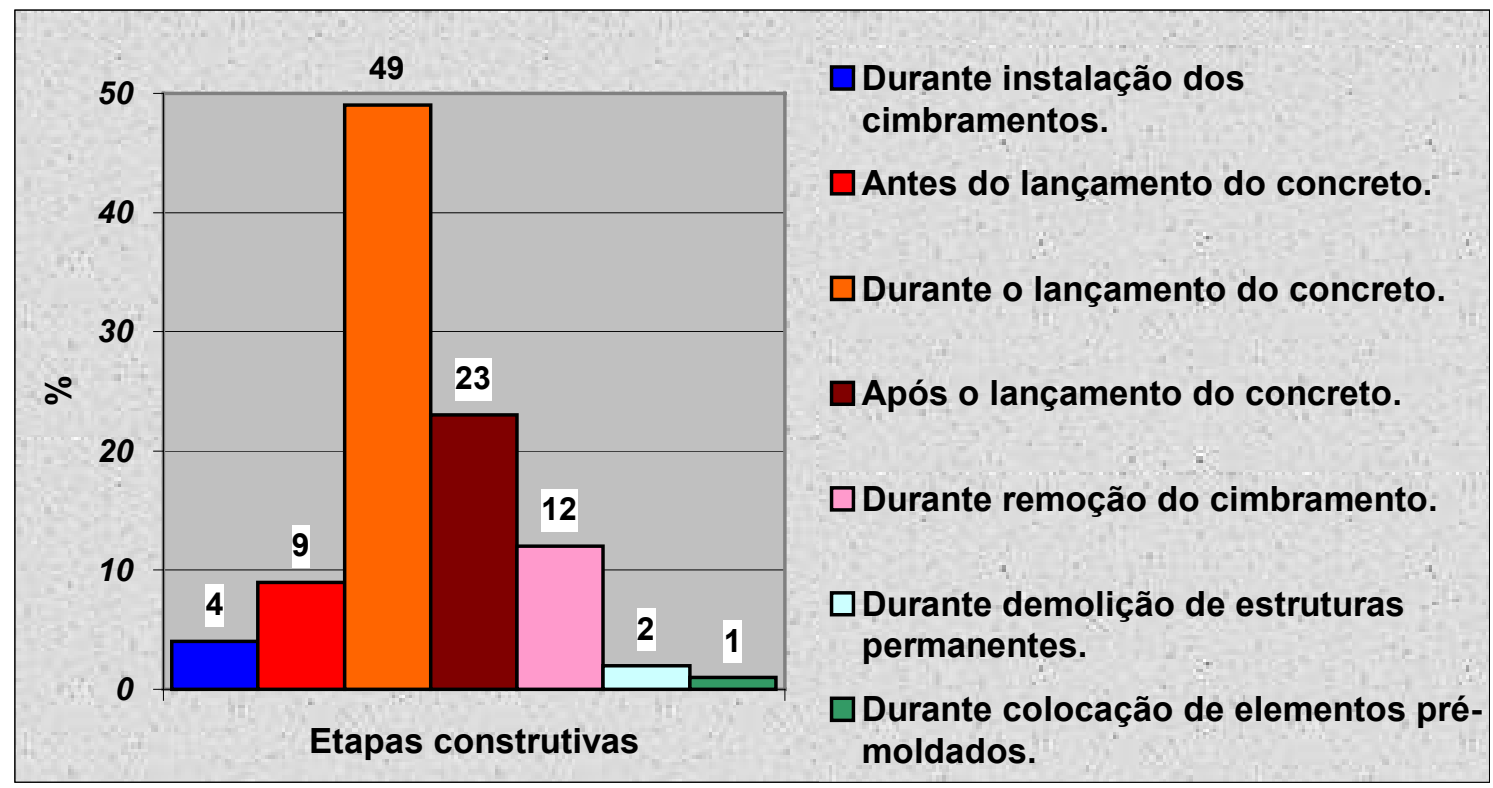

Figura 3.4 - Etapas construtivas e respectivas porcentagens para os colapsos de cimbramentos.

Os mesmos autores identificam 3 causas principais para o colapso dos cimbramentos:

1. Eventos que contribuem para deficiências de projeto e construção dos cimbramentos, como travamentos horizontais inadequados, componentes com defeitos, conexões impróprias, fundações inadequadas e projetos com falhas. 
2. O efeito do lançamento do concreto por causa do impacto exercido pelo mesmo, assim como os efeitos produzidos pela remoção imprópria ou prematura dos cimbramentos;

3. A falta de interação das partes envolvidas na revisão do projeto e na execução dos cimbramentos. Em muitos casos os construtores não seguem o projeto de construção dos cimbramentos e o engenheiro responsável pela execução da obra omite o trabalho de verificação desses cimbramentos.

\subsection{CUIDADOS COM O CIMBRAMENTO}

O cimbramento deve ser projetado e construído de modo a ter resistência às ações a que possa ser submetido durante as etapas construtivas e rigidez suficiente para assegurar que a integridade dos elementos estruturais não seja afetada.

De acordo com a NBR 14931:2003, na obra deve constar a descrição do método a ser seguido para construir e remover os cimbramentos. A retirada das fôrmas e escoramentos deve ser executada de modo a respeitar o comportamento da estrutura em serviço.

Os trabalhos que fornecem agilidade a uma obra apresentam condições especiais. Dentre esses trabalhos, a execução e montagem dos escoramentos necessitam de cuidados específicos. O escoramento deve ser projetado de modo a não sofrer, sob a ação de seu peso próprio, do peso próprio da estrutura e das cargas acidentais de construção, deformações prejudiciais ao formato da estrutura ou que possam causar esforços não previstos na mesma. No projeto de escoramentos devem ser consideradas as deformações e a flambagem dos elementos e as vibrações a que o escoramento estará sujeito. Além disso, devem ser tomadas as precauções necessárias para evitar recalques prejudiciais do solo ou na parte da estrutura que suporta o escoramento, pelas cargas por este transmitida.

A NBR 14931:2003 não fornece prazos em dias para a retirada de fôrmas e escoramentos, mas indica que estes só podem ser retirados quando o concreto estiver suficientemente endurecido para resistir às ações que sobre ele atuarem e não conduzir a deformações inaceitáveis, tendo em vista o baixo valor do módulo de elasticidade do concreto e a maior deformação diferida no tempo quando o concreto é solicitado com idades inferiores a 28 dias. 
Outra situação que requer cuidados refere-se à concretagem. Durante essa etapa as fôrmas ficam submetidas a um carregamento concentrado além de uma solicitação dinâmica momentânea. Assim, poderá ocorrer em um determinado ponto do cimbramento o levantamento das fôrmas e conseqüente desprendimento do topo das escoras caso não estejam bem fixas na estrutura, levando o cimbramento ao colapso.

Segundo o ACI COMMITEE 347 (1994) as reescoras apoiadas diretamente na laje e instaladas em pavimentos intermediários não podem se localizar fora do mesmo alinhamento das escoras dos pavimentos superiores caso a rigidez da laje não seja suficiente para combater a inversão de esforços e o efeito de punção. A figura 3.5 ilustra essa situação.

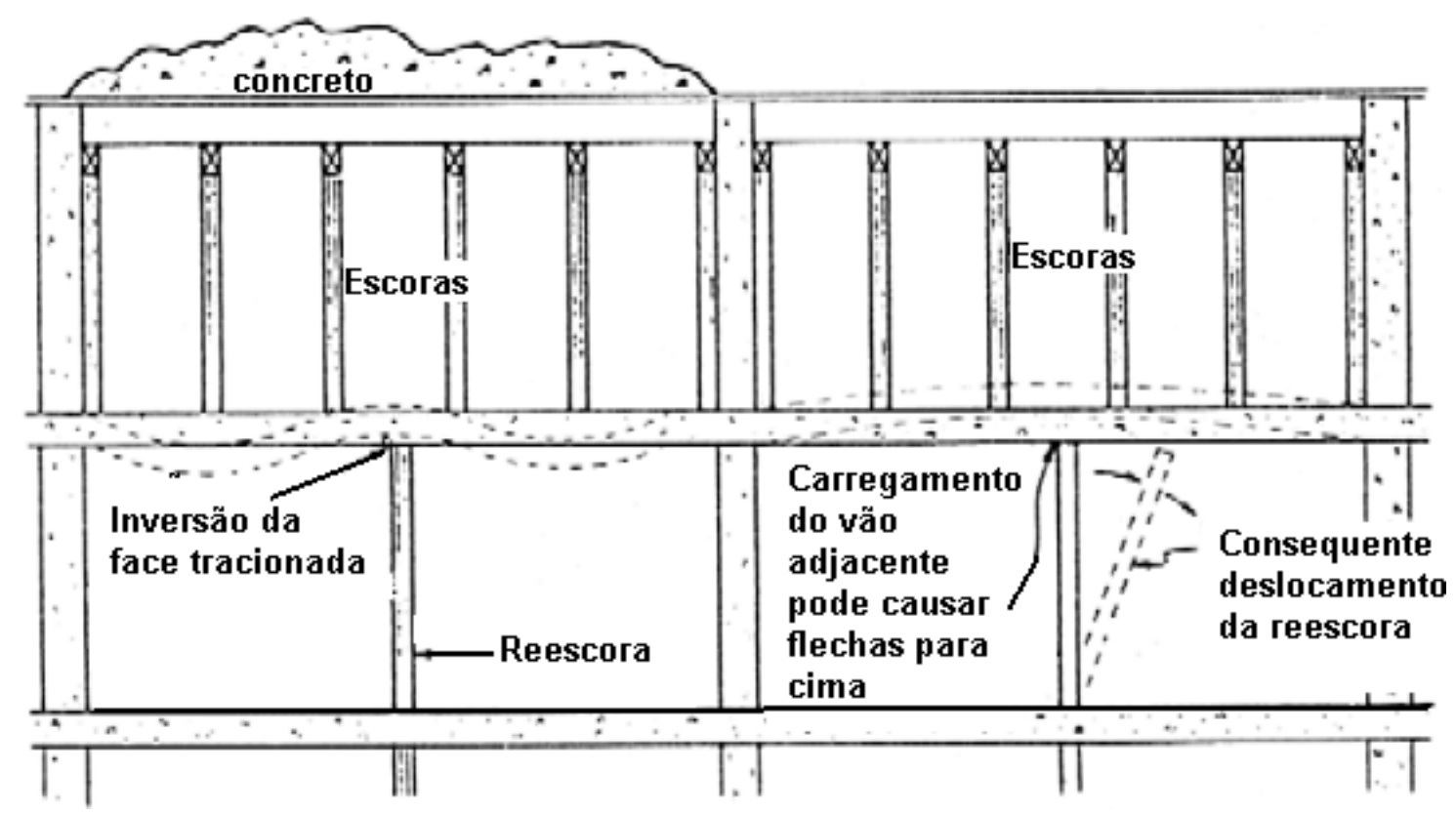

Figura 3.5 - Posição inadequada do reescoramento

Fonte: ACl Commitee 347 (1994).

Os escoramentos que sustentam um pavimento recém concretado são necessariamente suportados por pavimentos inferiores que, geralmente, não são projetados considerando o carregamento de construção. Por essa razão, o sistema temporário de apoio deve possuir número mínimo de pavimentos escorados e/ou reescorados necessários para permitir que o concreto desenvolva resistência suficiente para suportar o carregamento a que está submetido nessas etapas e não ficar submetido a um estado de tensões e deformações além dos previstos em projeto. 
Tradicionalmente, a responsabilidade pelo cimbramento tem sido do empreiteiro de escoramentos. No entanto, é dever de todas as partes envolvidas no projeto a responsabilidade pela execução da obra com segurança, o que inclui projetistas de fôrmas, engenheiros, arquitetos, trabalhadores e supervisores de obras. 


\section{CAPÍTULO 4 - MÉTODO DAS ESTRUTURAS PRIMÁRIAS E FUNDAMENTOS DA MODELAGEM}

A distribuição das ações de construção muda significativamente durante as etapas construtivas de uma estrutura. Como visto anteriormente, essas ações podem solicitar as estruturas com valores maiores do que as atuantes em serviço.

Para assegurar que as ações atuantes durante a construção não excedam a capacidade resistente da estrutura é necessário calcular a evolução do carregamento a cada etapa construtiva e comparar com os respectivos valores resistentes.

\subsection{UM BREVE HISTÓRICO}

A seguir tem-se um resumo dos vários modelos já desenvolvidos que analisam a evolução das ações de construção sobre o sistema temporário de apoio em uma estrutura.

O primeiro modelo de consideração da evolução das ações de construção em uma estrutura foi desenvolvido por NIELSEN (1952) ${ }^{1}$ apud RODRIGUES JÚNIOR (1996). Nielsen apresentou um estudo de interação entre o sistema de escoramento e a laje plana de concreto durante a construção. Os cálculos desenvolvidos foram considerados complexos e extensos, limitando assim, sua utilização prática.

GRUNDY e KABAILA (1963) desenvolveram o Método Simplificado, que admite as seguintes hipóteses:

${ }^{1}$ NIELSEN, K. E. C.(1952), Loads on Reinforced Concrete Floor Slabs and Their Deformations During Construction, Proc. No. 15, Swedish Cement na Concrete Research Institute, Royal Institute of Technology, Stockholm 
- A rigidez axial de escoras e reescoras é infinita relativamente à rigidez à flexão da laje. Por essa razão, quando um novo carregamento de construção é aplicado, todas as lajes interconectadas com escoras e reescoras têm a mesma deformação;

- O nível mais baixo de escora ou reescora é suportado por fundação completamente rígida;

- Todas as lajes possuem igual rigidez à flexão, apesar da variação de idade do concreto durante a construção,

LIU et al. (1986) desenvolveram um modelo computacional refinado para verificar as hipóteses do método simplificado e concluíram que o método é adequado para prever as ações das etapas construtivas, porém o máximo fator de carga deveria ser afetado por um fator de correção entre 1,05 e 1,10.

STIVAROS e HALVORSEN (1990) verificaram as operações de escoramento e reescoramento de edifícios de múltiplos pavimentos e concluíram que diferentes ciclos de construção utilizados para a execução dos pavimentos não afetam significativamente o carregamento de construção sobre as lajes. Cabe ressaltar que o ciclo de construção é importante para fornecer a idade correta do concreto nas etapas construtivas necessária às verificações dos estados limites.

CHEN e MOSALLAM (1991) mostraram que lajes recém concretadas, durante a cura, absorvem gradualmente seu peso próprio pelo ganho de resistência.

Com relação às ações horizontais e à utilização de elementos de travamentos diagonais no sistema de escoramento, CHEN e MOSALLAM (1992) verificaram o seguinte:

1. O efeito das ações horizontais na distribuição dos fatores de carga para o sistema temporário de apoio é pequeno;

2. A utilização de elementos de travamento horizontal e/ou diagonal nas escoras são muito importantes para garantirem a segurança e a estabilidade do cimbramento, conferindo-lhe maior resistência. Os deslocamentos laterais em estruturas travadas diagonalmente são menores que aquelas que não utilizam travamentos;

3. A utilização de travamentos nas escoras reduz as possibilidades de colapso do sistema de escoramento ligadas à pressão lateral causada pelo vento, movimento de equipamentos e ao impacto produzido pelo lançamento do concreto. 
EI SHAHHATA e CHEN (1992) desenvolveram um método melhorado usando uma aproximação baseada em deslocamentos para formular a relação entre carregamento e deslocamento na distribuição das ações de construção.

DUAN e CHEN (1995) consideraram a relação entre as rigidezes das lajes e do escoramento como fator chave para a distribuição das ações de construção.

\subsection{MÉTOdO DAS ESTRUTURAS PRIMÁRIAS}

Para que seja feita a verificação da segurança durante as etapas construtivas e para que sejam consideradas as ações prematuras no cálculo das deformações transversais do pavimento, é necessário determinar as proporções de absorção de carga entre o sistema de escoramento e os pavimentos por ele interligados.

PRADO (1999) desenvolveu um modelo simples e de uso expedito para a determinação da distribuição das ações de construção para o sistema temporário de apoio chamado de Método das Estruturas Primárias $\left(\mathrm{MEP}^{2}\right)$. Para o desenvolvimento deste método o autor fez uma vasta investigação entre os resultados do Método Simplificado, desenvolvido por GRUNDY e KABAILA (1963), e da Análise Seqüencial Construtiva. A partir desta investigação percebeu-se que o método simplificado era de fácil utilização, no entanto distorcia os valores das ações de construção. Já a análise seqüencial conduzia a valores de ações de construção com uma modelagem mais próxima das atividades realmente executadas na prática, porém com um trabalho exaustivo, o que inviabiliza a sua aplicação corrente nos escritórios de projeto.

Dessa forma, o MEP foi proposto como uma alternativa que apresentasse maior simplicidade nos modelos estruturais representativos das etapas construtivas além de resultados mais precisos das ações de construção. Segundo PRADO (1999), os resultados das ações de construção obtidas usando o MEP e da análise seqüencial tiveram boa convergência, inclusive quanto à determinação das etapas críticas do processo. No entanto, na comparação dos resultados entre o MEP e o método simplificado verificou-se que este, em geral, super estimava as ações nos pavimentos e escoramentos, valores que o método das estruturas primárias corrigiu muito bem.

\footnotetext{
${ }^{2}$ Serão utilizadas as iniciais de Método das Estruturas Primárias como referência a esse método.
} 


\subsubsection{CONSIDERAÇÕES SOBRE O MÉTODO}

O MEP possui as seguintes particularidades:

1. Utilizado para sistema de escoramento de qualquer material: madeira, aço, alumínio, etc;

2. Utilizado para qualquer sistema estrutural, por exemplo: laje/viga/pilar, laje plana, laje apoiada em paredes de alvenaria estrutural, etc;

3. Representa as ações de construção como fatores de carga (k);

4. Pode ser utilizado na previsão de ações de construção no processo construtivo convencional ou racionalizado;

5. É válido para processos de construção com qualquer número de pavimentos escorados e/ou reescorados pertencentes ao sistema temporário de apoio.

A avaliação das ações no sistema temporário de apoio durante a construção deve ser incremental, levando-se em conta a sobreposição gradual de pavimentos, de acordo com a seqüência natural de construção.

Assim, cada etapa construtiva corresponde a um sistema estrutural com determinado número de pavimentos, alguns interligados por escoras. Cada nova distribuição de ações, por causa de uma etapa construtiva qualquer, deve ser somada à situação imediatamente anterior de carregamento dos pavimentos e escoras, obtendo-se, assim, a situação momentânea de solicitação da estrutura (superposição de efeitos). Nessas situações, as ações nos pavimentos e escoramentos podem ser simplificadamente consideradas como uniformemente distribuídas.

A maneira como essas ações são distribuídas entre os pavimentos interligados por escoras a cada etapa pode ser determinada verificando-se as proporções de absorção de carga por escoras e pilares do pavimento nas diferentes operações de construção, representadas de modo aproximado por estruturas primárias.

\subsubsection{ESTRUTURAS PRIMÁRIAS}

O MEP prevê a utilização de modelos mecânicos representativos das etapas construtivas dos edifícios em concreto armado para a obtenção das proporções de absorção de carga tanto pelo pavimento quanto pelo sistema de escoramento para essas etapas. Esses modelos mecânicos são as chamadas Estruturas Primárias.

Para a representação das etapas construtivas serão utilizados números, e as etapas de concretagem serão definidas da seguinte forma: 
$n \mathrm{~A}$

onde:

- $\quad n$ corresponde a uma etapa construtiva;

- A representa o evento exclusivo de concretagem.

As etapas construtivas $n A$ são momentâneas e imediatamente posteriores às etapas $n-1$. Assim, as etapas $n$ são sempre seguintes às etapas $n-1$, mesmo quando precedidas cronologicamente por uma etapa $n A$. Por exemplo, para determinar a distribuição das ações de construção da etapa $2 \mathrm{~A}$ é necessário reportar-se à distribuição anterior, ou seja, a da etapa 1. Para determinar a distribuição das ações de construção da etapa 2 , reporta-se também à etapa 1 , já que a etapa anterior $2 \mathrm{~A}$ é momentânea.

Nas etapas A (concretagem) estão presentes a ação de peso próprio do pavimento $(1,0 \times \mathrm{g})$ e as ações variáveis $(0,85 \times \mathrm{g})$. O total de ações $(1,85 \times \mathrm{g})$ é aplicado ao modelo da figura 4.1 para que seja avaliada a transmissão de carga do concreto fresco do pavimento recém concretado para as escoras e pilares de sustentação das fôrmas. Determina-se, assim, uma proporção de absorção de carga pelo escoramento e pelos pilares. A estrutura mostrada na figura 4.1 será chamada de estrutura primária 1 , ou simplesmente $\mathrm{EP}^{3}{ }^{3}$. A absorção de carga dos pilares corresponde à absorção feita pelo pavimento. No caso do sistema estrutural em laje / paredes de alvenaria, as paredes serão responsáveis pelo suporte das cargas absorvidas pelo pavimento.

Ainda, para todos os pavimentos de quaisquer etapas que envolvam adição de carga e nas quais existam escoras ligando o primeiro pavimento à fundação considerada rígida, é suposto que a transmissão das cargas adicionadas até o solo siga a proporção de absorção de carga da EP1. Porém, é necessário que a distribuição de escoras e/ou reescoras de todos os pavimentos seja a mesma do modelo considerado na EP1, pois, caso contrário, a rigidez relativa escoramento/pavimento se altera e o modelo da estrutura primária muda em função da nova distribuição de escoramentos. Tal situação é representada pelas estruturas primárias 4 e 5 mostradas adiante.

\footnotetext{
${ }^{3}$ A partir desse instante as estruturas primárias também serão chamadas de EP seguidas pelo número da mesma.
} 


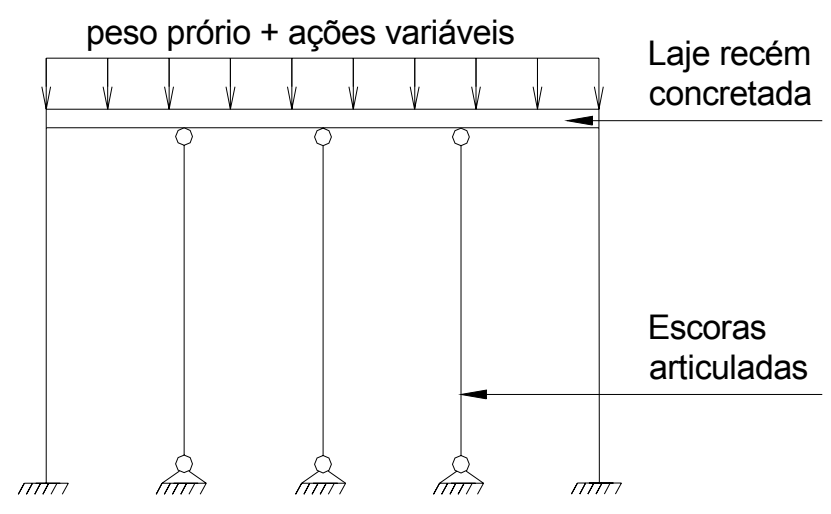

Figura 4.1 - Etapa de concretagem de um pavimento - EP1

As características mecâncias do concreto são consideradas aos 28 dias e a fundação é admitida como suporte rígido. Usualmente consideram-se os pilares engastados na base e as escoras articuladas nas extremidades.

Já para as etapas de descarregamento (retirada total de escoras ou reescoras) a proporção de distribuição das cargas se altera, havendo a necessidade do processamento do modelo da estrutura primária 2 (EP2) mostrada na figura 4.2. As propriedades do concreto também são consideradas aos 28 dias.

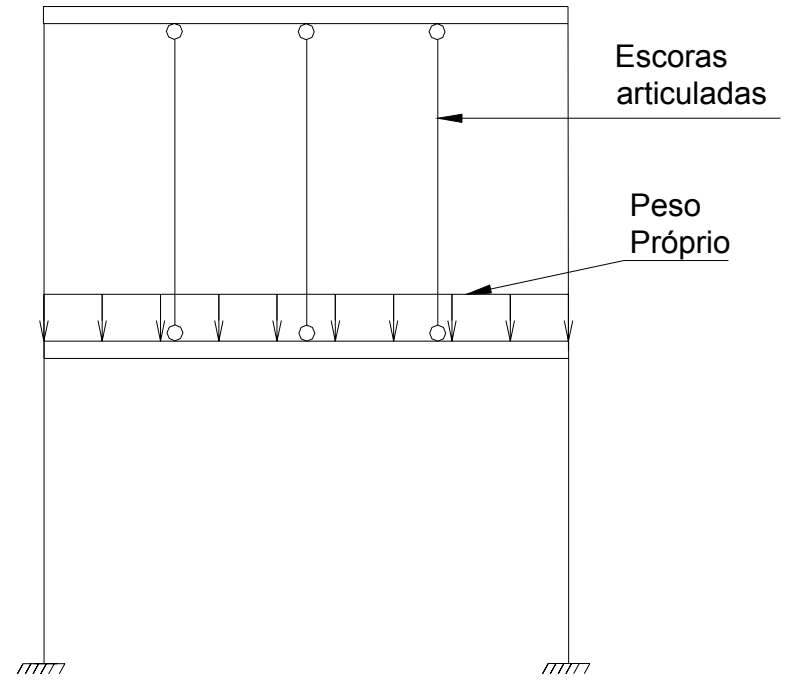

Figura 4.2 - Etapa de retirada total de escoras ou reescoras - EP2.

Aplicando o peso próprio ao pavimento inferior, uma porcentagem dessa carga é absorvida por ele próprio enquanto o restante é transmitido ao pavimento superior por meio das escoras tracionadas. Como as escoras normalmente estão comprimidas, uma solicitação desse tipo apenas alivia esses elementos. Esse raciocínio prossegue ao longo da altura da construção, distribuindo as ações das escoras retiradas aos pavimentos superiores, sempre na proporção obtida no processamento do modelo da 
EP2.

Quando não existirem escoras ligando o primeiro pavimento à fundação rígida, na distribuição das ações do pavimento recém concretado para o inferior utiliza-se simplificadamente as proporções de absorção de carga encontradas na modelagem da EP1. Porém, agora, para os demais pavimentos da etapa de concretagem e de qualquer outra etapa de carregamento altera-se a proporção.

Há a necessidade de se processar a EP3 (figura 4.3), onde agora não existem escoras apoiadas na fundação. As características do concreto também são consideradas aos 28 dias.

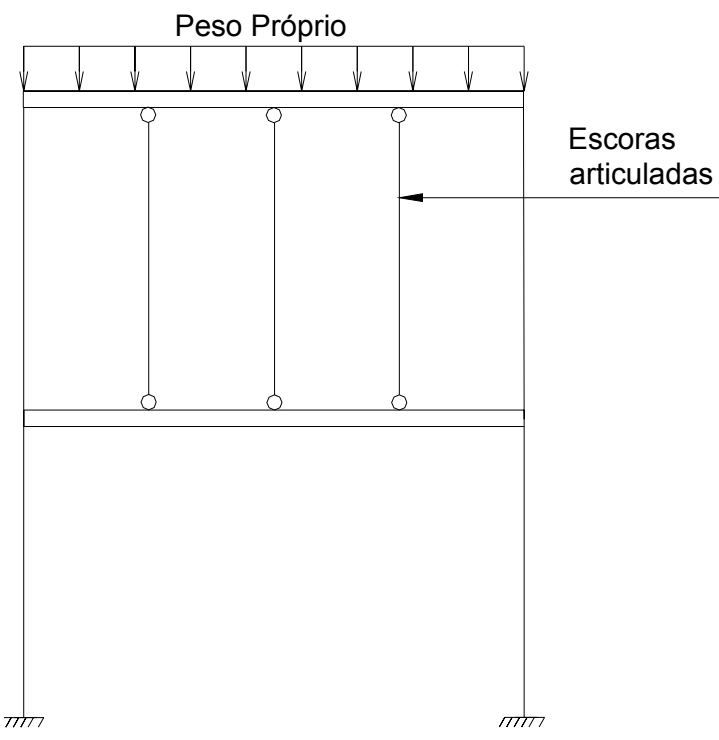

Figura 4.3 - Etapa construtiva quando não há escoras ligadas à fundação rígida - EP3.

Aplicado o peso próprio ao pavimento superior verifica-se a proporção de absorção de carga pelas escoras e pelos pilares que o sustentam. A carga transmitida às escoras é absorvida pelo pavimento inferior e a transmitida aos pilares correspondem à absorção do próprio pavimento.

As estruturas primárias EP1, EP2 e EP3 correspondem às necessárias para se calcular os fatores de carga que ocorrem no sistema temporário de apoio para o processo construtivo convencional que faça uso de pavimentos apenas escorados ou que possuam níveis reescorados, porém, que apresentem a mesma distribuição ${ }^{4}$ adotada para as escoras.

\footnotetext{
${ }^{4}$ Distribuição aqui se refere ao mesmo número de elementos (escoras ou reescoras) com o mesmo espaçamento entre eles.
} 
Para o processo construtivo racionalizado ou para o processo convencional com distribuição de reescoras diferente das escoras, é necessário o processamento de mais duas estruturas primárias (EP4 e EP5) além das anteriores. Essas estruturas são importantes pois levam em conta a alteração da rigidez relativa reescoramento/pavimento quando ocorre uma distribuição de reescoras diferente das escoras. A EP4 corresponde ao modelo com reescoras ligadas diretamente à fundação rígida e a EP5 com reescoras apenas entre dois pavimentos sucessivos. Deve-se então, na aplicação do MEP, transferir as cargas atuantes no sistema temporário de apoio que apresentem a situação descrita acima segundo as proporções de absorção de carga da EP4 e da EP5.

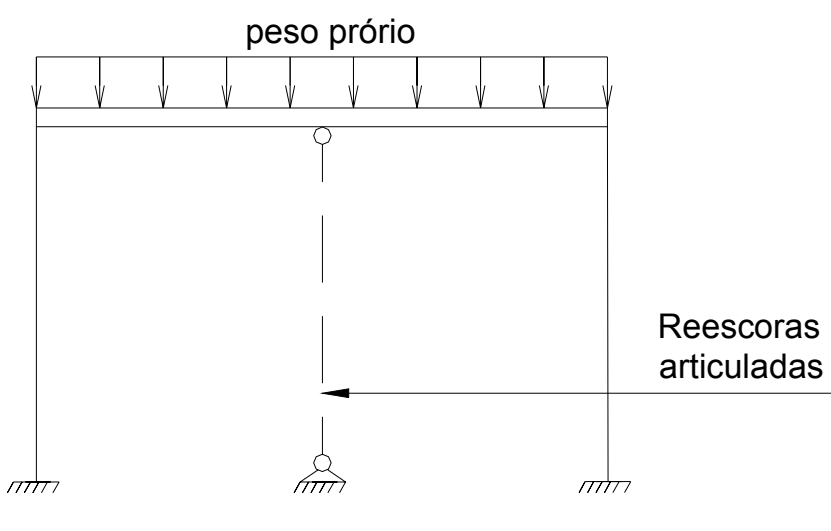

Figura 4.4 - Etapa com alteração de rigidez relativa escoramento/pavimento com reescoras ligadas à fundação - EP4

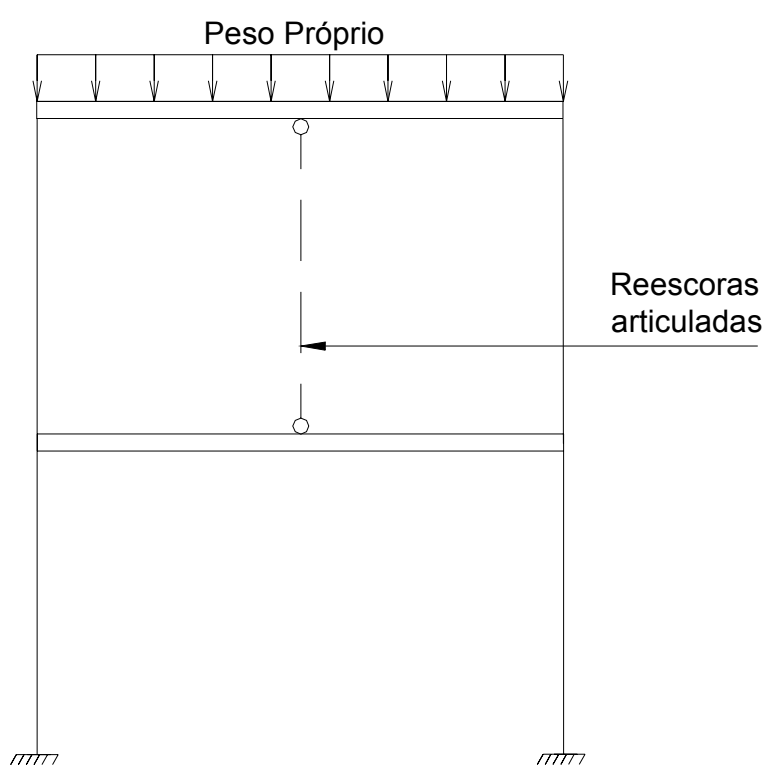

Figura 4.5 - Etapa com alteração de rigidez relativa escoramento/pavimento sem reescoras ligadas à fundação - EP5 
Da mesma forma, para EP4 e EP5, as características mecânicas do concreto são consideradas aos 28 dias e a fundação é admitida como suporte rígido, sendo os pilares engastados na base e as reescoras articuladas nas extremidades.

De acordo com o MEP interessa de fato: a posição do pavimento no sistema temporário de apoio, se se trata de concretagem, retirada total ou parcial de escoras e, finalmente, se há escoras ligadas à fundação. Resumindo, o ciclo de construção dos pavimentos pouco influencia os valores das ações de construção, sendo que tal fato foi constatado por STIVAROS e HALVORSEN (1990).

A aplicação do MEP deve ser encarada como uma etapa importante para a garantia da segurança de uma edificação e não como dificuldade ou perda de tempo. Pouco trabalho se adiciona ao cálculo estrutural convencional com uma análise adicional pelo MEP, pois as estruturas primárias são muito semelhantes às já utilizadas para o dimensionamento dos elementos estruturais do pavimento. A diferença é, praticamente, a introdução de elementos de barras articuladas nas extremidades para a simulação das escoras.

\subsection{ASPECTOS DA MODELAGEM ESTRUTURAL}

Para se determinar os esforços solicitantes durante o processo construtivo será necessária a realização da modelagem das estruturas primárias. Serão apresentados a seguir alguns aspectos importantes relacionados às modelagens estruturais.

\subsubsection{SUBDIVISÕES DO SISTEMA ESTRUTURAL: ELEMENTOS ESTRUTURAIS BÁSICOS}

Para que um edifício suporte todos os carregamentos que nele estão atuando é necessário que o mesmo possua algumas partes que, em conjunto, apresentem capacidade resistente. Esse conjunto é usualmente denominado de estrutura ou sistema estrutural.

Conforme CORREAA (1991) o comportamento estrutural de um edifício é de extrema complexidade. Para uma melhor compreensão do comportamento do sistema estrutural pode-se fazer subdivisões do sistema em suas partes constituintes. Assim, pode-se dividir o sistema estrutural em subsistemas estruturais mais simples.

No caso de edifícios, as lajes são elementos de superfície considerados como placas, estando sujeitos preponderantemente a ações normais ao seu plano. Entretanto, na análise de ações horizontais a laje de um pavimento pode ser considerada como uma chapa com ações contidas em seu plano, freqüentemente suposta rígida (hipótese do diafragma rígido). 
Os elementos lineares cujo comprimento longitudinal supera em pelo menos três vezes a maior dimensão da seção transversal são chamados de barras. É o caso das vigas, onde a flexão é predominante, e dos pilares, onde são mais importantes as forças normais de compressão.

Muitas dessas subdivisões do sistema estrutural se fazem naturalmente apenas pela observação das formas físicas reais dos elementos. Porém, algumas separações deverão ser feitas por meio dos conhecimentos do projetista estrutural, ajustando um determinado subsistema a um modelo teórico existente e priorizando as conexões deste subsistema aos demais.

\subsubsection{MÉTODOS NUMÉRICOS: MÉTODO DOS ELEMENTOS FINITOS}

Faz-se necessária a utilização de procedimentos numéricos para prever o comportamento do sistema estrutural, reduzindo-o a uma versão ideal discretizada. Esta é a essência dos métodos numéricos aplicados à análise estrutural, dentre os quais destaca-se o Método dos Elementos Finitos (MEF).

Conforme CORRÊA (1991), a formulação mais importante do Método dos Elementos Finitos está baseada em deslocamentos, verificando-se que a aplicação do método consiste resumidamente em:

1. Idealizar a estrutura como um conjunto de elementos interconectados por nós e selecionar funções que descrevam os deslocamentos em cada elemento;

2. Exprimir o comportamento de cada elemento em função dos deslocamentos nodais incógnitos e, em seguida, exprimir o comportamento global da estrutura por meio de equações em deslocamentos nodais;

3. E finalmente, determinar os resultados da análise (deslocamentos, deformações, tensões, etc.).

\subsubsection{SUGESTÕES DE MODELAGEM}

Algumas sugestões para modelagem de pavimentos de edifícios usando o Método dos Elementos Finitos são apresentadas pela referência COOK et al. (1989) apud BAPTISTA (1994). Apesar de serem muito úteis e práticas, não devem ser tomadas como regras inflexíveis, pois um analista experiente pode perceber algumas exceções que, em certos casos, podem ser exploradas com vantagem.

\footnotetext{
${ }^{5}$ COOK, R.D; MALTKUS, D.S; PLESHA, M.E. (1989) . Concepts and applications of Element
} Analysis. University of Wisconsin-Madison, John Wiley e Sons, Inc. 
Duas sugestões importantes podem ser vistas a seguir:

1. Utilizar elementos com forma regular. Ângulos dos cantos quadriláteros próximos de $90^{\circ}$;

2. Idealizar um modelo mecânico que represente o mais próximo possível a estrutura real. Uma das formas de se atingir tal situação é, por exemplo, a modelagem da ligação viga-pilar considerando trechos rígidos no caso de pilares com grande dimensão na direção do eixo longitudinal da viga.

Outras sujestões podem ser encontradas em CORRÊA (1991). 


\section{CAPÍTULO 5 - CARACTERÍSTICAS DO TRABALHO}

Depois de feito o estudo relacionado às ações de construção, aos sistemas de escoramentos para edifícios e identificado as características do método das estruturas primárias, pode-se então, apresentar a seguir as características adotadas por este trabalho relacionadas a esses assuntos.

\subsection{AÇÕES DE CONSTRUÇÃO}

Somente ações verticais estáticas serão consideradas. As ações permanentes serão basicamente constituídas pelo peso próprio de lajes e vigas.

Ações variáveis de construção serão admitidas somente no último pavimento do sistema temporário de apoio e aplicadas apenas durante as etapas de concretagem. Segundo PRADO (1999) a adoção das ações variáveis de construção apenas no último pavimento é justificada pelo fato de todas atividades do processo construtivo da estrutura estarem concentradas nesse pavimento.

Por causa da falta de indicações precisas na Norma Brasileira sobre o carregamento acidental nas etapas construtivas será utilizado, neste trabalho, um valor correspondente a $85 \%$ do peso próprio do pavimento, atuando só na etapa de concretagem para simular as ações variáveis de construção. PRADO (1999) indica que a adoção desse valor para as ações variáveis é coerente.

As ações verticais referentes ao peso próprio dos materiais são de fácil estimativa. Os materiais, além do concreto armado, são a madeira (normalmente Eucalipto Citriodora ou Pinus Elliotti) e o aço, utilizados em fôrmas e pontaletes. Os pesos específicos destes materiais são mostrados na tabela a seguir: 
Tabela 5.1 - Pesos específicos dos materiais

\begin{tabular}{cc}
\hline Material & $\begin{array}{c}\text { Peso Específico } \\
\left(\mathbf{k N / \mathbf { m } ^ { 3 } )}\right.\end{array}$ \\
\hline Concreto armado & 25 \\
\hline Aço & 78 \\
\hline Eucalipto Citriodora & 10 \\
\hline Pinus Elliottii & 5,2 \\
\hline
\end{tabular}

\subsection{SITUAÇÕES CONSTRUTIVAS ADOTADAS}

De acordo com o estudo relacionado às variáveis que influenciam os fatores de carga para o sistema temporário de apoio pode-se selecionar algumas para a modelagem estrutural das etapas construtivas.

Apesar de não existirem pesquisas relacionadas à influência do processo construtivo (convencional ou tradicional) na distribuição dos fatores de carga, esta é uma variável importante na introdução das ações de construção e precisa ser mais bem estudada.

O ciclo de construção não apresenta influência considerável nos fatores de carga que ocorrem no sistema temporário de apoio, porém é uma variável importante para fornecer a idade correta do pavimento necessária às verificações dos estados limites últimos e de serviço durante as etapas construtivas.

A tabela 5.2 indica as variáveis e opções escolhidas necessárias às análises propostas por este trabalho. 
Tabela 5.2 - Variáveis e opções.

\begin{tabular}{cc}
\hline VARIÁVEL & OPÇÕES \\
\hline \multirow{2}{*}{ Ciclo de construção } & 3 dias \\
7 dias \\
28 dias \\
\hline$f_{\text {ck }}$ & $20 \mathrm{MPa}$ \\
& $30 \mathrm{MPa}$ \\
\hline Material das escoras & Madeira \\
\hline Processo construtivo & Aço \\
\hline Sistema temporário de & Convencional \\
apoio & Racionalizado \\
\hline Sistema estrutural & $(1+1)$ \\
& Laje/ paredes de \\
& alvenaria \\
& Laje/ viga/ pilar \\
Laje plana
\end{tabular}

Depois de selecionadas as opções para cada variável, estas podem ser combinadas para compor as situações construtivas foco de análise do trabalho. Uma situação construtiva corresponde ao conjunto de seis opções, uma para cada variável. Por exemplo, uma situação construtiva seria considerar o seguinte conjunto de opções: ciclo de construção de 7 dias, resistência característica à compressão do concreto de $20 \mathrm{MPa}$, utilizando madeira para escoras, processo construtivo convencional, sistema temporário de apoio $(2+1)$ para o sistema estrutural laje plana.

Para a escolha das situações construtivas, mostradas na tabela 5.3, foi feita uma análise preliminar da influência de cada uma das variáveis nas verificações dos estados limites, com a aplicação do MEP. Para a realização dessa análise alteraramse as opções de uma única variável, por exemplo material das escoras, e mantiveram-se as opções restantes (para cada sistema estrutural) e, a partir daí, notou-se a possível influência nas verificações dos estados limites. Além disso, adotaram-se opções que fossem usuais, mais críticas e menos críticas para se compor as situações construtivas. Por exemplo, para a variável ciclo de construção adotam-se os valores 3,7 e 28 dias e para a resistência característica do concreto 20 e $30 \mathrm{MPa}$. 
Tabela 5.3 - Situações construtivas adotadas.

\begin{tabular}{|c|c|c|c|c|c|}
\hline $\begin{array}{l}\text { Sistema } \\
\text { Estrutural }\end{array}$ & $\begin{array}{c}\mathbf{f}_{\mathrm{ck}} \\
(\mathrm{MPa})\end{array}$ & $\begin{array}{c}\text { Sistema } \\
\text { Temp. } \\
\text { de Apoio }\end{array}$ & $\begin{array}{l}\text { Processo } \\
\text { Construtivo }\end{array}$ & $\begin{array}{l}\text { Material } \\
\text { Escora }\end{array}$ & $\begin{array}{l}\text { Ciclo } \\
\text { Cons. }\end{array}$ \\
\hline \multirow{4}{*}{ Laje plana } & \multirow{6}{*}{20} & \multirow{4}{*}{$(2+1)$} & \multirow{2}{*}{ Convencional } & Madeira & 7 \\
\hline & & & & Aço & 3 \\
\hline & & & \multirow{2}{*}{ Racionalizado } & Aço & 7 \\
\hline & & & & Aço & 3 \\
\hline \multirow{4}{*}{$\begin{array}{l}\text { Laje / paredes de } \\
\text { alvenaria }\end{array}$} & & \multirow{2}{*}{$(1+1)$} & Convencional & Aço & 3 \\
\hline & & & Racionalizado & Aço & 3 \\
\hline & \multirow{2}{*}{30} & \multirow{2}{*}{$(2+1)$} & Convencional & Madeira & 28 \\
\hline & & & Racionalizado & Aço & 28 \\
\hline
\end{tabular}

\subsection{ESCORAMENTO NÃO PATENTEADO}

Farão uso desse sistema de escoramento as situações construtivas que utilizam a madeira como material para as escoras.

Por meio de contatos com construtoras obtiveram-se as informações necessárias aos escoramentos não patenteados. A madeira utilizada é o Pinus Elliottii. O módulo de elasticidade desse tipo de madeira pode ser considerado igual a $6,85.10^{6} \mathrm{kN} / \mathrm{m}^{2}$ e o coeficiente de Poisson igual a 0,30 . Os pontaletes têm seção quadrada de $7,5 \mathrm{~cm} \times 7,5 \mathrm{~cm}$ e altura de acordo com o projeto de fôrmas. As longarinas são compostas por duas tábuas de $2,5 \mathrm{~cm} \times 15 \mathrm{~cm}$ espaçadas de $7,5 \mathrm{~cm}$ e as transversinas têm as mesmas dimensões das longarinas, como mostra desenho esquemático na figura 5.1 .

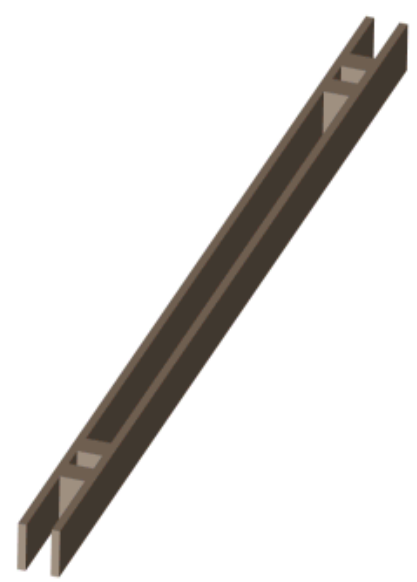

Figura 5.1 - Desenho esquemático de uma longarina.

\subsection{ESCORAMENTO PATENTEADO}

Farão uso desse sistema de escoramento as situações construtivas que 
utilizam o aço como material tanto no processo construtivo convencional como no processo racionalizado.

As escoras patenteadas utilizadas são as produzidas pela empresa $\mathrm{SH}$ FÔRMAS ANDAIMES E ESCORAMENTOS com sede no Rio de Janeiro. Por meio de contatos com a empresa e utilizando os catálogos técnicos produzidos pela mesma pode-se obter as informações a respeio desse escoramento. O material das escoras é o aço SAE 1020 cujo módulo de elasticidade corresponde a $2,1.10^{8} \mathrm{kN} / \mathrm{m}^{2}$ e o coeficiente de Poisson 0,3. O tubo interno da escora possui diâmetro de 48,3mm e espessura da parede de $3,35 \mathrm{~mm}$ e o tubo externo possui diâmetro de $60,3 \mathrm{~mm}$ e espessura da parede de $2,25 \mathrm{~mm}$.

Para o processo construtivo racionalizado são utilizados, além das escoras $\mathrm{SH}^{1}$, painéis de fôrmas com dimensões padronizadas indicadas pela mesma empresa. O conhecimento das dimensões dos painéis de fôrmas é importante pois a distribuição dos escoramentos pelo pavimento depende dessas dimensões.

A tabela 5.4 indica as dimensões dos painéis de fôrmas bem como a espessura máxima de uma laje para a utilização do respectivo painel.

Tabela 5.4 - Dimensões de painéis de fôrmas - processo construtivo racionalizado.

\begin{tabular}{ccc}
\hline $\begin{array}{c}\text { Dimensões } \\
(\mathbf{c m})\end{array}$ & $\begin{array}{c}\text { Peso } \\
\mathbf{( k g )}\end{array}$ & $\begin{array}{c}\text { Espessura } \\
\text { Máxima da } \\
\text { Laje } \\
\mathbf{( c m )}\end{array}$ \\
\hline $200 \times 100$ & 22,91 & 22 \\
\hline $200 \times 0,75$ & 19,15 & 30 \\
\hline $100 \times 100$ & 13,51 & 30 \\
\hline $0,75 \times 100$ & 11,51 & 30 \\
\hline $0,75 \times 0,75$ & 10,14 & 30 \\
\hline
\end{tabular}

Painéis de fôrmas de dimensões especiais são produzidos sob medida para arremates e ajustes.

A seqüência de montagem dos painéis de fôrmas é mostrada na figura 5.2. Para a montagem é necessária a utilização de um bastão metálico para auxiliar no apoio dos painéis.

\footnotetext{
${ }^{1}$ A SH FÔRMAS ANDAIMES E ESCORAMENTOS será referida utilizando-se apenas a sigla SH.
} 


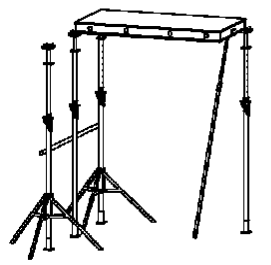

1. Posicionar Escora

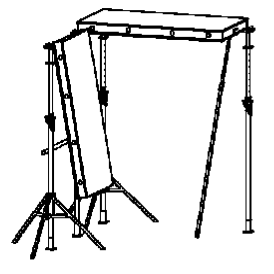

2. Encaixar Painel

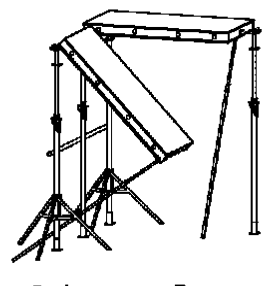

3. Levantar Painel

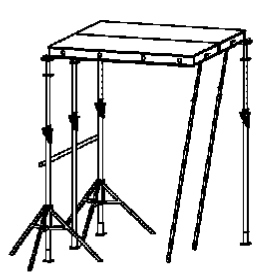

4. Apoiar no Bastāo

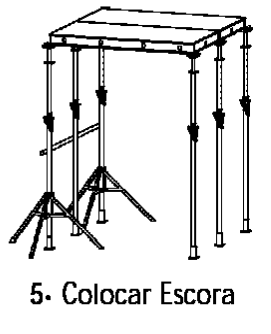

Figura 5.2 - Seqüência de montagem dos painéis de fôrmas no processo construtivo racionalizado.

Fonte:Catálogos técnicos SH

A figura 5.3 mostra a desmontagem dos painéis de fôrmas e retirada parcial das escoras para a realização do reescoramento com pré-carga.

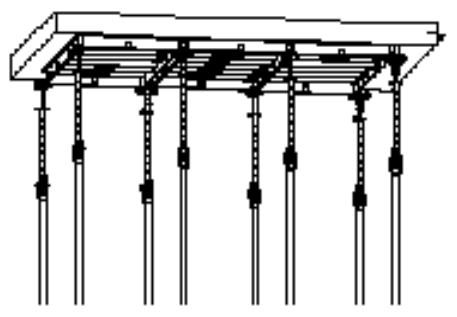

1 - Painéis instalados

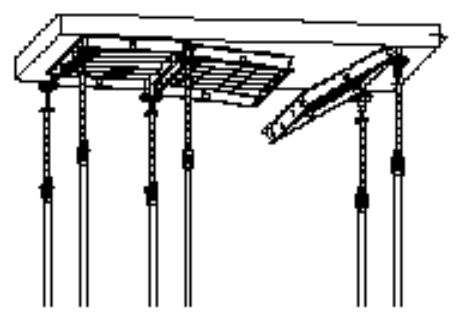

2 - Retirada parcial de escoras e fôrmas

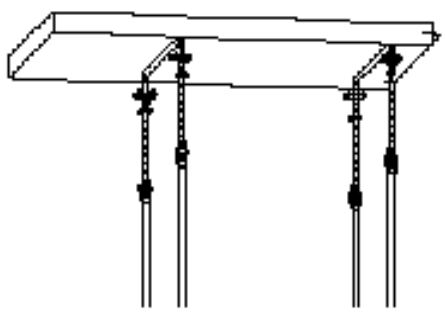

3 - Reescoramento executado

Figura 5.3 - Desmontagem dos painéis de fôrmas no processo construtivo racionalizado.

Fonte: Catálogos técnicos SH

\subsection{ESPAÇAMENTO ENTRE ESCORAS NOS PROCESSOS CONSTRUTIVOS}

O dimensionamento do espaçamento entre escoras no processo construtivo convencional é função de vários fatores, como: espessura da laje, espessura e dimensão das chapas de compensado, do material e das dimensões de longarinas e transversinas e do material das escoras. Para facilitar os trabalhos de dimensionamento do espaçamento do escoramento são utilizadas planilhas de cálculo produzidas pela $\mathrm{SH}$ e que levam em consideração os fatores citados anteriormente para tal dimensionamento. São utilizadas chapas de madeira plastificada com $18 \mathrm{~mm}$ de espessura para as fôrmas das lajes para todos os sistemas construtivos. 
No processo construtivo racionalizado o espaçamento entre escoras depende das dimensões dos painéis de fôrmas adotados para as lajes. Notar que são necessárias no mínimo quatro escoras para a sustentação de cada painel de fôrma.

\subsection{ESCOLHA DO PROGRAMA COMPUTACIONAL E ASPECTOS DA MODELAGEM}

O programa computacional em elementos finitos escolhido para permitir a modelagem tridimensional das estruturas necessárias à aplicação do método aproximado foi o "STRAP ${ }^{\circledR}$ - Structural Analisys Program" versão 9.0. Este é um programa de análise estrutural por elementos finitos (lineares, planos e sólidos) que dispõe de recursos para elaboração de diversos modelos estruturais. O STRAP é programa de 32 bits que trabalha em ambiente Windows e possui interface gráfica que facilita os trabalhos na tela do computador. O programa possui uma variedade de comandos que facilitam e agilizam a geração de nós, barras e elementos finitos em duas ou três dimensões, criando instantaneamente: grelhas, superfícies, malhas de elementos finitos, cópia de partes do modelo, etc. Para a realização da pesquisa utilizou-se uma versão disponível no departamento de engenharia de estruturas da EESC. A tela de entrada de geometria desse programa pode ser visto na figura 5.4.

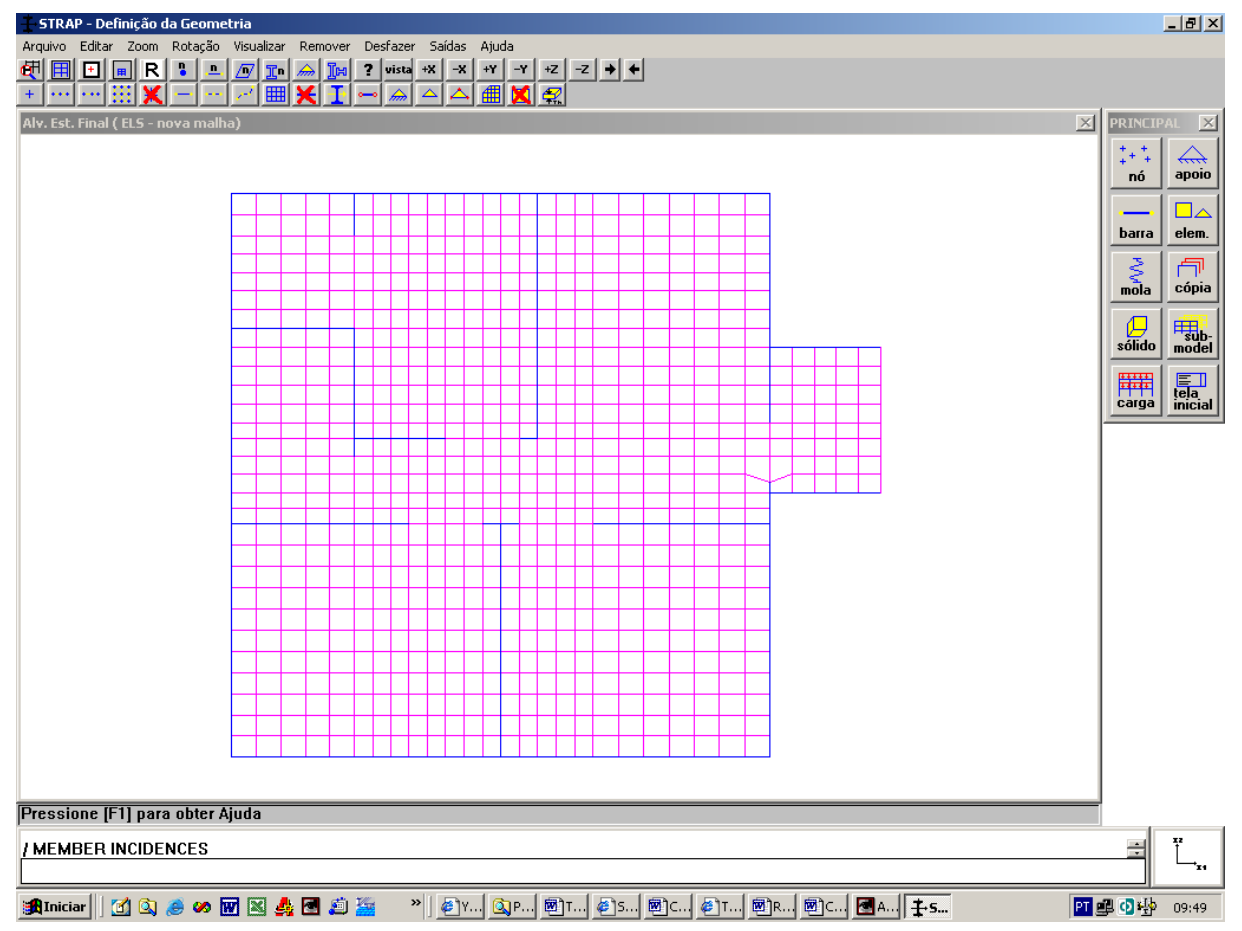

Figura 5.4 - Tela de entrada de geometria do STRAP - versão 9.0 
Vigas e pilares são modelados como elementos de barra com pilares engastados na base. São utilizadas barras de grande rigidez para a simulação de trechos rígidos no caso de pilares com grande dimensão na direção do eixo longitudinal da viga. Da mesma forma as escoras são modeladas como elementos barra, porém articuladas nas extremidades, pois estas resistem simplesmente a esforços de compressão. Para a realização das modelagens no programa computacional utiliza-se um único elemento barra que possua coeficiente de mola equivalente ao coeficiente de mola dos dois tubos (interno e externo) que constituem a escora. Dessa forma, usa-se nas modelagens um elemento com diâmetro externo de $40 \mathrm{~mm}$ e espessura da parede de $4 \mathrm{~mm}$.

Outros elementos constituintes do cimbramento, tais como: longarinas, transversinas e fôrmas não farão parte das modelagens propostas por este trabalho.

Para o sistema laje/alvenaria estrutural as paredes serão modeladas por elementos mola, pois representam bem a deformabilidade das paredes.

\subsection{CONSIDERAÇÕES SOBRE AS VERIFICAÇÕES DOS ESTADOS LIMITES}

Com os resultados das análises estruturais durante a construção, obtidos pelo método das estruturas primárias, serão verificados os estados limites últimos e de serviço como descrito a seguir.

A verificação de segurança da estrutura pronta é realizada considerando-se a combinação última normal. A NBR 8681:2003, para essa combinação, utiliza os coeficientes de ponderação (majoração) das ações $\gamma_{g}=1,4$ e $\gamma_{q}=1,4$ respectivamente para as ações características verticais permanentes e ações características verticais variáveis. E para os coeficientes de ponderação (minoração) da resistência $\gamma_{c}=1,4 \mathrm{e}$ $\gamma_{s}=1,15$, respectivamente para as resistências do concreto e do aço. Porém, para a verificação da segurança em etapas construtivas a mesma norma indica a utilização da combinação última de construção cujos coeficientes de ponderação das ações valem $\gamma_{g}=1,3$ e $\gamma_{q}=1,2$. E para os coeficientes de ponderação das resistências $\gamma_{c}=1,2$ e $\gamma_{s}=1,15$

Segundo a NBR 8681:2003 na combinação de utilização para verificação das deformações do pavimento a ação permanente do peso próprio do concreto armado deve entrar com seu valor característico, sem ponderação. Para as ações variáveis de construção é coerente adotar, também, simplesmente os valores característicos, 
uma vez que essas são introduzidas e logo retiradas com a mesma intensidade. Ainda de acordo com esta norma, as ações permanentes referentes à entrada em serviço devem ser consideradas com os valores característicos, enquanto as ações variáveis de sobrecarga de utilização entram na combinação quase-permanente. Nesse caso, a parcela quase-permantente se forma com a aplicação do fator de utilização $\psi_{2}=0,3$, para locais sem elevada concentração de pessoas.

Serão feitas no capítulo 6 algumas definições específicas de deslocamentos de pontos do pavimento e, a seguir, são apresentados alguns conceitos gerais ligados às deformações dos elementos estruturais.

Depois de aplicados os carregamentos nos pavimentos pode-se encontrar as deformações finais nos elementos estruturais somando-se as deformações imediatas e as obtidas ao longo do tempo. As deformações imediatas são as deformações elásticas majoradas por um fator relativo à fissuração e as deformações ao longo do tempo dizem respeito à deformação lenta e à deformação por retração.

A deformação imediata leva em conta o acréscimo de deformação pela perda de rigidez por fissuração na flexão do elemento estrutural. A expressão da inércia efetiva da seção de concreto (Ie) utilizada neste trabalho foi desenvolvida por BRANSON (1963)² apud PRADO (1999). A aplicação da expressão de Branson só deve ser feita caso o momento fletor atuante na seção crítica do vão considerado $\left(M_{a}\right)$ seja superior ao momento de fissuração $\left(M_{r}\right)$, calculado aqui segundo a NBR 6118:2003. Assim, para o cálculo do deslocamento imediato, majora-se a flecha elástica pela razão entre o momento de inércia da seção bruta de concreto (Ig) e o momento de inércia efetivo (Ie).

A deformação lenta corresponde ao aumento progressivo da deformação sob ação de carga, também denominado de fluência. Segundo o Anexo A da NBR 6118:2003 o valor da fluência pode ser encontrado ponderando os deslocamentos imediatos pelo coeficiente de fluência $\varphi_{(t, t o)}$. Neste trabalho o acréscimo de deformação por fluência será admitido a partir do último dia do ciclo de construção adotado para cada situação construtiva, ou seja, do terceiro, do sétimo ou do vigésimo oitavo dia.

Já o fenômeno de deformação por retração ocorre quando, por exemplo, existe perda de umidade por evaporação. A deformação por retração inicia-se logo após o processo de cura do elemento e ocorre durante toda vida da estrutura. Esta

${ }^{2}$ BRANSON, D. E. (1963). Instantaneous and time-dependent deflections of simple and continuous reinforced concrete beams. Report No7, Part I. Alabama Highway Research Department, Bureal of Public Roads, Aug., pp. 1-78 
deformação não depende da ação atuante no elemento estrutural. No caso de lajes, por serem elementos bidimensionais, a retração ocorre em todas as direções do plano. Porém, neste trabalho será feito o cálculo somente para a direção do menor vão por apresentar os maiores esforços.

O valor da flecha no tempo infinito do elemento estrutural deve situar-se abaixo de determinados limites. Os valores limites de deslocamento transversal supõem elementos de vão $L$ e são indicados em relação ao plano médio que contém os apoios. Por exemplo, segundo a NBR 6118:2003, o valor limite para flechas é de L/250 para deslocamentos visíveis em elementos estruturais.

\subsubsection{METODOLOGIA PARA VERIFICAÇÃO DOS ESTADOS LIMITES DURANTE AS ETAPAS CONSTRUTIVAS.}

PRADO (1999) propõe uma nova metodologia para a verificação dos estados limites a partir da utilização do MEP e considerando as etapas construtivas. A metodologia proposta será chamada de situação construtiva de projeto.

Depois de feito o dimensionamento dos elementos estruturais do pavimento considerando a combinação última normal há a necessidade de se determinar quais os valores máximos dos esforços solicitantes atuantes nos elementos estruturais dos pavimentos ao longo da construção para cada idade onde ocorrem as operações construtivas, segundo o MEP. Deve-se tomar muito cuidado uma vez que uma determinada solicitação aplicada aos 21 dias pode ser menos crítica do que uma com valor inferior aplicada anteriormente, por exemplo aos 7 dias.

O MEP fornece os valores das ações atuantes durante a construção em função do peso próprio do pavimento (g). Assim, simplificadamente, pode-se considerar que o pavimento possui peso próprio majorado pelo fator de carga (k) indicado no método das estruturas primárias. Essa ação majorada deve entrar na combinação última de construção a ser aplicada no pavimento isolado considerandose a idade correta do concreto. Deve ser considerada para as etapas construtivas as verificações das tensões últimas e comparações entre as armaduras necessárias durante essas etapas e as armaduras existentes correspondentes para todos os esforços presentes nas peças analisadas, garantindo-se a segurança de todos os elementos estruturais contra o esgotamento da capacidade resistente.

Para a verificação do estado limite de serviço, no que se refere à deformação excessiva, também são utilizados os resultados do MEP, determinando-se os deslocamentos em pontos do pavimento de maior solicitação durante a construção. 
Do modo como foi definido neste trabalho, os pavimentos são concretados nas etapas A, espaçadas por um intervalo fixo de dias denominado ciclo de construção. Nas etapas imediatamente seguintes às etapas $A$ há a mudança de idade do pavimento, somando-se um ciclo. Deve-se lembrar que as etapas A não participam do somatório dos efeitos das etapas construtivas para se encontrar os esforços solicitantes ou deslocamentos. Assim, utilizando o MEP, as ações atuantes numa etapa imediatamente anterior a uma etapa $A$ resumem o estado de deslocamento até o seu respectivo ciclo. É proposta, então, uma história de carregamentos por ciclos. Novamente, para verificar os deslocamentos até o ciclo em questão considera-se o pavimento isolado com a idade correta do concreto e com o seu peso próprio majorado pelo correspondente fator de carga.

Após as etapas construtivas, o pavimento é liberado das ações de construção, ficando então submetido a um fator de carga $k=1,0$ (peso próprio). Posteriormente, o mesmo será solicitado por carregamentos dependentes do sistema de vedação e revestimento adotados no projeto até, finalmente, entrar em serviço.

\subsection{IDADES PARA AS ENTRADAS DOS CARREGAMENTOS}

Serão adotadas as seguintes idades e os respectivos carregamentos para os ciclos de construção de 3 e 7 dias:

- Antes dos 28 dias: ações de construção calculadas pelo MEP;

- 28 dias: peso próprio do pavimento;

- 120 dias: contra piso, revestimento e sistema de vedação interno que, nesse caso, são paredes de alvenaria e divisórias leves utilizadas respectivamente para os sistemas estruturais laje/viga/pilar e laje plana;

- 365 dias: sobrecarga de utilização (entrada em serviço);

- 10000 dias: idade considerada para o tempo infinito e cálculo das flechas.

As diferenças nas idades anteriores das entradas dos carregamentos para o ciclo de construção de 28 dias se refere ao peso próprio que entra aos 112 dias e as ações de construção anteriores a essa data. 


\subsection{CARACTERÍSTICAS Do CONCRETO JOVEM}

O desenvolvimento das características de resistência e rigidez do concreto com a idade será estimado com base nas expressões da NBR 6118:2003. Será considerado concreto utilizando cimento portland comum (CP I), condições normais de cura úmida durante 7 dias consecutivos e temperatura de $25^{\circ} \mathrm{C}$.

O valor do coeficiente de Poisson $\left(v_{c}\right)$ adotado para o concreto é o indicado pela NBR 6118:2003 que vale 0,2. 


\section{CAPÍTULO 6 - ESTUDO DE CASOS E ANÁLISES}

Este capítulo apresenta as análises propostas relativas à comparação entre as condições usualmente empregadas nos projetos de edifícios de concreto armado e as provenientes das situações construtivas. Os resultados serão confrontados com os valores especificados pela NBR 6118:2003 referentes às verificações de segurança dos elementos estruturais e à utilização dos mesmos.

\subsection{DEFINIÇÕES E CONSIDERAÇÕES INICIAIS}

Antes de apresentar análises e resultados, é necessário introduzir algumas definições que facilitam o entendimento do presente texto.

1. Situação Construtiva de Projeto: condição empregada para as verificações dos estados limites das estruturas de concreto durante as etapas construtivas. Considera-se, além das idades corretas do concreto nos carregamentos de construção, idades pré-estabelecidas para os carregamentos considerados usualmente em projeto. É nessa situação que se determinam as armaduras necessárias $\left(A_{s n}\right.$ e $\left.A_{s w n}\right)$ dos elementos estruturais.

2. Situação Construtiva: corresponde ao conjunto de seis opções, uma para cada variável escolhida a ser estudada;

3. Situação Crítica: situação construtiva responsável pelas maiores solicitações nos pavimentos durante a construção; 
4. Deslocamento Final $\left(\Delta_{f}\right)$ : deslocamento obtido no tempo infinito considerando a situação construtiva de projeto;

5. Situação Usual de Projeto: condição usualmente empregada para as verificações dos estados limites últimos e de serviço das estruturas de concreto. Uma das considerações da situação usual de projeto é, por simplicidade, admitir todos os carregamentos atuando de uma só vez no pavimento com idade de 28 dias. É nessa situação que se determinam as armaduras existentes $\left(A_{s e}\right.$ e $\left.A_{\text {swe }}\right)$ nos elementos estruturais.

6. Deslocamento Usual $\left(\Delta_{u}\right)$ : deslocamento obtido no tempo infinito considerando a situação usual de projeto;

7. Deslocamento Limite: valor limite especificado pela NBR 6118:2003 para o deslocamento de um ponto, relativo ao vão L. Por exemplo, o valor máximo para a aceitabilidade sensorial é de L/250.

8. Deslocamento Limite Total $\left(\Delta_{t}\right)$ : corresponde à soma do deslocamento limite e da contra flecha (L/350) permitida por norma. Esse valor indica o máximo deslocamento no tempo infinito que poderia ser encontrado em um ponto do elemento estrutural.

Determinadas escoras em aço possuem capacidade de carga maior que escoras de madeira e conseqüentemente viabilizam maior espaçamento ao sistema de escoramento. Porém, para as escoras em madeira e aço adotadas, a diferença entre os espaçamentos máximos com os dois materiais mostrou-se pequena. Dessa forma, adotou-se a mesma distribuição de escoras no processo construtivo convencional para cada sistema estrutural independente do material das escoras. Para verificar a viabilidade dessa adoção examinou-se para todas as situações construtivas a carga atuante nas escoras durante as etapas construtivas e constatouse que estavam abaixo da carga máxima das mesmas, já considerados os coeficientes de segurança.

O processo construtivo das estruturas de concreto e o sistema temporário de apoio são responsáveis por tornar, a partir de uma dada etapa construtiva, os valores dos fatores de carga convergentes. Assim, será considerada a distribuição dos fatores de carga até um certo número de pavimentos de tal forma que os fatores de carga não tenham seu valor alterado significativamente. Situação comum observada nas análises foi atingir a convergência dos fatores de carga nas etapas construtivas 
subseqüentes às etapas em que não mais haviam escoras ligadas à fundação.

Os deslocamentos elásticos $\left(\Delta_{\mathrm{e}}\right)$ apresentados nas tabelas a seguir correspondem aos deslocamentos de entrada em serviço do pavimento (365 dias). Notar que o valor de $\Delta_{e}$ nessa situação não depende das etapas construtivas. Já os deslocamentos imediatos levam em consideração a perda de rigidez do elemento estrutural introduzida, inicialmente, pelas etapas construtivas e finalmente pela entrada em serviço do pavimento. Deve-se somar a esses deslocamentos os já definidos no capítulo 5 para se encontrar as flechas no tempo infinito.

Todas as verificações do estado limite último na situação construiva de projeto são feitas nas etapas de concretagem, pois elas produziram para essa análise sempre as maiores solicitações nos pontos escolhidos dos pavimentos.

Juntamente ao cálculo da armadura é verificada a segurança contra a ruptura do concreto em sua área comprimida.

Para as verificações das deformações excessivas são considerados pontos do pavimento que apresentem tanto as maiores solicitações quanto as maiores razões deslocamento/vão. O cálculo do deslocamento transversal de um ponto dependerá do tipo de apoio nos extremos do vão considerado. Caso os apoios sejam indeslocáveis (paredes ou pilares), o deslocamento no ponto é o valor que corresponde à deformação máxima do elemento estrutural. Caso os apoios sejam deslocáveis (vigas), considera-se por simplicidade que a flecha no ponto é o valor do deslocamento máximo do elemento estrutural menos a média aritmética dos deslocamentos nos apoios.

\subsection{LAJE PLANA APOIADA EM PILARES}

O primeiro caso de análise a ser realizado é o de um edifício com sistema estrutural em laje plana utilizado para escritórios, estudado por FRANÇA (1985) quanto à estabilidade global. A planta de formas de meio pavimento tipo simétrico é apresentada na figura 6.1 .

Os carregamentos considerados no pavimento, além do peso próprio do mesmo, correspondem a: $1,0 \mathrm{kN} / \mathrm{m}^{2}$ referente a piso e revestimento, $1,0 \mathrm{kN} / \mathrm{m}^{2}$ referente às divisórias leves (sistema de vedação interno) e $3,0 \mathrm{kN} / \mathrm{m}^{2}$ referente à sobrecarga de utilização. 


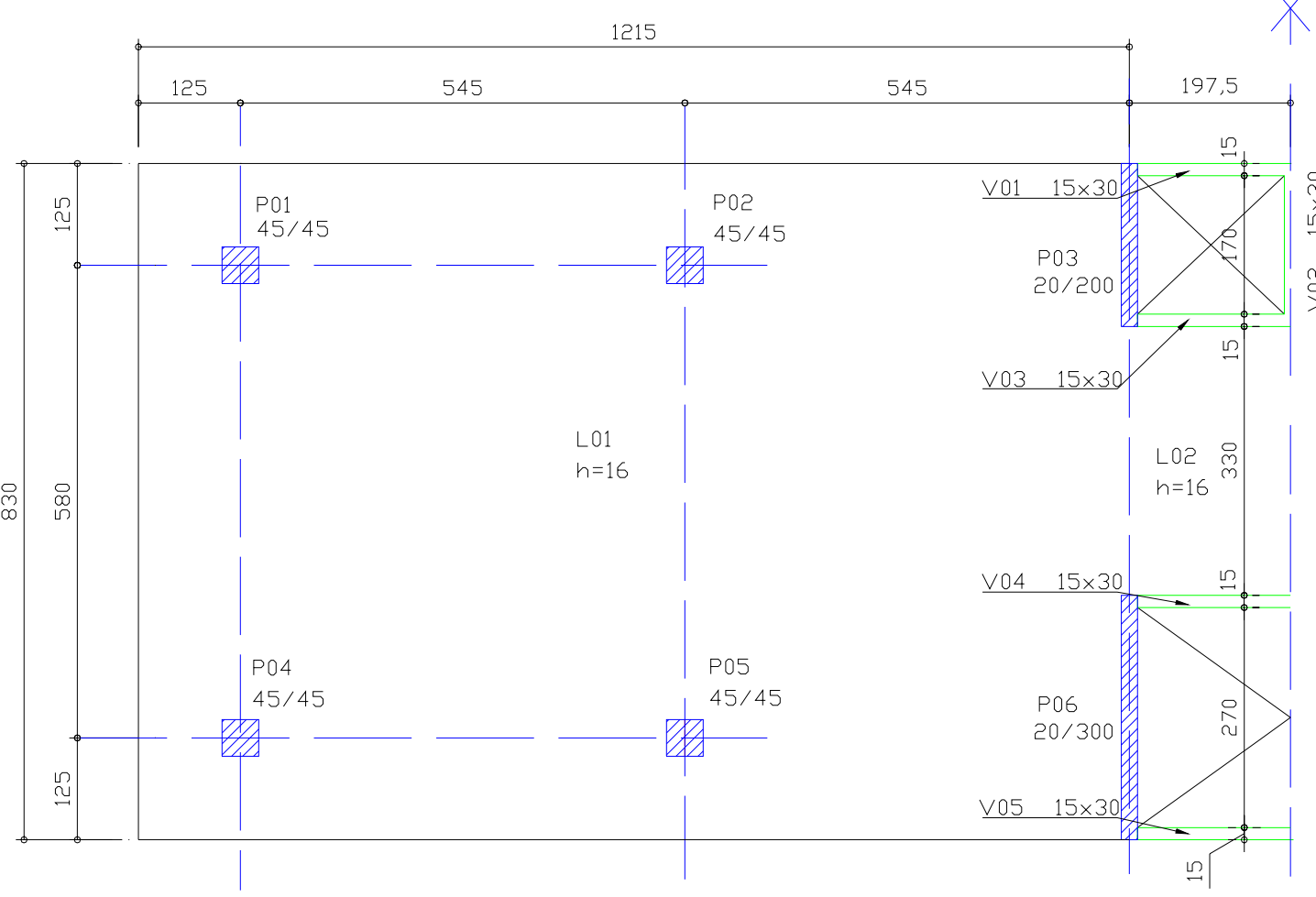

Figura 6.1 - Planta de formas de meio pavimento tipo (cm) - Laje Plana.

$\mathrm{Na}$ tabela 6.1 são apresentados quantitativos e medidas relativas a meio pavimento tipo.

Tabela 6.1 - Quantitativos e medidas para meio pavimento tipo - Laje Plana.

\begin{tabular}{|c|c|c|c|c|c|}
\hline $\begin{array}{c}\text { Espessura } \\
\text { da laje } \\
\text { (m) }\end{array}$ & $\begin{array}{l}\text { Distância } \\
\text { de piso a } \\
\text { piso } \\
\text { (m) }\end{array}$ & $\begin{array}{c}\text { Peso } \\
\text { próprio do } \\
\text { pavimento } \\
\text { (kN) }\end{array}$ & $\begin{array}{c}\text { Área em } \\
\text { planta } \\
\left(\mathrm{m}^{2}\right)\end{array}$ & $\begin{array}{c}1,0 \mathrm{~g} \\
\left(\mathrm{kN} / \mathrm{m}^{2}\right)\end{array}$ & $\begin{array}{c}0,85 \mathrm{~g} \\
\left(\mathrm{kN} / \mathrm{m}^{2}\right)\end{array}$ \\
\hline 0,16 & 2,90 & 440,60 & 107,70 & 4,10 & 3,48 \\
\hline
\end{tabular}

6.2.1 SISTEMAS DE ESCORAMENTOS E PONTOS PARA VERIFICAÇÃO DOS ESTADOS LIMITES.

Para o processo construtivo convencional a distribuição do escoramento pelo pavimento pode ser visto na figura 6.2. O aspecto da laje de concreto e do sistema de escoramento para esse sistema construtivo, depois de modelados no STRAP, são vistos em perspectiva na figura 6.3. 


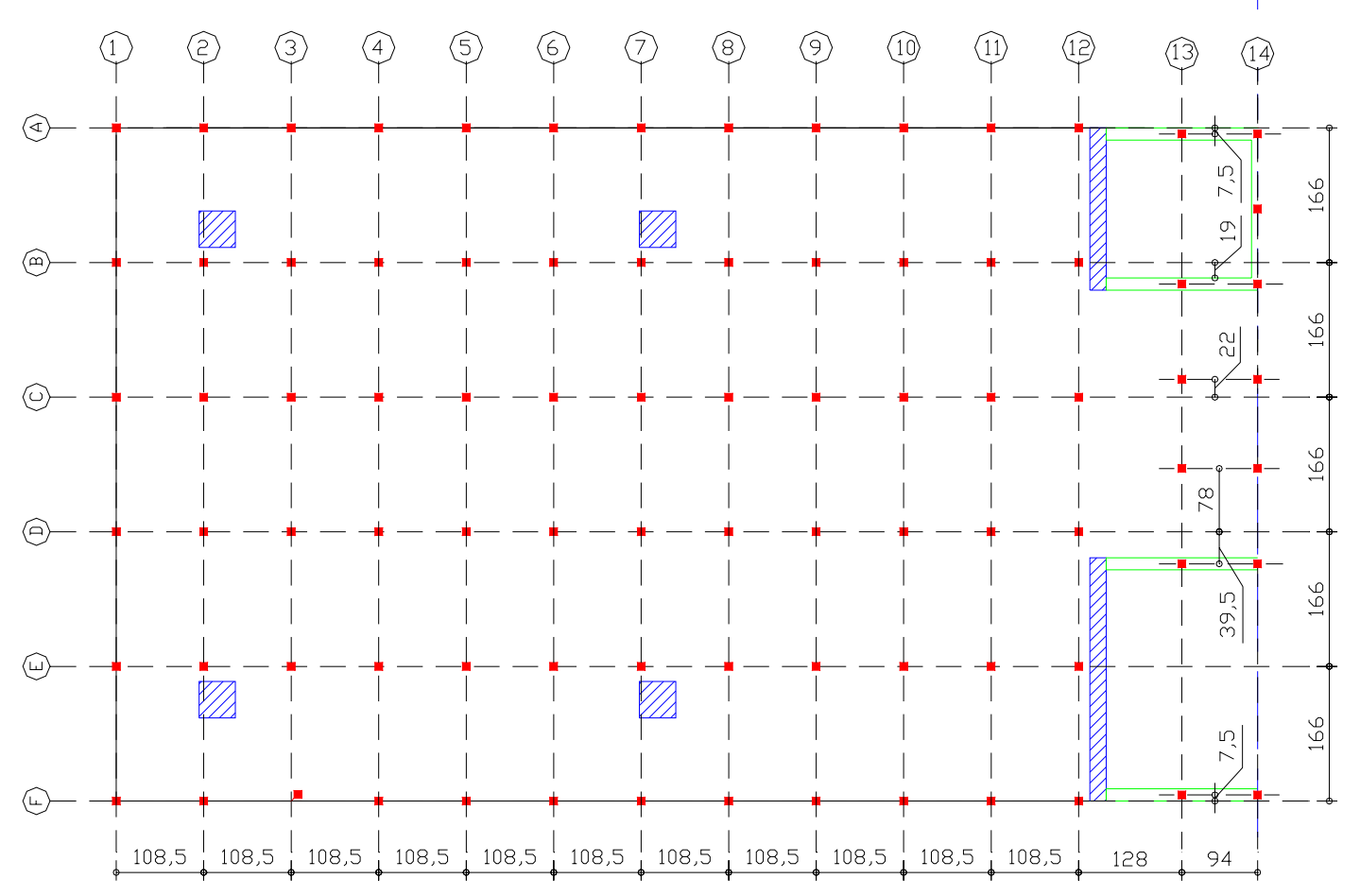

Figura 6.2 - Distribuição das escoras pelo pavimento para o processo construtivo convencional $(\mathrm{cm})$ - Laje Plana.

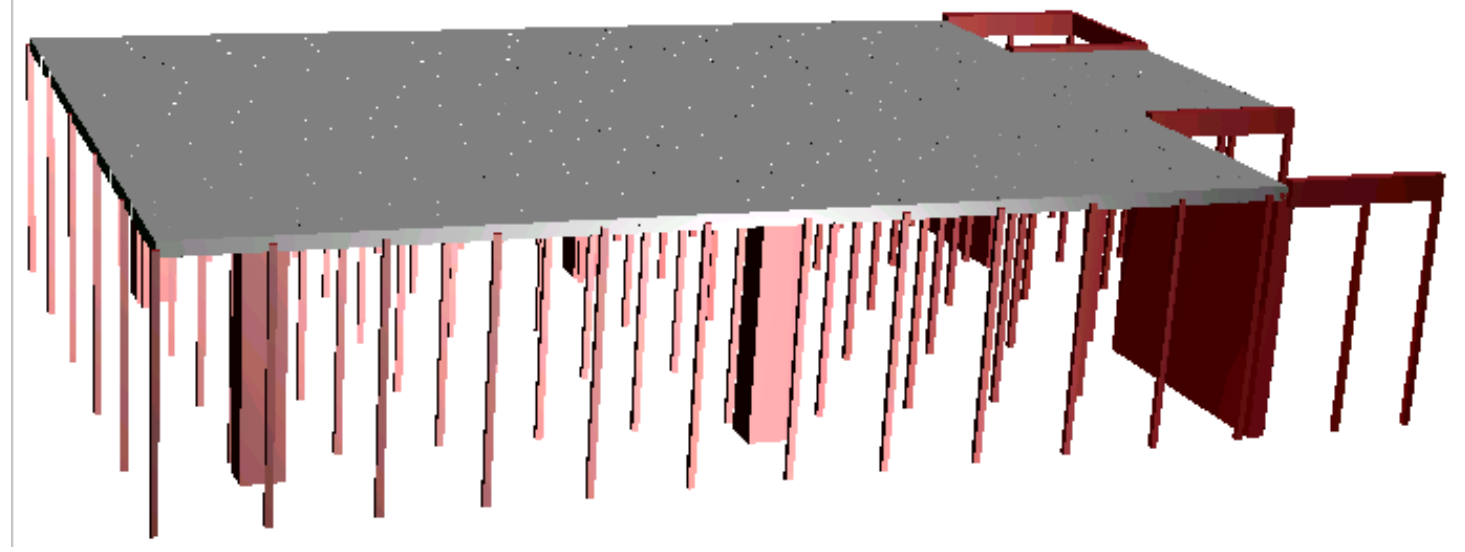

Figura 6.3 - Aspecto do pavimento tipo para o processo construtivo convencional (etapa construtiva) - Laje Plana

Para o processo construtivo racionalizado, as figuras 6.4 e 6.5 indicam a distribuição do escoramento metálico respectivamente para escoras e reescoras com pré-carga. O espaçamento máximo entre escoras é de 2,0m x 1,0m para a laje L01, o que corresponde a um painel de fôrma. A distribuição das reescoras com précarga, depois de retirada parcial das escoras, é de $2,0 \mathrm{~m} \times 2,0 \mathrm{~m}$. 


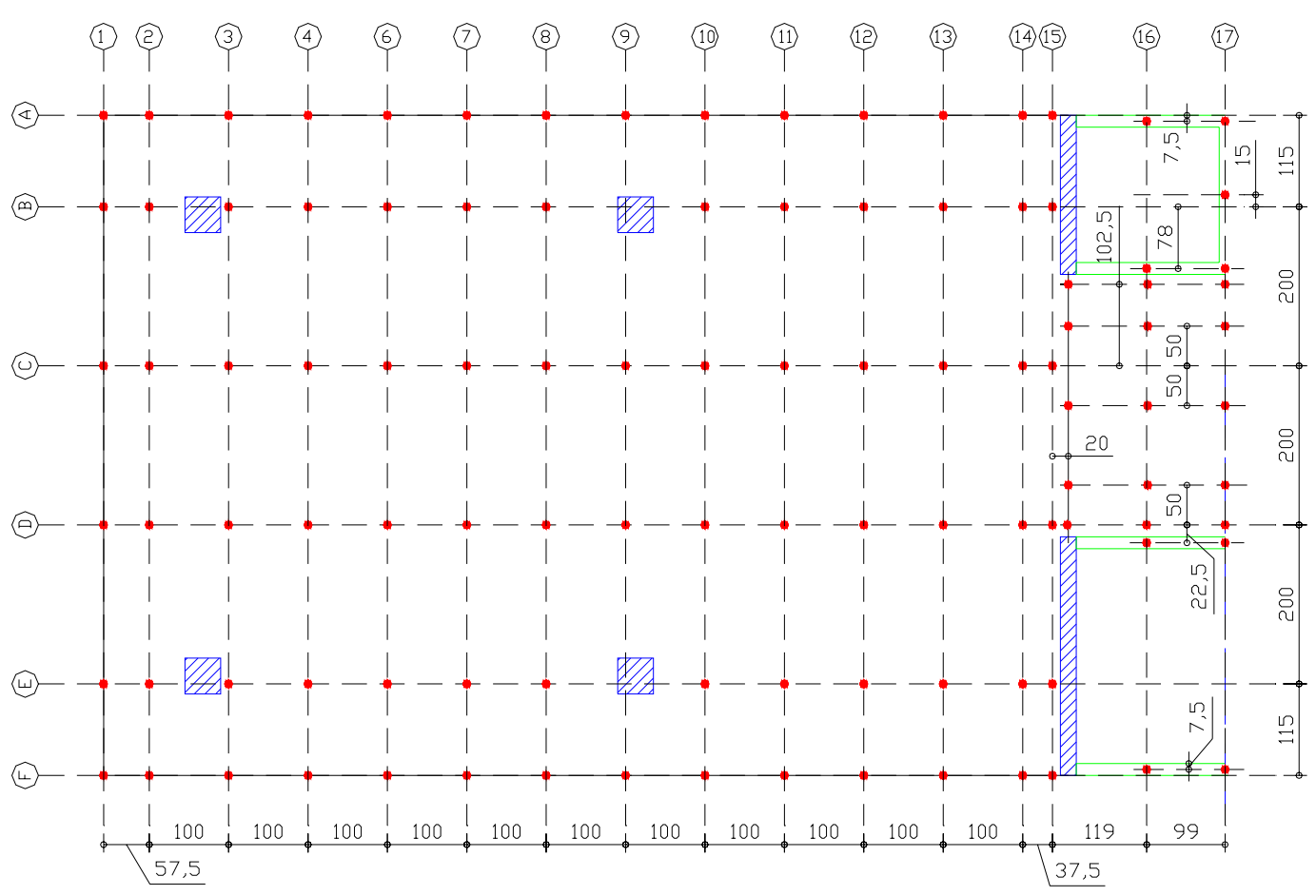

Figura 6.4 - Distribuição das escoras pelo pavimento para o processo construtivo racionalizado $(\mathrm{cm})$ - Laje Plana.

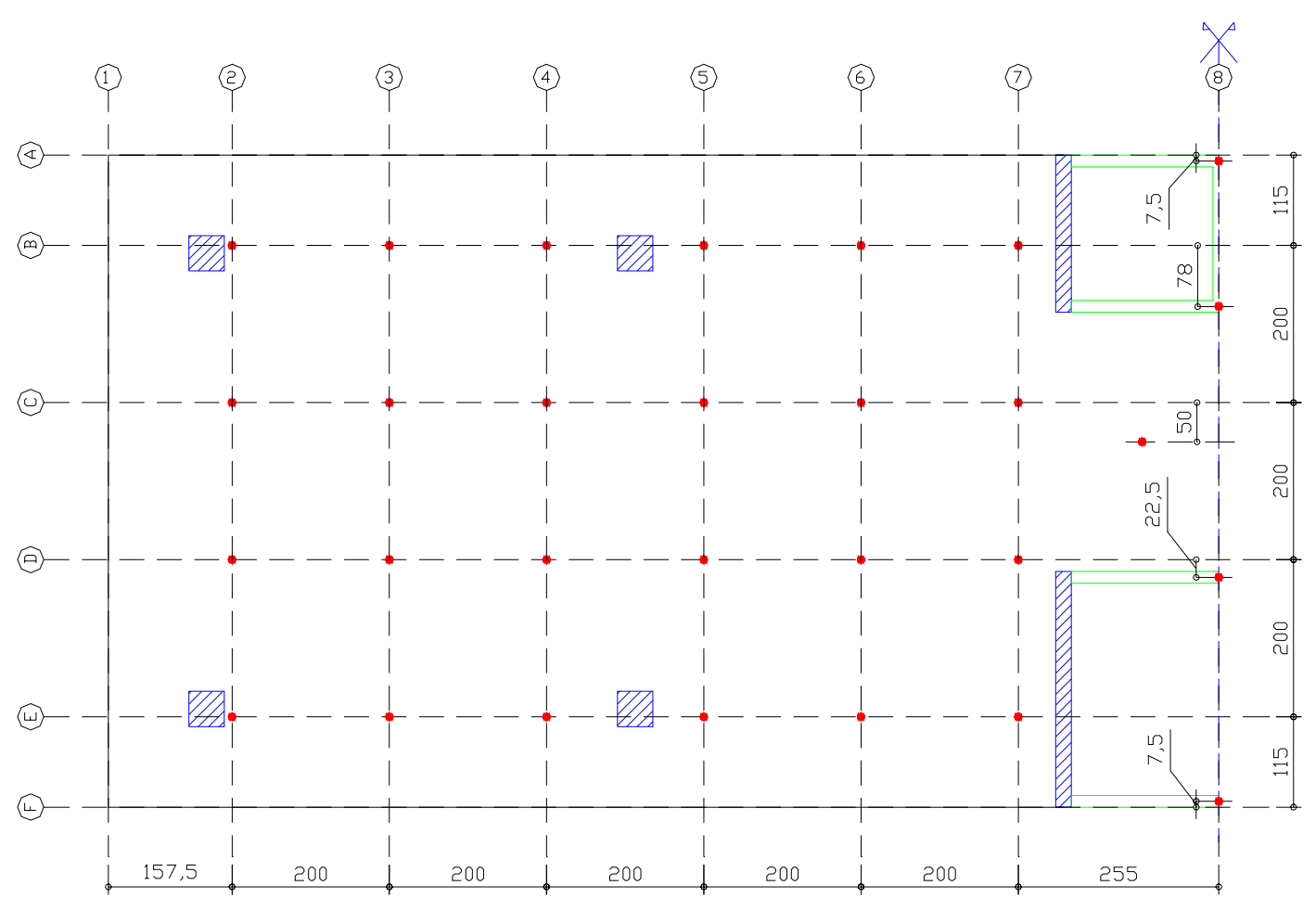

Figura 6.5 - Distribuição das reescoras com pré-carga pelo pavimento para o processo construtivo racionalizado $(\mathrm{cm})$ - Laje Plana 
As tabelas 6.2 e 6.3 identificam as proporções de absorção de carga obtidas pelas modelagens das estruturas primárias. Com esses valores pode-se encontrar os fatores de carga que ocorrem no sistema temporário de apoio durante as etapas construtivas do pavimento adotado com sistema estrutural laje plana.

Tabela 6.2 - Proporções de absorção de carga - Laje Plana e $f_{c k}=30 M P a$.

\begin{tabular}{|c|c|c|c|c|}
\hline \multirow{2}{*}{$\begin{array}{l}\text { Processo } \\
\text { construtivo }\end{array}$} & \multirow{2}{*}{$\begin{array}{c}\text { Material } \\
\text { das } \\
\text { escoras }\end{array}$} & \multirow{2}{*}{$\begin{array}{c}\text { Estrutura } \\
\text { primária }\end{array}$} & \multicolumn{2}{|c|}{$\begin{array}{c}\text { Proporção de Absorção de } \\
\text { carga (\%) }\end{array}$} \\
\hline & & & Escoras & Pavimento \\
\hline \multirow{3}{*}{ Convencional } & \multirow{3}{*}{ Madeira } & EP1 & 60 & 40 \\
\hline & & EP2 & 28 & 72 \\
\hline & & EP3 & 39 & 61 \\
\hline \multirow{5}{*}{ Racionalizado } & \multirow{5}{*}{ Aço } & EP1 & 74 & 26 \\
\hline & & EP2 & 37 & 63 \\
\hline & & EP3 & 42 & 58 \\
\hline & & EP4 & 57 & 43 \\
\hline & & EP5 & 34 & 66 \\
\hline
\end{tabular}

Tabela 6.3 - Proporções de absorção de carga - Laje Plana e $\mathrm{f}_{\mathrm{ck}}=20 \mathrm{MPa}$.

\begin{tabular}{llccc}
\hline \multirow{2}{*}{$\begin{array}{c}\text { Processo } \\
\text { Construtivo }\end{array}$} & $\begin{array}{c}\text { Material } \\
\text { das } \\
\text { Escoras }\end{array}$ & $\begin{array}{c}\text { Estrutura } \\
\text { Primária }\end{array}$ & \multicolumn{2}{c}{$\begin{array}{c}\text { Proporção de Absorção } \\
\text { de Carga (\%) }\end{array}$} \\
\cline { 3 - 5 } & \multirow{3}{*}{ Madeira } & EP1 & 64 & 36 \\
\cline { 3 - 5 } Convencional & & EP2 & 30 & 70 \\
\cline { 3 - 5 } & \multirow{3}{*}{ Aço } & EP3 & 42 & 58 \\
\cline { 3 - 5 } & & EP1 & 75 & 25 \\
\cline { 3 - 5 } & & EP2 & 32 & 68 \\
\cline { 3 - 5 } & & EP3 & 47 & 53 \\
\hline \multirow{3}{*}{ Racionalizado } & \multirow{2}{*}{ Aço } & EP1 & 76 & 24 \\
\cline { 3 - 5 } & & EP2 & 38 & 62 \\
\cline { 3 - 5 } & & EP3 & 43 & 57 \\
\cline { 3 - 5 } & & EP4 & 60 & 40 \\
\cline { 3 - 5 } & & EP5 & 35 & 65 \\
\hline
\end{tabular}

\subsubsection{EXEMPLO DE APLICAÇÃO DO MEP}

A situação construtiva utilizada como exemplo detalhado de aplicação do MEP é a seguinte:

- Sistema estrutural: laje plana;

- Sistema temporário de apoio: $(2+1)$; 
- Processo construtivo: convencional;

- Material de escoras e reescoras: madeira;

- Ciclo de construção: 7 dias;

- $\mathrm{f}_{\mathrm{ck}}: 20 \mathrm{MPa}$.

Nessa situação construtiva as proporções de absorção de carga pelas escoras e pelo pavimento podem ser vistas na tabela 6.3. Essas proporções não depedem do número de pavimentos escorados/reescorados e do ciclo de construção adotados na situação construtiva.

O caminhamento das cargas por pavimentos e escoramentos durante a construção segue o esquema da figura 6.6. As convenções no início da figura identificam as cargas absorvidas e acumuladas na etapa construtiva. Notar que a carga acumulada é incremental (leva em conta as etapas $n$ anteriores) e a carga absorvida é a que será distribuída pelo sistema temporário de apoio segundo as proporções de absorção de carga.

Os fatores de carga atuantes nos pavimentos até a etapa considerada são representados pela carga acumulada nos pilares, da mesma forma, os fatores de carga atuantes nas escoras até a etapa considerada são representados pela carga acumulada nas escoras. Estes fatores de carga são utilizados para se encontrar as ações de construção que atuam em pavimentos e escoramentos necessários às verificações dos estados limites na situação construtiva de projeto.

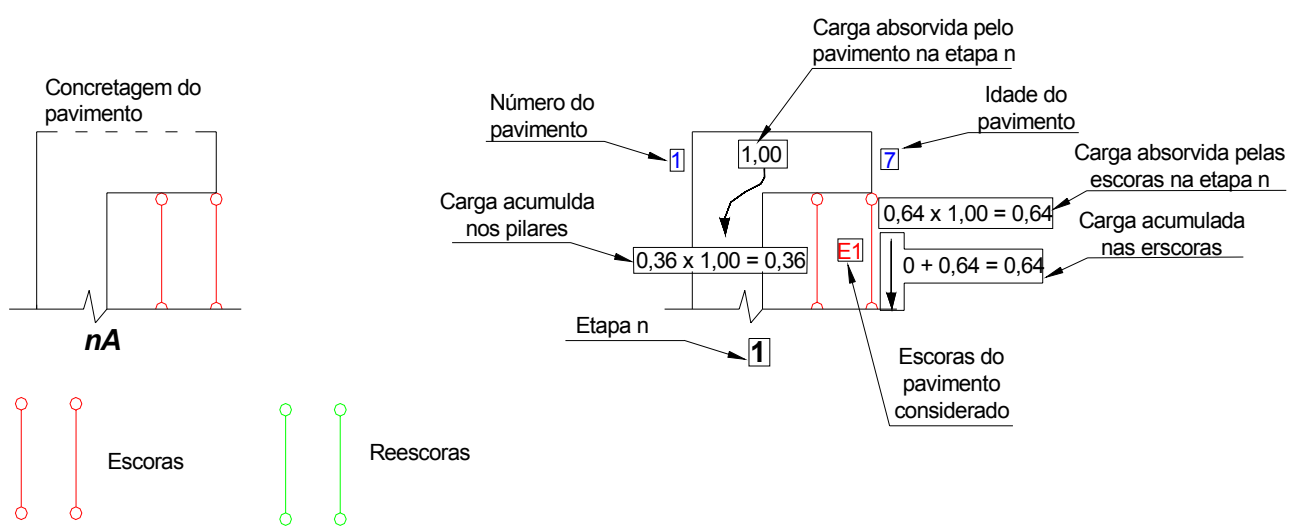

Figura 6.6 a - Caminhamento das cargas por pavimentos e escoramentos - Laje Plana 


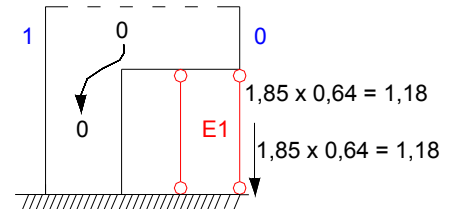

$1 A$

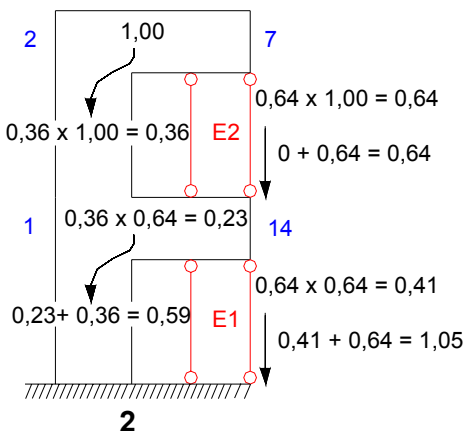

2

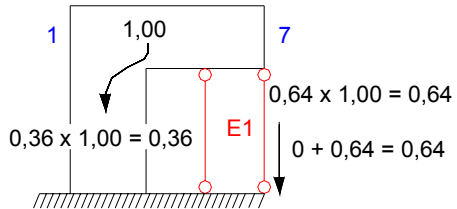

1

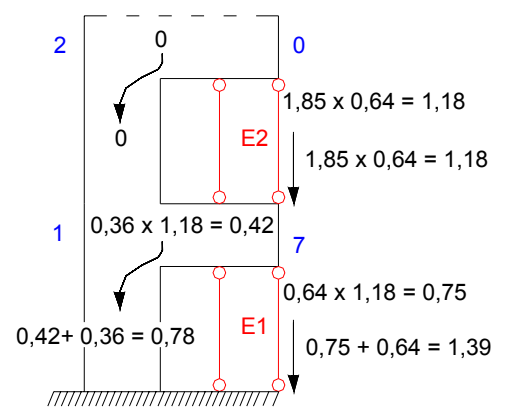

$2 A$
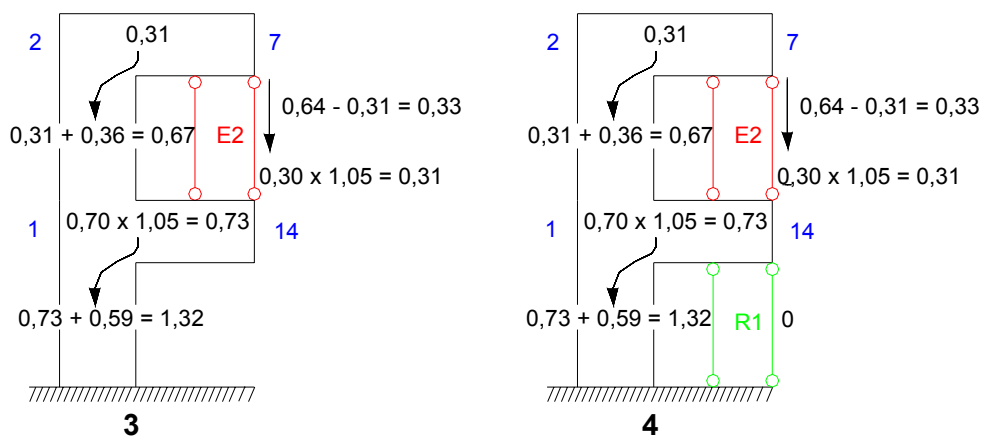

Figura 6.6 b - Caminhamento das cargas por pavimentos e escoramentos - Laje Plana. 

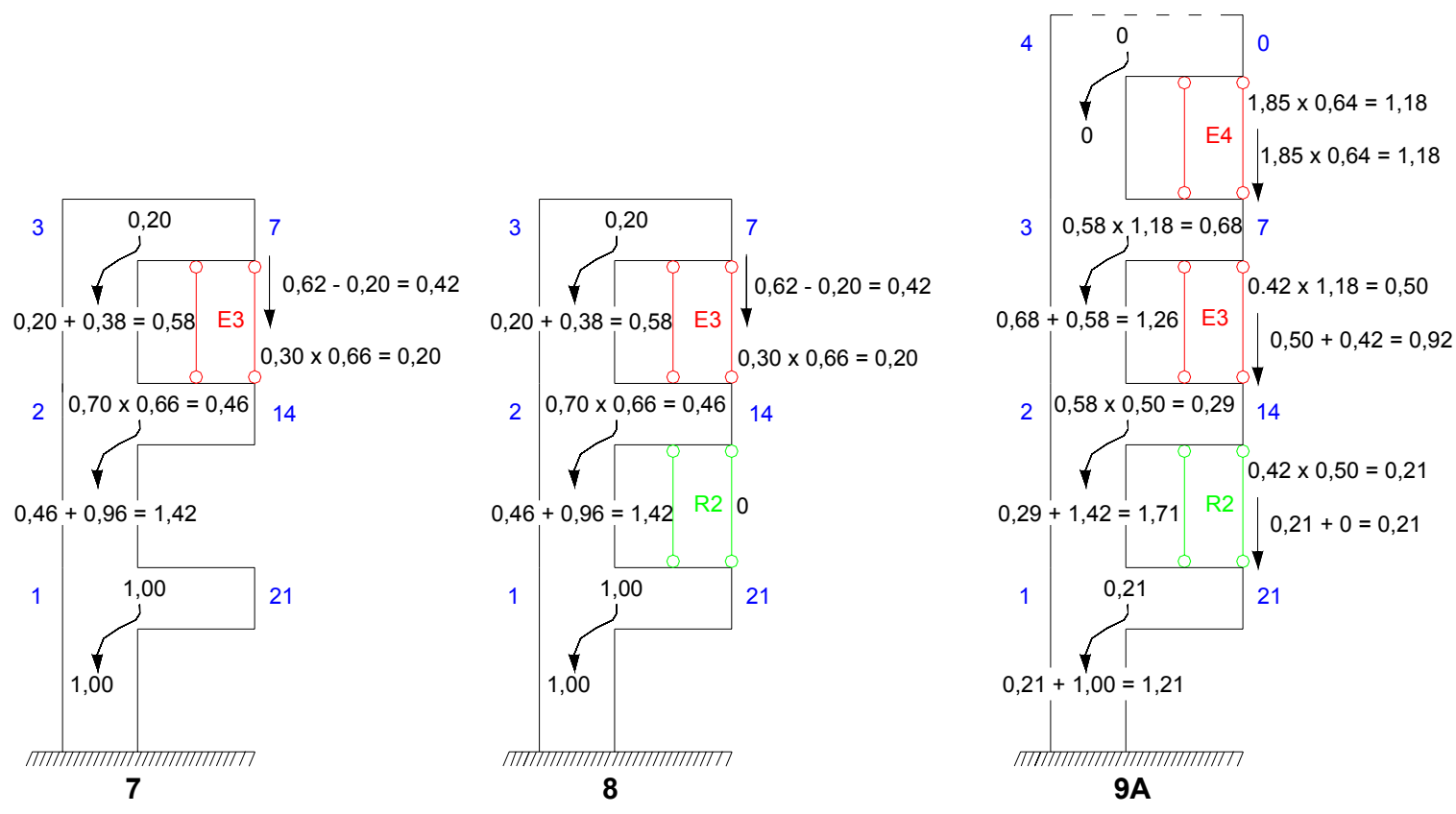

Figura $6.6 \mathrm{c}$ - Caminhamento das cargas por pavimentos e escoramentos - Laje Plana.

Descrevem-se abaixo as etapas indicadas pelo MEP para o cálculo dos fatores de carga que ocorrem nos pavimentos e escoramentos para a situação construtiva do exemplo.

\section{- ETAPA 1A - Concretagem do $1^{\circ}$ pavimento;}

Utilizam-se as proporções de absorção de carga encontradas na modelagem da EP1. Nesta etapa o pavimento não absorve carga pois o concreto está fresco e, conseqüentemente, a carga acumulada transmitida aos pilares vale zero. O pavimento está submetido ao carregamento $1,85 \times \mathrm{g}$ e as escoras absorvem $64 \%$ desse valor, ficando submetidas à carga acumulada de 1,18.

\section{- ETAPA 1 - Amadurecimento do concreto do $1^{\circ}$ pavimento;}

A carga absorvida pelo pavimento nesta etapa corresponde apenas ao peso próprio do mesmo $(k=1,00)$. Este fator de carga será transmitido para escoras e pilares segundo as proporções de absorção de carga da EP1. É importante lembrar que as absorções de carga dos pilares representam a absorção do próprio pavimento.

As etapas de concretagem (anteriores) não contribuem no valor de carga acumulada das escoras E1. Dessa forma as escoras ficam submetidas à carga 
acumulada correspondente a $64 \%$ da carga absorvida pelo pavimento $(0,64 \times 1,00=0,64)$. Já os pilares absorvem o restante do carregamento, ou seja, $36 \%$ da carga absorvida pelo pavimento na etapa $(0,36 \times 1,00=0,36)$. A carga acumulada nas escoras E1 é transmitida diretamente para a fundação. Da mesma forma, os pilares do primeiro pavimento transmitem a carga acumulada que recebem diretamente para a fundação.

Deve-se reafirmar as diferenças entre as etapas 1 e 1A: além do amadurecimento do concreto, na etapa 1 deixam de atuar as ações variáveis de construção.

\section{- ETAPA 2A - Concretagem do $2^{\circ}$ pavimento;}

Como existem escoras ligadas diretamente à fundação, realiza-se a transmissão da carga introduzida por essa etapa para pavimentos e escoras segundo as proporções de absorção de carga encontradas na EP1.

O procedimento utilizado para a transmissão de carga do pavimento concretado para as escoras E2 e para os pilares do segundo pavimento é exatamente o da etapa $1 \mathrm{~A}$.

O primeiro pavimento absorve $36 \%$ da carga absorvida pelas escoras E2 nessa etapa $(0,36 \times 1,18=0,42)$ e transmite aos pilares que, por sua vez, acrescentam a esse valor o que possuem na etapa $1(0,42+0,36=0,78)$. As escoras $E 1$ absorvem o restante, ou seja, $64 \%$ da carga absorvida pelas escoras E2 nessa etapa $(0,64 \times 1,18=0,75)$ e acrescentam a esse valor o que possuem na etapa 1 $(0,75+0,64=1,39)$.

\section{- ETAPA 2 - Amadurecimento do concreto do $2^{\circ}$ pavimento;}

Da mesma forma que na etapa $2 \mathrm{~A}$, como existem escoras ligadas diretamente à fundação, realiza-se a transmissão de carga para pavimentos e escoras segundo as proporções de absorção de carga encontradas na EP1.

$\mathrm{Na}$ etapa 2 o concreto do segundo pavimento já possui determinado amadurecimento. Nesta etapa a carga absorvida pelo pavimento corresponde apenas ao peso próprio do mesmo $(\mathrm{k}=1,00)$. $\mathrm{O}$ procedimento de transmissão de carga deste pavimento para as escoras E2 e para os pilares do segundo pavimento é o mesmo da etapa 1.

O primeiro pavimento absorve $36 \%$ da carga absorvida pelas escoras E2 
nessa etapa $(0,36 \times 0,64=0,23)$ e transmite aos pilares que, por sua vez, acrescentam a esse valor o que possuem na etapa $1(0,23+0,36=0,59)$. As escoras $E 1$ absorvem $64 \%$ da carga absorvida pelas escoras E2 nessa etapa $(0,64 \times 0,64=0,41)$ e é acrescentado a esse valor o que possuem na etapa $1(0,41+0,64=1,05)$. Lembrando que as etapas $n A$ não participam do somatório de cargas. A carga acumulada nas escoras E1 $(1,05)$ é transmitida diretamente para a fundação. Da mesma forma, a carga acumulada dos pilares do primeiro pavimento $(0,59)$ é acrescentada à carga acumulada dos pilares do segundo pavimento $(0,36)$ e esse total $(0,59+0,36=0,95)$ é transmitido diretamente para a fundação. Percebe-se que a fundação deve receber um total de carga correspondente ao peso próprio da quantidade de pavimentos já concretados, que nesse caso são dois. Para conferir esse valor basta somar a carga transmitida pelas escoras E1 à fundação à carga transmitida pelos pilares do primeiro pavimento também à fundação que, na etapa em estudo vale $0,95+1,05=$ 2,00 (peso próprio de dois pavimentos). A verificação da quantidade de carga que é transmitida à fundação, como foi feito, vale para todas etapas construtivas a menos das etapas $n A$.

\section{- ETAPA 3 - Retirada total das escoras E1;}

$\mathrm{Na}$ etapa de retirada total das escoras, a transmissão de carga é realizada segundo as proporções de absorção de carga encontradas na modelagem da EP2.

As escoras E1, no instante da retirada total, possuem carga acumulada $\mathrm{k}=1,05$ (etapa anterior). Desse valor, $70 \%$ é absorvido pelo pavimento $(0,70 \times 1,05=0,73)$. Essa carga é transmitida aos pilares que acrescentam a esse valor o que já possuem na etapa $2(0,73+0,59=1,32)$. Do restante de carga que não é absorvido pelo pavimento corresponde, então, ao valor absorvido pelas escoras E2. É necessário atenção, pois a proporção de absorção de carga indicada pela EP2 para as escoras de $30 \%$ representa um alívio das mesmas em relação à carga retirada. Nesse caso o valor do alívio nas escoras E2 vale $0,31(0,30 \times 1,05=0,31)$. A carga acumulada nas escoras E2 nessa etapa corresponde ao valor que possuem na etapa 2 menos o valor do alívio $(0,64-0,31=0,33)$.

\section{- ETAPA 4 - Reposição das escoras retiradas;}

Nesta etapa ocorre a reposição total das escoras retiradas do primeiro pavimento que atuam, agora, como reescoras (R1). Permanecendo a hipótese de que essas reescoras são instaladas sem pré-carga, esse novo evento não altera a 
distribuição de cargas da etapa anterior.

\section{- ETAPAS - 5A, 5, 6, 7 e 8;}

Nas etapas 5A e 5 o procedimento utilizado para a transmissão das cargas é semelhante ao das etapas $2 \mathrm{~A}$ e 2 . Já nas etapas 6 e 7 (retirada total das escoras) o procedimento é semelhante ao da etapa 3 . Na etapa 8 o segundo pavimento é reescorado, não ocorrendo modificação nos valores das cargas fixados na etapa 7 .

\section{- ETAPA 9A - Concretagem do $4^{\circ}$ pavimento;}

O MEP indica que a transmissão de carga do pavimento concretado para as escoras E4 e pilares do quarto pavimento segue o procedimento aplicado na etapa $1 \mathrm{~A}$, porém, como não há mais escoras ligadas diretamente à fundação mudam as proporções de absorção de carga entre pavimento e escoras a partir do terceiro pavimento. É necessário utilizar as proporções de absorção de carga indicadas pela modelagem da EP3, que representam as etapas que não possuem escoras ligadas à fundação.

Assim, o terceiro pavimento absorve $58 \%$ da carga absorvida pelas escoras E4 $(0,58 \times 1,18=0,68)$ e transmite aos pilares que, por sua vez, acrescentam a esse valor o que já possuem na etapa $8(0,68+0,58=1,26)$. As escoras $E 3$ absorvem $42 \%$ da carga absorvida pelas escoras $E 4(0,42 \times 1,18=0,50)$ e acrescenta-se a esse valor o que possuem na etapa $8(0,50+0,42=0,92)$.

O segundo pavimento absorve $58 \%$ da carga absorvida pelas escoras E3 $(0,58 \times 0,50=0,29)$ e transmite aos pilares que, por sua vez, acrescentam a esse valor o que possuem na etapa $8(0,29+1,42=1,71)$. As reescoras $\mathrm{R} 2$ absorvem $42 \%$ da carga absorvida pelas escoras E3 $(0,42 \times 0,50=0,21)$, como na etapa 8 as reescoras R2 não possuem carga, estas permanecem com carga acumulada de 0,21. Como não existem escoras ligando o primeiro pavimento à fundação, este absorve integralmente a carga acumulada das reescoras R2 e a transmite aos pilares do primeiro pavimento que, por sua vez, acrescentam a esse valor o que possuem na etapa $8(0,21+1,00=1,21)$.

$\mathrm{Na}$ etapa de número 9 ocorre o amadurecimento do concreto após mais um ciclo de 7 dias. O sistema temporário de apoio é semelhante ao da etapa 5 , porém com o primeiro pavimento livre de escoras. Assim, o procedimento utilizado para a transmissão de carga, a partir dessa etapa, segue a mesma metodologia das etapas ora descritas. Conseqüentemente, os valores de carga acumulada em pilares e 
escoras, para cada etapa, tendem a convergir.

No exemplo de aplicação do MEP, os maiores fatores de carga ocorrem nas etapas de concretagem $(n A)$. Dessa forma, esses fatores de carga devem ser majorados convenientemente pelos coeficientes de ponderação da combinação última de construção para se realizarem as verificações do estado limite último propostas pelo trabalho. As etapas restantes já fornecem os valores dos fatores de carga (característicos) que serão utilizados para a verificação do estado limite de serviço.

Depois de feita a distribuição dos fatores de carga pode-se realizar as verificações de segurança e deformação excessiva. Para essas verificações serão considerados os pontos PL1 e PL2 mostrados na figura 6.7. Apesar do vão considerado para o ponto PL3 entre apoios (pilares) ser maior que o vão considerado para o ponto PL1 (pilares P02 e P05), este último apresenta maiores esforços e maior relação deslocamento/vão em comparação com o PL3.

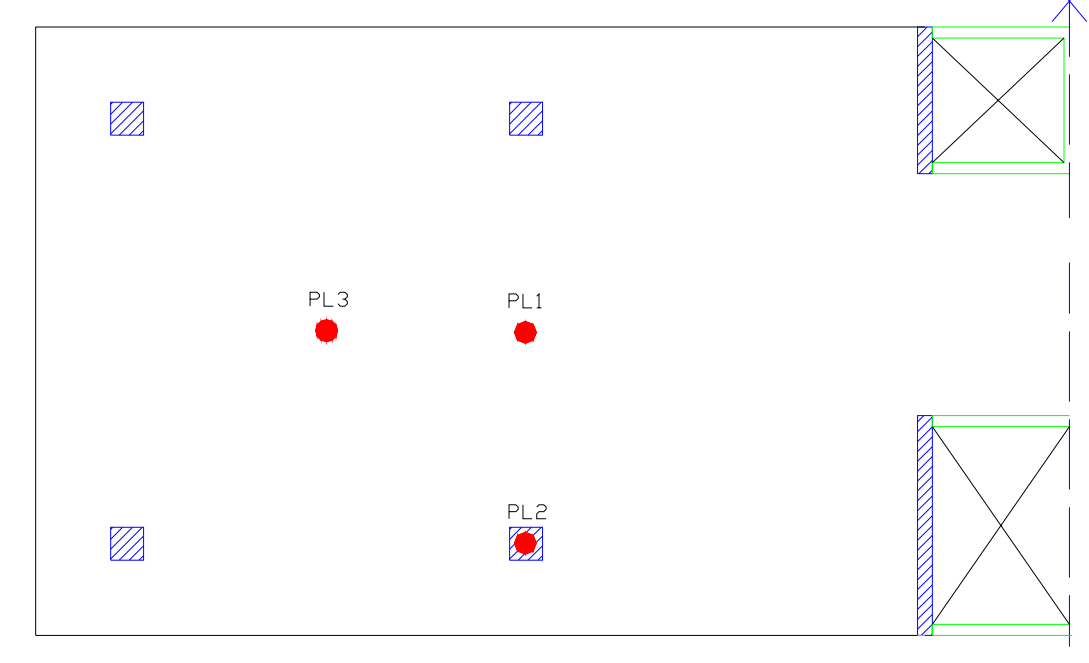

Figura 6.7 - Pontos do pavimento para verificação da segurança e da deformação excessiva - Laje Plana.

\subsubsection{VERIFICAÇÃO DO ESTADO LIMITE ÚLTIMO}

\subsubsection{Pontos PL1 e PL2 e $f_{c k}=20 M P a$.}

As armaduras longitudinais existentes $\left(A_{s e}\right)$ nos pontos PL1 e PL2 na situação usual de projeto podem ser vistas na tabela 6.4 . 
Tabela 6.4 - $\mathrm{A}_{\mathrm{se}}$ para pontos de laje - Laje Plana e $\mathrm{f}_{\mathrm{ck}}=20 \mathrm{MPa}$.

\begin{tabular}{cc}
\hline \multicolumn{2}{c}{$\mathbf{A}_{\text {se }}\left(\mathrm{cm}^{2} / \mathrm{m}\right)$} \\
\hline PL1 & PL2 \\
\hline 4,52 & 7,45 \\
\hline
\end{tabular}

A tabela 6.5 mostra além das situações construtivas, os fatores de carga $(k)$, as idades, e as armaduras longitudinais necessárias $\left(A_{s n}\right)$. Essas armaduras foram determinadas considerando-se a situação construtiva de projeto para os pavimentos que apresentam nos pontos considerados as maiores solicitações durante as etapas construtivas e, conseqüentemente, as maiores taxas de armadura. A penúltima coluna (Pav.) identifica os pavimentos nessa situação e a última coluna (Con. Pav.) identifica o pavimento cuja concretagem provoca tal situação.

Tabela 6.5 - $\mathrm{A}_{\mathrm{sn}}$ para os pontos PL1 e PL2 - Laje Plana e $\mathrm{f}_{\mathrm{ck}}=20 \mathrm{MPa}$.

\begin{tabular}{|c|c|c|c|c|c|c|c|c|c|}
\hline \multirow{2}{*}{$\begin{array}{c}\text { Sist. } \\
\text { Temp. }\end{array}$} & \multirow{2}{*}{$\begin{array}{l}\text { Proc. } \\
\text { Cons. }\end{array}$} & \multirow{2}{*}{ Mate. } & \multirow{2}{*}{$\begin{array}{l}\text { Ciclo } \\
\text { Cons. }\end{array}$} & \multirow{2}{*}{ k } & \multirow{2}{*}{$\begin{array}{l}\text { Idade } \\
\text { (dias) }\end{array}$} & \multicolumn{2}{|c|}{$A_{s n}\left(\mathrm{~cm}^{2} / \mathrm{m}\right)$} & \multirow{2}{*}{ Pav. } & \multirow{2}{*}{$\begin{array}{l}\text { Con } \\
\text { Pav. }\end{array}$} \\
\hline & & & & & & PL1 & PL2 & & \\
\hline \multirow{4}{*}{$(2+1)$} & \multirow{2}{*}{ Conv. } & Mad. & 7 & 1,78 & 14 & 2,55 & 4,00 & 2 & 4 \\
\hline & & Aço & 3 & 1,89 & 6 & 2,74 & 4,34 & 2 & 4 \\
\hline & \multirow{2}{*}{ Rac. } & Aço & 7 & 1,93 & 21 & 2,77 & 4,35 & 1 & 4 \\
\hline & & Aço & 3 & 1,93 & 9 & 2,79 & 4,38 & 1 & 4 \\
\hline \multirow{2}{*}{$(1+1)$} & Conv. & Aço & 3 & 1,92 & 3 & 2,82 & 4,48 & 2 & 3 \\
\hline & Rac. & Aço & 3 & 1,96 & 3 & 2,88 & 4,58 & 3 & 4 \\
\hline
\end{tabular}

A situação crítica corresponde ao sistema temporário de apoio (1+1) com processo construtivo racionalizado, utilizando escoras/reescoras de aço e ciclo de construção de 3 dias. Essa situação ocorre no terceiro pavimento durante a concretagem do quarto piso. A tabela 6.6 permite a comparação entre armadura existente e necessária para a situação crítica analisada.

Tabela 6.6 - Comparação entre armaduras - Laje Plana e $\mathrm{f}_{\mathrm{ck}}=20 \mathrm{MPa}$.

\begin{tabular}{cccc}
\hline Ponto & $\begin{array}{c}\mathbf{A}_{\text {se }} \\
\left(\mathbf{c m}^{2} / \mathbf{m}\right)\end{array}$ & $\begin{array}{c}\mathbf{A}_{\text {sn }} \\
\left(\mathbf{c m}^{2} / \mathbf{m}\right)\end{array}$ & $\begin{array}{c}\mathbf{A}_{\text {sn }} / \mathbf{A}_{\text {se }} \\
(\mathbf{\%})\end{array}$ \\
\hline PL1 & 4,52 & 2,88 & 64 \\
\hline PL2 & 7,45 & 4,58 & 61 \\
\hline
\end{tabular}

Percebe-se que as armaduras necessárias na situação crítica estão abaixo 
das existentes, garantindo a segurança estrutural durante as etapas construtivas.

\subsubsection{Pontos PL1 e PL2 e $f_{c k}=30 M P a$}

As armaduras longitudinais existentes $\left(A_{s e}\right)$ nos pontos PL1 e PL2, na situação usual de projeto e $\mathrm{f}_{\mathrm{ck}}=30 \mathrm{MPa}$, podem ser vistas na tabela 6.7.

Tabela 6.7 - $A_{\text {se }}$ para os pontos PL1 e PL2 - Laje Plana e $f_{c k}=30 M P a$.

\begin{tabular}{cc}
\hline \multicolumn{2}{c}{$\boldsymbol{A}_{\text {se }}\left(\mathbf{c m}^{2} / \mathbf{m}\right)$} \\
\hline PL1 & PL2 \\
\hline 4,42 & 7,16 \\
\hline
\end{tabular}

$\mathrm{Na}$ tabela 6.8 verificam-se as armaduras necessárias considerando-se as situações construtivas de projeto.

Tabela $6.8-\mathrm{A}_{\mathrm{sn}}$ para pontos de laje - Laje Plana e $\mathrm{f}_{\mathrm{ck}}=30 \mathrm{MPa}$

\begin{tabular}{|c|c|c|c|c|c|c|c|c|c|}
\hline \multirow{2}{*}{$\begin{array}{l}\text { Sist. } \\
\text { Temp. }\end{array}$} & \multirow{2}{*}{$\begin{array}{l}\text { Proc. } \\
\text { Cons. }\end{array}$} & \multirow{2}{*}{ Mate. } & \multirow{2}{*}{$\begin{array}{l}\text { Ciclo } \\
\text { Cons. }\end{array}$} & \multirow{2}{*}{$k$} & \multirow{2}{*}{$\begin{array}{l}\text { Idade } \\
\text { (dias) }\end{array}$} & \multicolumn{2}{|c|}{$A_{s n}\left(\mathrm{~cm}^{2} / \mathrm{m}\right)$} & \multirow{2}{*}{ Pav. } & \multirow{2}{*}{$\begin{array}{l}\text { Con } \\
\text { Pav }\end{array}$} \\
\hline & & & & & & PL1 & PL2 & & \\
\hline \multirow{2}{*}{$(2+1)$} & Conv. & Mad. & 28 & 1,73 & 56 & 2,46 & 3,84 & 2 & 4 \\
\hline & Rac. & Aço & 28 & 1,89 & 84 & 2,69 & 4,19 & 1 & 4 \\
\hline
\end{tabular}

Para o $\mathrm{f}_{\mathrm{ck}}=30 \mathrm{MPa}$, sistema temporário de apoio $(2+1)$ e ciclo de 28 dias a situação crítica corresponde ao processo construtivo racionalizado. Essa situação ocorre no primeiro pavimento durante a concretagem do quarto piso. A tabela 6.9 mostra a porcentagem a que corresponde a armadura necessária da armadura existente para a situação crítica.

Tabela 6.9 - Comparação entre armaduras - Laje Plana e $\mathrm{f}_{\mathrm{ck}}=30 \mathrm{MPa}$.

\begin{tabular}{cccc}
\hline Ponto & $\begin{array}{c}\mathbf{A}_{\text {se }} \\
\left(\mathbf{c m}^{2} / \mathbf{m}\right)\end{array}$ & $\begin{array}{c}\mathbf{A}_{\text {sn }} \\
\left(\mathbf{c m}^{2} / \mathbf{m}\right)\end{array}$ & $\begin{array}{c}\mathbf{A}_{\text {snl }} / \mathbf{A}_{\text {se }} \\
(\%)\end{array}$ \\
\hline PL1 & 4,42 & 2,69 & 61 \\
\hline PL2 & 7,16 & 4,19 & 58 \\
\hline
\end{tabular}

Foi feita a verificação à punção para a laje do pavimento tanto na situação usual quanto na situação construtiva de projeto. A NBR 6118:2003 indica a verificação de armadura em pelo menos duas regiões, na face do pilar e a distância $2 \mathrm{~d}$ da face do pilar, onde d é a altura útil da laje. Para essas duas regiões os esforços resistentes são superiores aos solicitantes tanto na situação usual quanto 
na situação construtiva de projeto, sendo desnecessário armar a laje para combater à punção junto a todos os pilares do pavimento.

\subsubsection{VERIFICAÇÃO DO ESTADO LIMITE DE SERVIÇO}

6.2.4.1 Deslocamento limite total para o ponto PL1.

Pode-se verificar na tabela 6.10 o vão L entre os apoios (pilares P02 e P05) e os limites normalizados para os deslocamentos em análise.

Tabela 6.10 - Deslocamento limite total no ponto PL1 - Laje Plana.

\begin{tabular}{cccc}
\hline $\mathbf{L}$ & $\mathbf{L} / 250$ \\
$\mathbf{( c m})$ & $\mathbf{( c m )}$ & $\begin{array}{c}\mathbf{L} / 350 \\
(\mathbf{c m})\end{array}$ & $\begin{array}{c}\Delta_{\mathbf{t}} \\
(\mathbf{c m})\end{array}$ \\
\hline 580 & 2,32 & 1,65 & 3,97 \\
\hline
\end{tabular}

6.2.4.2 Ponto PL1 e $f_{c k}=20 M P a$.

Os deslocamentos na situação usual de projeto são mostrados na tabela 6.11.

Tabela 6.11 - Deslocamento usual no ponto PL1 - Laje Plana e $\mathrm{f}_{\mathrm{ck}}=20 \mathrm{MPa}$.

\begin{tabular}{cccccc}
\hline $\begin{array}{c}\Delta_{\mathbf{e}} \\
\mathbf{( c m )}\end{array}$ & $\mathbf{I g} / \mathbf{I e}$ & $\begin{array}{c}\Delta_{\mathbf{i}} \\
(\mathbf{c m})\end{array}$ & $\begin{array}{c}\Delta_{\mathbf{l}} \\
(\mathbf{c m})\end{array}$ & $\begin{array}{c}\Delta_{\mathbf{r}} \\
(\mathbf{c m})\end{array}$ & $\begin{array}{c}\Delta_{\mathrm{u}} \\
(\mathbf{c m})\end{array}$ \\
\hline 0,61 & 1,73 & 1,05 & 2,22 & 0,38 & 3,65 \\
\hline
\end{tabular}

A tabela 6.12 apresenta os deslocamentos finais do ponto PL1 na situação construtiva de projeto.

Tabela 6.12 - Deslocamentos finais no ponto PL1 - Laje Plana e $\mathrm{f}_{\mathrm{ck}}=20 \mathrm{Mpa}$.

\begin{tabular}{|c|c|c|c|c|c|c|c|c|c|c|}
\hline $\begin{array}{l}\text { Sist. } \\
\text { Temp. }\end{array}$ & $\begin{array}{l}\text { Proc. } \\
\text { Cons. }\end{array}$ & Mate. & $\begin{array}{l}\text { Ciclo } \\
\text { Cons. }\end{array}$ & $\begin{array}{c}\Delta_{e} \\
(\mathbf{c m})\end{array}$ & Ig/Ie & $\begin{array}{c}\Delta_{\mathrm{i}} \\
(\mathbf{c m})\end{array}$ & $\begin{array}{c}\Delta_{\mathrm{l}} \\
(\mathbf{c m})\end{array}$ & $\begin{array}{c}\Delta_{\mathrm{r}} \\
(\mathbf{c m})\end{array}$ & $\begin{array}{c}\Delta_{\mathrm{f}} \\
(\mathbf{c m})\end{array}$ & Pav. \\
\hline \multirow{4}{*}{$(2+1)$} & \multirow{2}{*}{ Conv. } & Mad. & 7 & 0,61 & 1,75 & 1,07 & 1,06 & 0,38 & 2,51 & 2 \\
\hline & & Aço & 3 & 0,61 & 2,36 & 1,45 & 1,43 & 0,38 & 3,26 & 2 \\
\hline & \multirow{2}{*}{ Rac. } & Aço & 7 & 0,61 & 1,79 & 1,10 & 1,09 & 0,38 & 2,57 & 1 \\
\hline & & Aço & 3 & 0,61 & 2,11 & 1,30 & 1,28 & 0,38 & 2,96 & 1 \\
\hline \multirow{2}{*}{$(1+1)$} & Conv. & Aço & 3 & 0,61 & 1,77 & 1,09 & 1,08 & 0,38 & 2,55 & 1 \\
\hline & Rac. & Aço & 3 & 0,61 & 1,77 & 1,09 & 1,08 & 0,38 & 2,55 & 1 \\
\hline
\end{tabular}


Uma análise comum para os deslocamentos finais exibidos pela tabela 6.12 se refere ao fato de todos estarem acima do limite $L / 250$, ou seja, necessita-se de contra flecha para compensar os deslocamentos excessivos.

A situação crítica corresponde ao sistema temporário de apoio $(2+1)$ com processo construtivo convencional utilizando escoras/reescoras de aço e ciclo de construção de 3 dias. Essa situação ocorre para a história de carregamento obtida durante as etapas construtivas do segundo pavimento.

Para a situação crítica analisada anteriormente o deslocamento é de $3,26 \mathrm{~cm}$, ou $82 \%$ do deslocamento limite total, o que satisfaz a verificação do estado limite de serviço com relação às deformações excessivas. Porém, percebe-se a necessidade da utilização de contra flecha com valor mínimo de $0,94 \mathrm{~cm}$ (diferença entre o deslocamento da situação crítica e o valor limite L/250) no ponto considerado da laje para compensar a flecha excessiva.

Outra situação construtiva interessante a analisar é a menos crítica, constituída pela seguinte situação construtiva: sistema temporário de apoio $(2+1)$ com processo construtivo convencional utilizando escoras/reescoras de madeira e ciclo de construção de 7 dias. Para esta situação o deslocamento final do ponto PL1 é de $2,51 \mathrm{~cm}$ (localizado também no segundo pavimento), ou seja, $63 \%$ do deslocamento limite total. Percebe-se a necessidade da utilização de contra flecha com valor mínimo de $0,19 \mathrm{~cm}$. A situação menos crítica, em comparação com a mais crítica, apresenta decréscimo de $23 \%$ no deslocamento final e de $26 \%$ na razão de inércias bruta/equivalente.

O deslocamento usual de $3,65 \mathrm{~cm}$ corresponde a $92 \%$ do deslocamento limite total, dentro do limite normalizado. Porém, há necessidade da utilização de contra flecha com valor mínimo de $1,33 \mathrm{~cm}$. Fato interessante corresponde ao acréscimo de $13 \%$ de deslocamento encontrado na situação usual em relação ao deslocamento da situação crítica. Esta diferença a mais de deslocamento indica que a situação usual de projeto, para este sistema construtivo, é mais conservativa e está a favor da segurança.

\subsubsection{Ponto PL1 e $f_{c k}=30 M P a$.}

Para $\mathrm{f}_{\mathrm{ck}}=30 \mathrm{MPa}$, os valores de deslocamentos encontrados na situação usual de projeto são exibidos na tabela 6.13 . 
Tabela 6.13 - Deslocamento usual no ponto PL1 - Laje Plana e $\mathrm{f}_{\mathrm{ck}}=30 \mathrm{MPa}$.

\begin{tabular}{cccccc}
\hline $\begin{array}{c}\Delta_{\mathbf{e}} \\
\mathbf{( c m )}\end{array}$ & $\mathbf{I g} / \mathbf{I e}$ & $\begin{array}{c}\Delta_{\mathbf{i}} \\
\mathbf{( c m )}\end{array}$ & $\begin{array}{c}\Delta_{\mathbf{l}} \\
\mathbf{( c m )}\end{array}$ & $\begin{array}{c}\Delta_{\mathbf{r}} \\
(\mathbf{c m})\end{array}$ & $\begin{array}{c}\Delta_{\mathbf{u}} \\
(\mathbf{c m})\end{array}$ \\
\hline 0,50 & 1,44 & 0,72 & 1,52 & 0,38 & 2,62 \\
\hline
\end{tabular}

A tabela 6.14 apresenta os deslocamentos finais do ponto PL1 considerando a situação construtiva de projeto.

Tabela 6.14 - Deslocamentos finais no ponto PL1 - Laje Plana e $\mathrm{f}_{\mathrm{ck}}=30 \mathrm{MPa}$.

\begin{tabular}{|c|c|c|c|c|c|c|c|c|c|c|}
\hline $\begin{array}{l}\text { Sist. } \\
\text { Temp. }\end{array}$ & $\begin{array}{l}\text { Proc. } \\
\text { Cons. }\end{array}$ & Mate. & $\begin{array}{l}\text { Ciclo } \\
\text { Cons. }\end{array}$ & $\begin{array}{c}\Delta_{\mathrm{e}} \\
(\mathrm{cm})\end{array}$ & $\mathbf{I g} / \mathbf{I e}$ & $\begin{array}{c}\Delta_{\mathrm{i}} \\
\text { (cm) }\end{array}$ & $\begin{array}{c}\Delta_{\mathrm{l}} \\
\text { (cm) }\end{array}$ & $\begin{array}{c}\Delta_{\mathrm{r}} \\
\text { (cm) }\end{array}$ & $\begin{array}{c}\Delta_{f} \\
(\mathbf{c m})\end{array}$ & Pav. \\
\hline \multirow{2}{*}{$(2+1)$} & Conv. & Mad & 28 & 0,50 & 1,44 & 0,72 & 0,71 & 0,38 & 1,81 & 2 \\
\hline & Rac. & Aço & 28 & 0,50 & 1,44 & 0,72 & 0,71 & 0,38 & 1,81 & 2 \\
\hline
\end{tabular}

Análise comum para os deslocamentos finais de $1,81 \mathrm{~cm}$ se refere ao fato de estarem abaixo do limite $\mathrm{L} / 250$ e corresponderem a $45 \%$ do deslocamento limite total. Assim, não se necessita da utilização de contra flecha. Para o $f_{c k}=30 \mathrm{MPa} e$ ciclo de 28 dias os deslocamentos finais diminuem 44\% comparados à situação crítica com $\mathrm{f}_{\mathrm{ck}}=20 \mathrm{MPa}$.

Aumentando-se $\circ f_{c k}$ do concreto aumenta-se $o$ valor do momento de fissuração e se, além disso, for utilizado um ciclo de construção que apresente a menor influência no estado de fissuração, ou seja, 28 dias, ocorrerá uma diminuição considerável na relação entre os momentos de inércia ( $\mathrm{Ig} / \mathrm{Ie}$ ) na região da laje considerada. Com essa relação menor, os deslocamentos também são menores. Tal análise pode ser feita para o ponto PL1 em que ocorre um decréscimo de $39 \%$ no valor da relação entre os momentos de inércia para $\mathrm{f}_{\mathrm{ck}}=30 \mathrm{MPa}$ e ciclo de 28 dias comparado com a situação crítica com $\mathrm{f}_{\mathrm{ck}}=20 \mathrm{MPa}$. Dessa forma, deslocamentos excessivos anteriores para a situação crítica com $\mathrm{f}_{\mathrm{ck}}=20 \mathrm{MPa}$ não ocorrem para a situação com $\mathrm{f}_{\mathrm{ck}}=30 \mathrm{MPa}$ e ciclo de 28 dias.

$\mathrm{Na}$ situação usual de projeto o deslocamento é de $2,62 \mathrm{~cm}, 66 \%$ do deslocamento limite total. Como esse valor de deslocamento está acima do deslocamento limite L/250, deve-se utilizar contra flecha mínima de $0,30 \mathrm{~cm}$. O acréscimo de deslocamento na situação usual é de $45 \%$ em relação aos deslocamentos das situações construtivas. Esta diferença a mais de deslocamento indica que a situação usual de projeto para $\mathrm{f}_{\mathrm{ck}}=30 \mathrm{MPa}$ também está a favor da segurança. 


\subsection{LAJES APOIADAS EM PAREDES DE ALVENARIA ESTRUTURAL}

O segundo caso aqui estudado é o de um edifício residencial com sistema estrutural laje / paredes de alvenaria obtido do livro de CORRÊA e RAMALHO (2003). A figura 6.8 apresenta o arranjo arquitetônico de meio pavimento tipo simétrico.

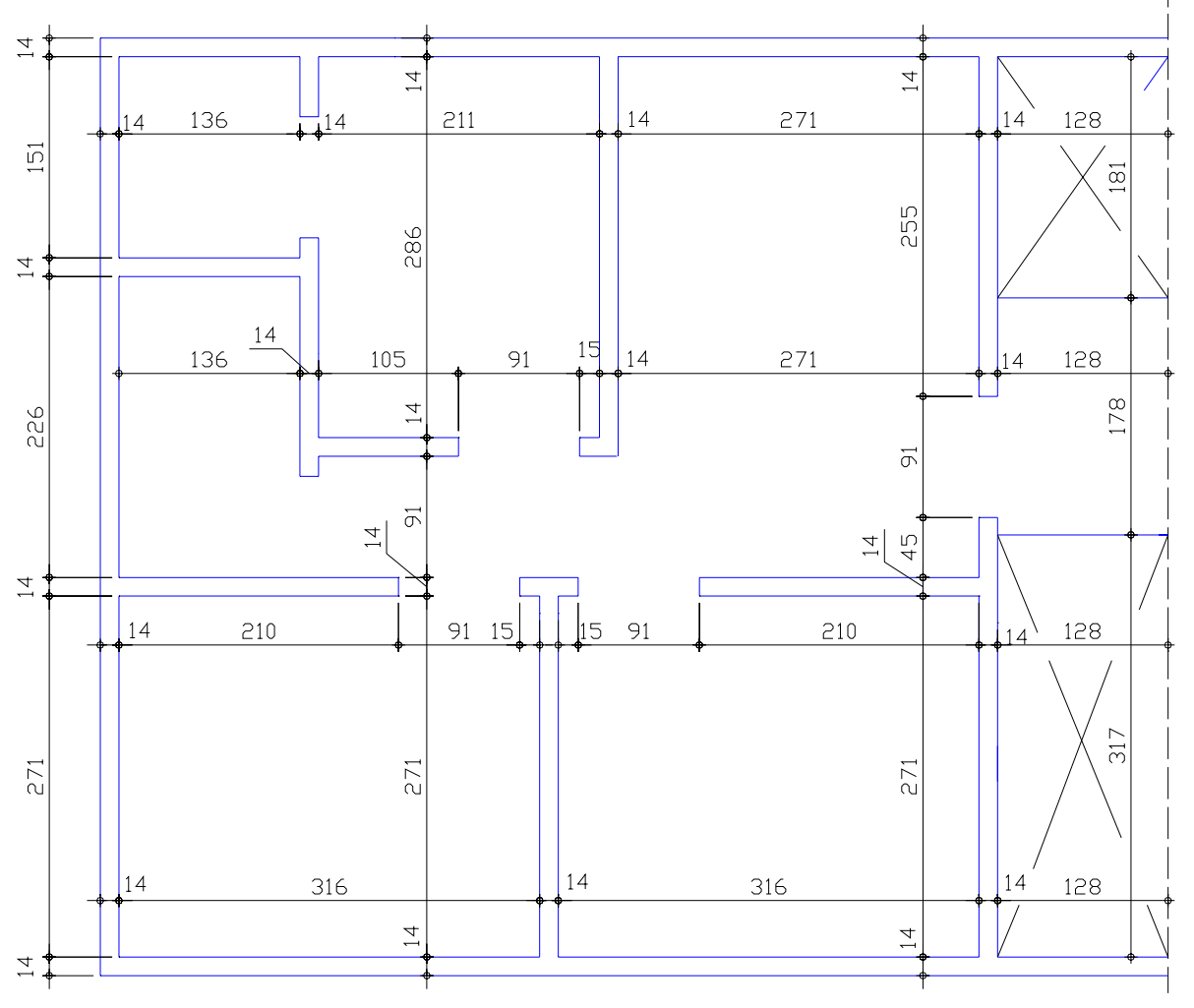

Figura 6.8 - Arranjo arquitetônico de meio pavimento tipo $(\mathrm{cm})$ - Laje / Paredes de Alvenaria.

$\mathrm{Na}$ tabela 6.15 são apresentados quantitativos e medidas relativas a meio pavimento tipo.

Tabela 6.15 - Quantitativos e medidas para meio pavimento tipo - Laje / Paredes de Alvenaria.

\begin{tabular}{ccccccc}
\hline $\begin{array}{c}\text { Espessura } \\
\text { da laje } \\
(\mathbf{m})\end{array}$ & $\begin{array}{c}\text { Distância } \\
\text { de piso a } \\
\text { piso } \\
(\mathbf{m})\end{array}$ & $\begin{array}{c}\text { Altura } \\
\text { das } \\
\text { paredes } \\
(\mathbf{m})\end{array}$ & $\begin{array}{c}\text { Peso } \\
\text { próprio do } \\
\text { pavimento } \\
\mathbf{( k N )}\end{array}$ & $\begin{array}{c}\text { Área em } \\
\text { planta } \\
\left(\mathbf{m}^{2}\right)\end{array}$ & $\begin{array}{c}\mathbf{1 , 0 g} \\
\left(\mathbf{k N} / \mathbf{m}^{\mathbf{2}}\right)\end{array}$ & $\mathbf{0 , 8 5 \mathbf { g }}$ \\
\hline 0,08 & 2,80 & 2,72 & 95,80 & 47,90 & 2,00 & 1,70 \\
\hline
\end{tabular}


Os carregamentos considerados no pavimento, além do peso próprio do mesmo, correspondem a: $1,0 \mathrm{kN} / \mathrm{m}^{2}$ referente a piso e revestimento e $1,5 \mathrm{kN} / \mathrm{m}^{2}$ referente à sobrecarga de utilização.

\subsubsection{SISTEMAS DE ESCORAMENTOS E PONTOS PARA VERIFICAÇÃO DOS ESTADOS} LIMITES

Para o processo construtivo convencional a distribuição do escoramento pelo pavimento tipo pode ser vista na figura 6.9. O aspecto da laje de concreto e do sistema de escoramento para esse sistema construtivo, depois de modelados no STRAP, são vistos em perspectiva na figura 6.10.

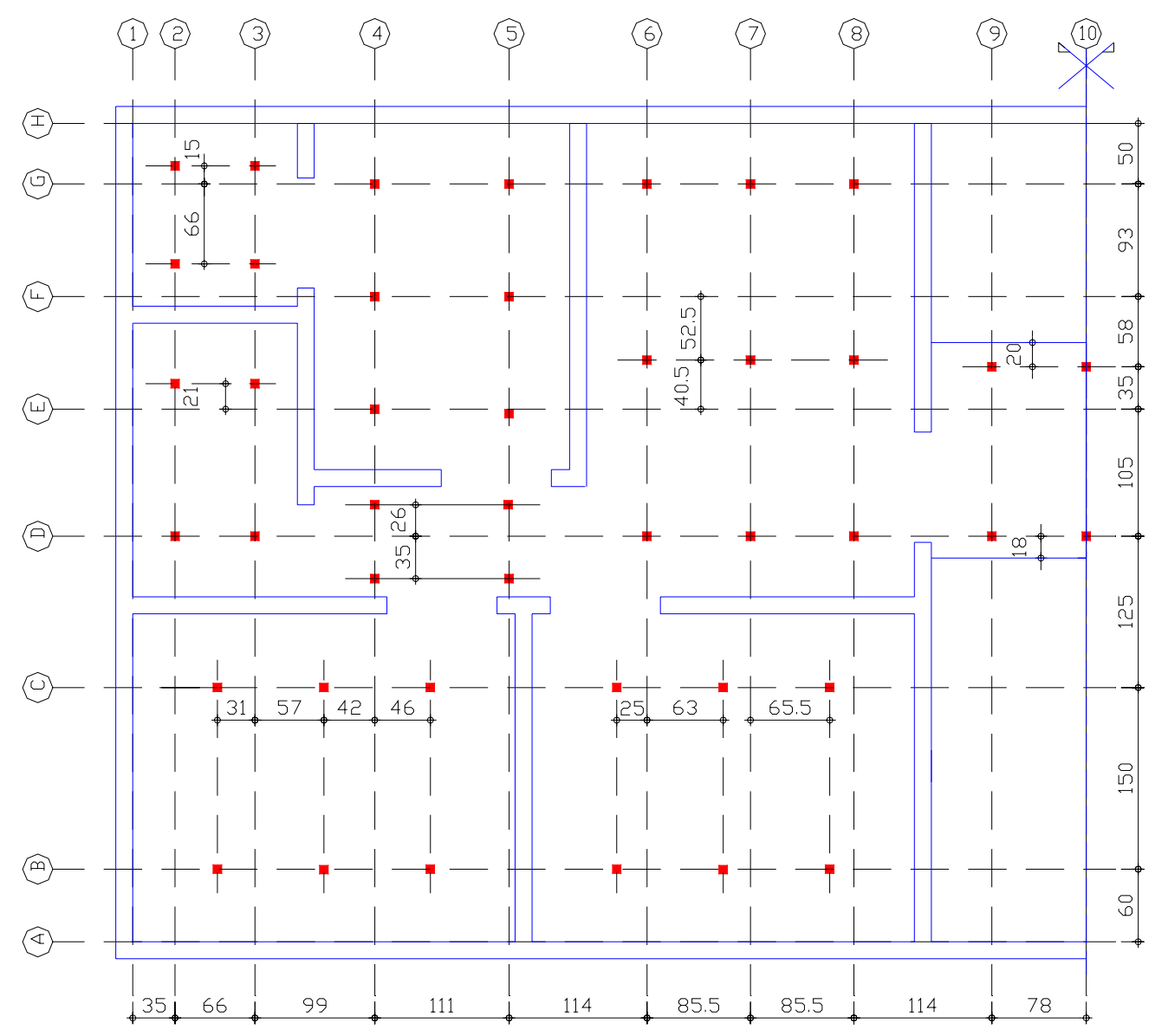

Figura 6.9 - Distribuição dos escoramentos para o processo construtivo convencional (cm) - Laje / Paredes de Alvenaria. 


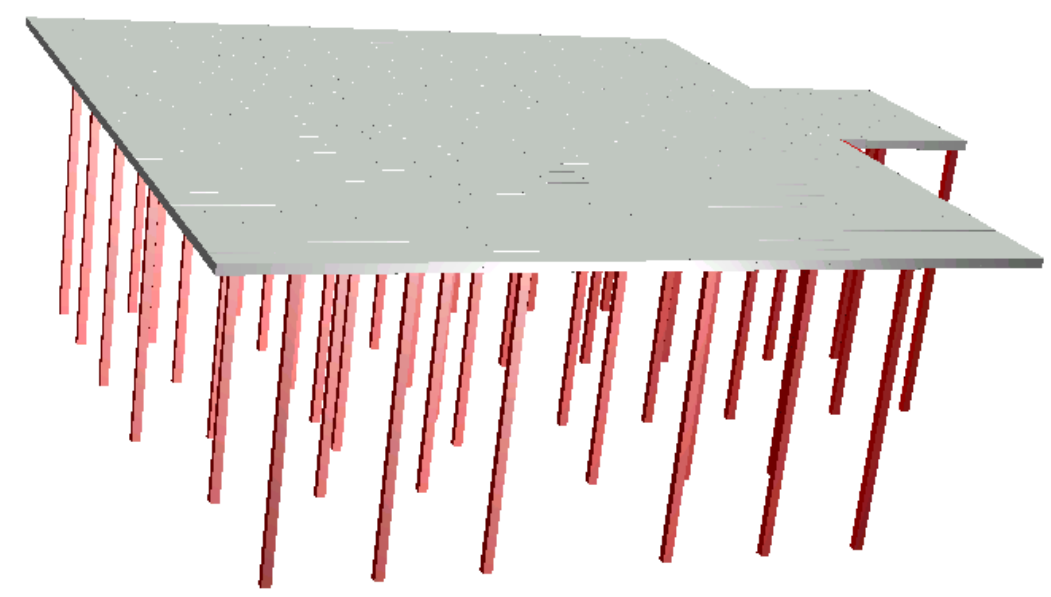

Figura 6.10 - Aspecto do pavimento tipo para o processo construtivo convencional (etapa construtiva) - Laje / Paredes de Alvenaria.

Não será utilizado o processo construtivo racionalizado para esse sistema estrutural porque os vãos são relativamente pequenos e a racionalização proporcionada por esse processo não é atingida.

As tabelas 6.16 e 6.17 identificam as proporções de absorção de carga obtidas pelas modelagens das estruturas primárias. Com esses valores pode-se encontrar os fatores de carga que ocorrem no sistema temporário de apoio durante as etapas construtivas do pavimento adotado com sistema estrutural laje / paredes de alvenaria.

Tabela 6.16 - Proporções de absorção de carga - Laje / Paredes de Alvenaria e $\mathrm{f}_{\mathrm{ck}}=20 \mathrm{MPa}$.

\begin{tabular}{lcccc}
\hline \multirow{2}{*}{$\begin{array}{c}\text { Processo } \\
\text { Construtivo }\end{array}$} & $\begin{array}{c}\text { Material } \\
\text { das } \\
\text { Escoras }\end{array}$ & $\begin{array}{c}\text { Estrutura } \\
\text { Primária }\end{array}$ & \multicolumn{2}{c}{$\begin{array}{c}\text { Proporção de Absorção } \\
\text { de Carga (\%) }\end{array}$} \\
\cline { 3 - 5 } & \multirow{3}{*}{ Madeira } & Escoras & Pavimento \\
\cline { 3 - 5 } & & EP2 & 39 & 61 \\
\cline { 3 - 5 } Convencional & EP3 & 26 & 74 \\
\cline { 3 - 5 } & \multirow{3}{*}{ Aço } & EP1 & 54 & 75 \\
\cline { 3 - 5 } & & EP2 & 31 & 69 \\
\cline { 3 - 5 } & & EP3 & 31 & 69 \\
\hline
\end{tabular}


Tabela 6.17 - Proporções de absorção de carga - Laje / Paredes de Alvenaria e $\mathrm{f}_{\mathrm{ck}}=30 \mathrm{MPa}$.

\begin{tabular}{|c|c|c|c|c|}
\hline \multirow{2}{*}{$\begin{array}{l}\text { Processo } \\
\text { Construtivo }\end{array}$} & \multirow{2}{*}{$\begin{array}{c}\text { Material } \\
\text { das } \\
\text { Escoras }\end{array}$} & \multirow{2}{*}{$\begin{array}{l}\text { Estrutura } \\
\text { Primária }\end{array}$} & \multicolumn{2}{|c|}{$\begin{array}{c}\text { Proporção de Absorção } \\
\text { de Carga (\%) }\end{array}$} \\
\hline & & & Escoras & Pavimento \\
\hline \multirow{3}{*}{ Convencional } & \multirow{3}{*}{ Madeira } & EP1 & 37 & 63 \\
\hline & & EP2 & 25 & 75 \\
\hline & & EP3 & 24 & 76 \\
\hline
\end{tabular}

Para as verificações de segurança e deformação excessiva são considerados os pontos do pavimento mostrados na figura 6.11.

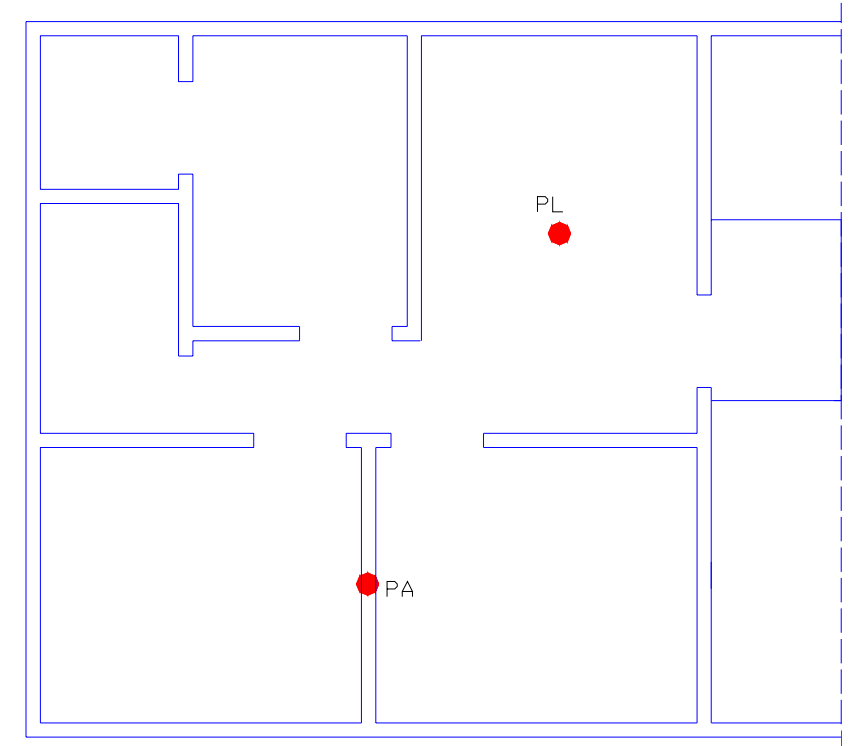

Figura 6.11 - Pontos do pavimento para verificação da segurança e da deformação excessiva - Laje / Paredes de Alvenaria.

\subsubsection{VERIFICAÇÃO DO ESTADO LIMITE ÚLTIMO}

Vale lembrar que a armadura correspondente a $0,80 \mathrm{~cm}^{2} / \mathrm{m}$ nas tabelas a seguir é o valor da armadura mínima utilizada tanto para as armaduras existentes $\left(A_{s e}\right)$ quanto para as necessárias $\left(A_{s n}\right)$.

\subsubsection{Pontos PL e PA e $f_{c k}=20 M P a$.}

As armaduras longitudinais existentes $\left(A_{s e}\right)$ nos pontos $P L$ e PA na situação usual de projeto podem ser vistas na tabela 6.18. 
Tabela 6.18 - $A_{s e}$ para pontos de laje - Laje / Paredes de Alvenaria e $f_{c k}=20 M P a$.

\begin{tabular}{cc}
\hline \multicolumn{2}{c}{$\mathbf{A}_{\text {se }}\left(\mathrm{cm}^{2} / \mathbf{m}\right)$} \\
\hline $\mathbf{P L}$ & PA \\
\hline 0,80 & 1,37 \\
\hline
\end{tabular}

A tabela 6.19 mostra as armaduras longitudinais necessárias $\left(A_{s n}\right)$ considerando a situação construtiva de projeto para os pontos considerados.

Tabela 6.19 - $A_{s n}$ para os pontos PL e PA - Laje / Paredes de Alvenaria e $f_{c k}=20 M P a$.

\begin{tabular}{|c|c|c|c|c|c|c|c|c|c|}
\hline \multirow{2}{*}{$\begin{array}{l}\text { Sist. } \\
\text { Temp. }\end{array}$} & \multirow{2}{*}{$\begin{array}{l}\text { Proc. } \\
\text { Cons. }\end{array}$} & \multirow{2}{*}{ Mate. } & \multirow{2}{*}{$\begin{array}{l}\text { Ciclo } \\
\text { Cons. }\end{array}$} & \multirow{2}{*}{ k } & \multirow{2}{*}{$\begin{array}{l}\text { Idade } \\
\text { (dias) }\end{array}$} & \multicolumn{2}{|c|}{$A_{s n}\left(\mathrm{~cm}^{2} / \mathrm{m}\right)$} & \multirow{2}{*}{ Pav. } & \multirow{2}{*}{$\begin{array}{l}\text { Con. } \\
\text { Pav. }\end{array}$} \\
\hline & & & & & & PL & PA & & \\
\hline \multirow{2}{*}{$(2+1)$} & \multirow{2}{*}{ Conv. } & Mad. & 7 & 1,52 & 7 & 0,80 & 0,80 & 4 & 5 \\
\hline & & Aço & 3 & 1,69 & 3 & 0,80 & 0,80 & 4 & 5 \\
\hline$(1+1)$ & Conv. & Aço & 3 & 1,86 & 3 & 0,80 & 0,85 & 2 & 3 \\
\hline
\end{tabular}

As armaduras nos pontos PL e PA das situações construtivas correspondem ao valor mínimo, com exceção da situação construtiva com sistema temporário de apoio (1+1), processo construtivo convencional, utilizando escoras/reescoras de aço e ciclo de construção de 3 dias no ponto PA. Essa situação, que é a crítica, ocorre no segundo pavimento durante a concretagem do terceiro piso. A tabela 6.20 mostra a porcentagem a que corresponde a armadura necessária da armadura existente para a situação crítica.

Tabela 6.20 - Comparação entre armaduras - Laje / Paredes de Alvenaria e $\mathrm{f}_{\mathrm{ck}}=20 \mathrm{MPa}$.

\begin{tabular}{cccc}
\hline Ponto & $\begin{array}{c}\mathbf{A}_{\text {se }} \\
\left(\mathbf{c m}^{2} / \mathbf{m}\right)\end{array}$ & $\begin{array}{c}\mathbf{A}_{\text {sn }} \\
\left(\mathbf{c m}^{2} / \mathbf{m}\right)\end{array}$ & $\begin{array}{c}\mathbf{A}_{\text {sn }} / \mathbf{A}_{\text {se }} \\
(\mathbf{\%})\end{array}$ \\
\hline $\mathrm{PL}$ & 0,80 & 0,80 & 100 \\
\hline $\mathrm{PA}$ & 1,37 & 0,85 & 62 \\
\hline
\end{tabular}

Percebe-se que a armadura necessária no ponto PL é igual à armadura existente, isso ocorre porque ambas correspondem ao valor mínimo. Já no ponto PA a armadura necessária equivale a $62 \%$ da armadura existente. Essas situações não oferecem nenhum risco à segurança estrutural.

\subsubsection{Pontos PL e PA e $f_{c k}=30 \mathrm{MPa}$}

As armaduras longitudinais existentes $\left(A_{s e}\right)$ na situação usual de projeto para 
a resistência característica do concreto de $30 \mathrm{MPa}$ são apresentadas na tabela 6.21.

Tabela 6.21 - $A_{s e}$ para pontos de laje - Laje / Paredes de Alvenaria e $f_{c k}=30 M P a$.

\begin{tabular}{cc}
\hline \multicolumn{2}{c}{$\mathbf{A}_{\text {se }}\left(\mathrm{cm}^{2} / \mathbf{m}\right)$} \\
\hline $\mathbf{P L}$ & PA \\
\hline 0,80 & 1,30 \\
\hline
\end{tabular}

A tabela 6.22 mostra as armaduras longitudinais necessárias $\left(A_{s n}\right)$ considerando a situação construtiva de projeto.

Tabela 6.22 - $A_{s n}$ para pontos de laje - Laje / Paredes de Alvenaria e $f_{c k}=30 M P a$.

\begin{tabular}{|c|c|c|c|c|c|c|c|c|c|}
\hline \multirow{2}{*}{$\begin{array}{c}\text { Sist. } \\
\text { Temp. }\end{array}$} & \multirow{2}{*}{$\begin{array}{l}\text { Proc. } \\
\text { Cons. }\end{array}$} & \multirow{2}{*}{ Mate. } & \multirow{2}{*}{$\begin{array}{l}\text { Ciclo } \\
\text { Cons. }\end{array}$} & & \multirow{2}{*}{$\begin{array}{l}\text { Idade } \\
\text { (dias) }\end{array}$} & \multicolumn{2}{|c|}{$A_{s n}\left(\mathrm{~cm}^{2} / \mathrm{m}\right)$} & \multirow{2}{*}{ Pav. } & \multirow{2}{*}{$\begin{array}{l}\text { Con. } \\
\text { Pav. }\end{array}$} \\
\hline & & & & & & PL & PA & & \\
\hline$(2+1)$ & Conv. & Mad. & 28 & 1,48 & 28 & 0,80 & 0,80 & 4 & 5 \\
\hline
\end{tabular}

Essa situação ocorre no quarto pavimento durante a concretagem do quinto piso. A tabela 6.23 mostra a porcentagem a que corresponde a armadura necessária da armadura existente para a situação construtiva.

Tabela 6.23 - Comparação entre armaduras - Laje / Paredes de Alvenaria e $\mathrm{f}_{\mathrm{ck}}=30 \mathrm{MPa}$.

\begin{tabular}{cccc}
\hline Ponto & $\begin{array}{c}\mathbf{A}_{\text {se }} \\
\left(\mathbf{c m}^{2} / \mathbf{m}\right)\end{array}$ & $\begin{array}{c}\mathbf{A}_{\text {sn }} \\
\left(\mathbf{c m}^{2} / \mathbf{m}\right)\end{array}$ & $\begin{array}{c}\mathbf{A}_{\text {sn }} / \mathbf{A}_{\text {se }} \\
(\mathbf{\%})\end{array}$ \\
\hline $\mathrm{PL}$ & 0,80 & 0,80 & 100 \\
\hline$P A$ & 1,30 & 0,80 & 51 \\
\hline
\end{tabular}

As comparações da tabela 6.23 são semelhantes às já apresentadas para $f_{c k}=20 M P a$ e também não oferecem nenhum risco à segurança estrutural.

\subsubsection{VERIFICAÇÃO DO ESTADO LIMITE DE SERVIÇO}

\subsubsection{Deslocamento limite total para o ponto PL.}

Pode-se verificar o vão $L$ entre apoios (paredes) e os limites normalizados dos deslocamentos na tabela 6.24 
Tabela 6.24 - Deslocamento limite total no ponto PL - Laje / Paredes de Alvenaria.

\begin{tabular}{cccc}
\hline $\mathbf{L}$ & $\mathbf{L} / 250$ & $\mathbf{L} / 350$ & $\Delta_{\mathbf{t}}$ \\
$(\mathbf{c m})$ & $(\mathbf{c m})$ & $\mathbf{( c m )}$ & $(\mathbf{c m})$ \\
\hline 285 & 1,14 & 0,81 & 1,95 \\
\hline
\end{tabular}

\subsubsection{Ponto PL e $f_{c k}=20 M P a$.}

Os valores de deslocamentos na situação usual de projeto são mostrados na tabela 6.25 .

Tabela 6.25 - Deslocamento usual no ponto PL - Laje / Paredes de Alvenaria e $\mathrm{f}_{\mathrm{ck}}=20 \mathrm{MPa}$.

\begin{tabular}{cccccc}
\hline $\begin{array}{c}\Delta_{\mathbf{e}} \\
(\mathbf{c m})\end{array}$ & $\mathbf{I g} / \mathbf{I e}$ & $\begin{array}{c}\Delta_{\mathrm{i}} \\
(\mathbf{c m})\end{array}$ & $\begin{array}{c}\Delta_{\mathrm{I}} \\
(\mathbf{c m})\end{array}$ & $\begin{array}{c}\Delta_{\mathrm{r}} \\
(\mathbf{c m})\end{array}$ & $\begin{array}{c}\Delta_{\mathrm{u}} \\
(\mathbf{c m})\end{array}$ \\
\hline 0,09 & 1,00 & 0,09 & 0,19 & 0,31 & 0,59 \\
\hline
\end{tabular}

A tabela 6.26 apresenta os deslocamentos finais do ponto PL na situação construtiva de projeto.

Tabela 6.26 - Deslocamentos finais no ponto PL - Laje / Paredes de Alvenaria e $\mathrm{f}_{\mathrm{ck}}=20 \mathrm{MPa}$.

\begin{tabular}{|c|c|c|c|c|c|c|c|c|c|c|}
\hline $\begin{array}{l}\text { Sist. } \\
\text { Temp. }\end{array}$ & $\begin{array}{l}\text { Proc. } \\
\text { Cons. }\end{array}$ & Mate. & $\begin{array}{l}\text { Ciclo } \\
\text { Cons. }\end{array}$ & $\begin{array}{c}\Delta_{\mathrm{e}} \\
(\mathrm{cm})\end{array}$ & Ig/Ie & $\begin{array}{c}\Delta_{\mathrm{i}} \\
(\mathbf{c m})\end{array}$ & $\begin{array}{c}\Delta_{\mathrm{l}} \\
(\mathbf{c m})\end{array}$ & $\begin{array}{c}\Delta_{\mathrm{r}} \\
(\mathbf{c m})\end{array}$ & $\begin{array}{c}\Delta_{f} \\
(\mathbf{c m})\end{array}$ & Pav. \\
\hline \multirow{2}{*}{$(2+1)$} & \multirow{2}{*}{ Conv. } & Mad & 7 & 0,09 & 1,00 & 0,09 & 0,08 & 0,31 & 0,48 & 2 \\
\hline & & Aço & 3 & 0,09 & 1,00 & 0,09 & 0,08 & 0,31 & 0,48 & 2 \\
\hline$(1+1)$ & Conv. & Aço & 3 & 0,09 & 1,00 & 0,09 & 0,08 & 0,31 & 0,48 & 2 \\
\hline
\end{tabular}

O deslocamento final de $0,48 \mathrm{~cm}$ está abaixo do limite $L / 250$ e corresponde a $25 \%$ do deslocamento limite total. Assim, não se necessita da utilização de contra flecha. Para o $f_{c k}=20 \mathrm{MPa}$ os deslocamentos finais correspondem a $81 \%$ do deslocamento usual.

$\mathrm{Na}$ situação usual de projeto o deslocamento é de $0,59 \mathrm{~cm}, 30 \%$ do deslocamento limite total. Como o deslocamento usual está abaixo do deslocamento limite L/250, não se necessita utilizar contra flecha. O acréscimo de deslocamento na situação usual é de $23 \%$ em relação aos deslocamentos das situações construtivas. Esta diferença a mais de deslocamento indica que a situação usual de projeto para $\mathrm{f}_{\mathrm{ck}}=20 \mathrm{MPa}$ está a favor da segurança. 


\subsubsection{Ponto PL e $f_{c k}=30 M P a$.}

Para essa resistência característica os valores de deslocamentos encontrados na situação usual de projeto são exibidos na tabela 6.27.

Tabela 6.27 - Deslocamento usual no ponto PL - Laje / Paredes de Alvenaria e $\mathrm{f}_{\mathrm{ck}}=30 \mathrm{MPa}$.

\begin{tabular}{cccccc}
\hline $\begin{array}{c}\Delta_{\mathbf{e}} \\
(\mathbf{c m})\end{array}$ & $\mathbf{I g} / \mathbf{I e}$ & $\begin{array}{c}\Delta_{\mathrm{i}} \\
(\mathbf{c m})\end{array}$ & $\begin{array}{c}\Delta_{\mathrm{l}} \\
(\mathbf{c m})\end{array}$ & $\begin{array}{c}\Delta_{\mathbf{r}} \\
(\mathbf{c m})\end{array}$ & $\begin{array}{c}\Delta_{\mathrm{u}} \\
(\mathbf{c m})\end{array}$ \\
\hline 0,08 & 1,00 & 0,08 & 0,17 & 0,31 & 0,56 \\
\hline
\end{tabular}

A tabela 6.28 apresenta os deslocamentos finais do ponto PL na situação construtiva de projeto.

Tabela 6.28 - Deslocamento final no ponto PL - Laje / Paredes de Alvenaria e $\mathrm{f}_{\mathrm{ck}}=30 \mathrm{MPa}$.

\begin{tabular}{ccccccccccc}
\hline $\begin{array}{c}\text { Sist. } \\
\text { Temp. }\end{array}$ & $\begin{array}{l}\text { Proc. } \\
\text { Cons. }\end{array}$ & Mate. & $\begin{array}{c}\text { Ciclo } \\
\text { Cons. }\end{array}$ & $\begin{array}{c}\Delta_{\mathbf{e}} \\
(\mathbf{c m})\end{array}$ & $\mathbf{I g} / \mathbf{I e}$ & $\begin{array}{c}\Delta_{\mathbf{i}} \\
(\mathbf{c m})\end{array}$ & $\begin{array}{c}\Delta_{\mathbf{l}} \\
(\mathbf{c m})\end{array}$ & $\begin{array}{c}\Delta_{\mathbf{r}} \\
(\mathbf{c m})\end{array}$ & $\begin{array}{c}\Delta_{\mathbf{f}} \\
(\mathbf{c m})\end{array}$ & Pav. \\
\hline$(2+1)$ & Conv. & Mad. & 28 & 0,08 & 1,00 & 0,08 & 0,07 & 0,31 & 0,46 & 2 \\
\hline
\end{tabular}

O deslocamento final de $0,46 \mathrm{~cm}$ está abaixo do limite $\mathrm{L} / 250$ e corresponde a $23 \%$ do deslocamento limite total. Assim, não se necessita utilizar contra flecha. Para o $\mathrm{f}_{\mathrm{ck}}=30 \mathrm{MPa}$ e ciclo de 28 dias o deslocamento final corresponde a $82 \%$ do deslocamento usual.

$\mathrm{Na}$ situação usual de projeto o deslocamento é de $0,56 \mathrm{~cm}, 29 \%$ do deslocamento limite total. Como esse valor de deslocamento está abaixo do deslocamento limite L/250, não se necessita utilizar contra flecha. $O$ acréscimo de deslocamento na situação usual é de $22 \%$ em relação aos deslocamentos da situação construtiva. Esta diferença a mais de deslocamento indica que a situação usual de projeto para $\mathrm{f}_{\mathrm{ck}}=30 \mathrm{MPa}$ também está a favor da segurança.

Para o pavimento com sistema estrutural laje apoiada em paredes de alvenaria, independente do processo construtivo e para cada $f_{c k}$, os deslocamentos finais são os mesmos. Tal situação ocorre porque os momentos atuantes durante as etapas construtivas não ultrapassam os momentos de fissuração e, portanto, o pavimento trabalha em regime elástico linear. Este feito está relacionado aos vãos relativamente pequenos. Nota-se que, apesar de pequenos, tais vãos são representativos da maioria dos edifícios em alvenaria estrutural construídos no Brasil. 


\subsection{LAJES APOIADAS EM VIGAS E PILARES}

O terceiro caso estudado é o de um edifício residencial com sistema estrutural laje/viga/pilar adaptado do projeto desenvolvido pelo escritório DC Matos Engenharia de Projetos e Consultoria Ltda. A figura 6.12 apresenta a planta de formas de meio pavimento tipo simétrico e a indicação da espessura de cada painel de laje.

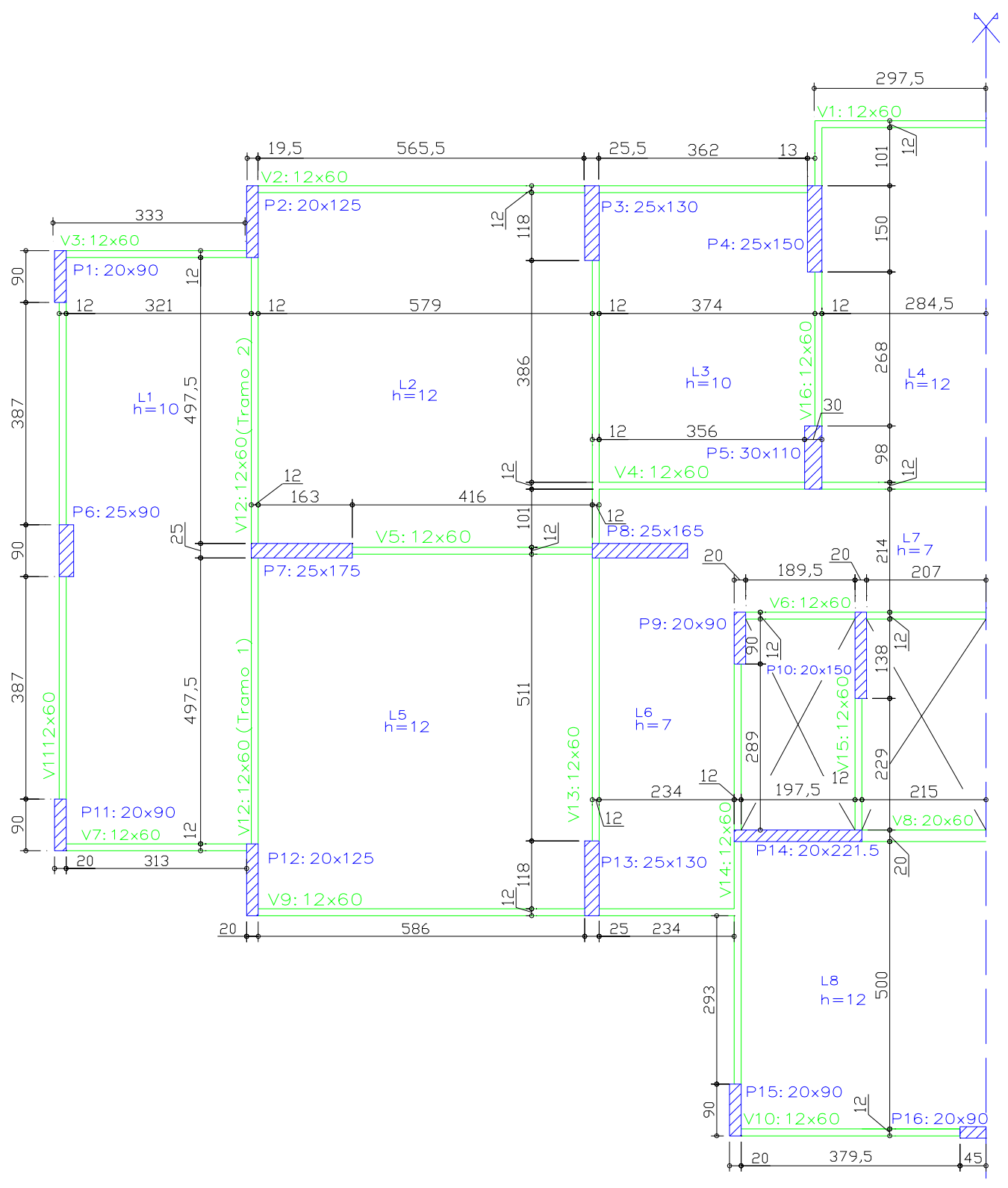

Figura 6.12 - Planta de formas de meio pavimento tipo $(\mathrm{cm})$ - Laje/Viga/Pilar.

Na tabela 6.29 são apresentados quantitativos e medidas relativas a meio pavimento tipo. 
Tabela 6.29 - Quantitativos e medidas para meio pavimento tipo - Laje/Viga/Pilar.

\begin{tabular}{ccccc}
\hline $\begin{array}{c}\text { Distância } \\
\text { de piso a } \\
\text { piso } \\
(\mathbf{m})\end{array}$ & $\begin{array}{c}\text { Peso } \\
\text { próprio do } \\
\text { pavimento } \\
\mathbf{( k N )}\end{array}$ & $\begin{array}{c}\text { Área em } \\
\text { planta } \\
\left(\mathbf{m}^{2}\right)\end{array}$ & $\begin{array}{c}\mathbf{1 , 0 g} \\
\left(\mathbf{k N} / \mathbf{m}^{2}\right)\end{array}$ & $\begin{array}{c}\mathbf{0 , 8 5 g} \\
\left(\mathbf{k N} / \mathbf{m}^{\mathbf{2}}\right)\end{array}$ \\
\hline 3,00 & 700,30 & 197,50 & 3,54 & 3,01 \\
\hline
\end{tabular}

Os carregamentos considerados no pavimento, além do peso próprio do mesmo, correspondem a: $1 \mathrm{kN} / \mathrm{m}^{2}$ referente a piso e revestimento, $3 \mathrm{kN} / \mathrm{m}^{2}$ referente às paredes de alvenaria (sistema de vedação interno) e 1,5kN/m² referente à sobrecarga de utilização.

\subsubsection{SISTEMAS DE ESCORAMENTOS E PONTOS PARA VERIFICAÇÃO DOS ESTADOS LIMITES}

O aspecto da laje de concreto e do sistema de escoramento para o processo construtivo convencional, depois de modelados no STRAP, são vistos em perspectiva na figura 6.13. A distribuição do escoramento para esse processo construtivo pode ser vista na figura 6.14 .

As figuras 6.15 e 6.16 indicam, para o processo construtivo racionalizado, a distribuição do escoramento metálico respectivamente para escoras e reescoras com pré-carga. O espaçamento máximo entre escoras é de $2,0 \mathrm{~m} \times 1,0 \mathrm{~m}$, que corresponde a um painel de fôrma. O espaçamento máximo das reescoras com précarga, depois de retirada parcial das escoras, é de 2,0m x 2,0m.

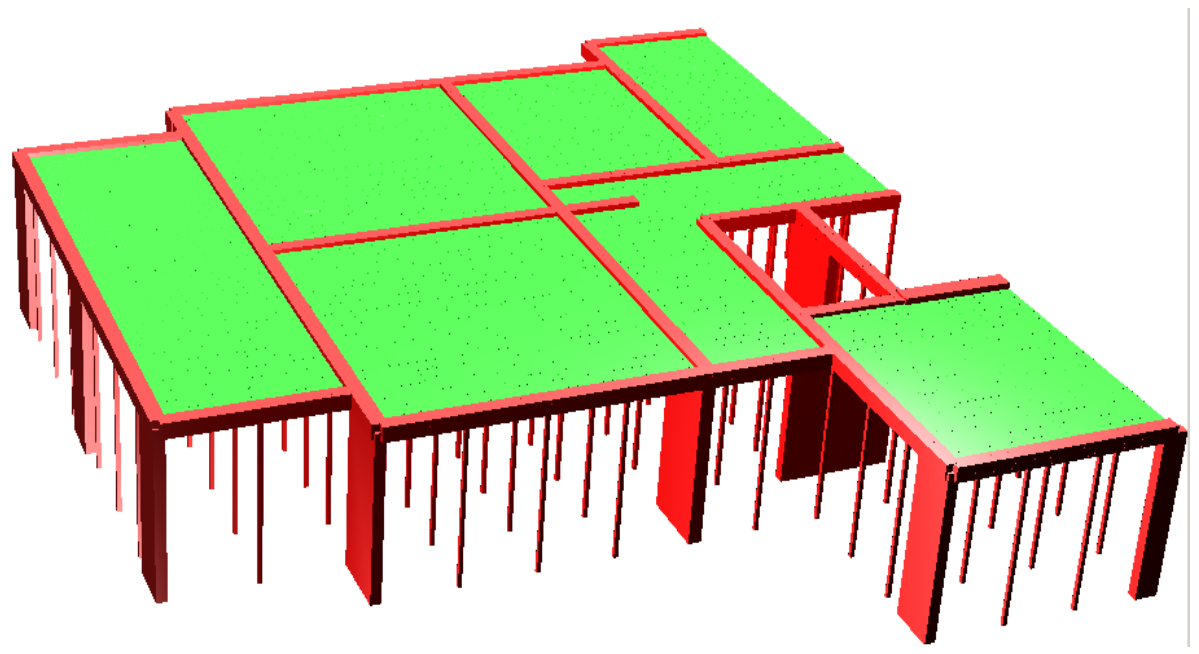

Figura 6.13 - Aspecto do pavimento tipo para o processo construtivo convencional (etapa construtiva) - Laje/Viga/Pilar. 


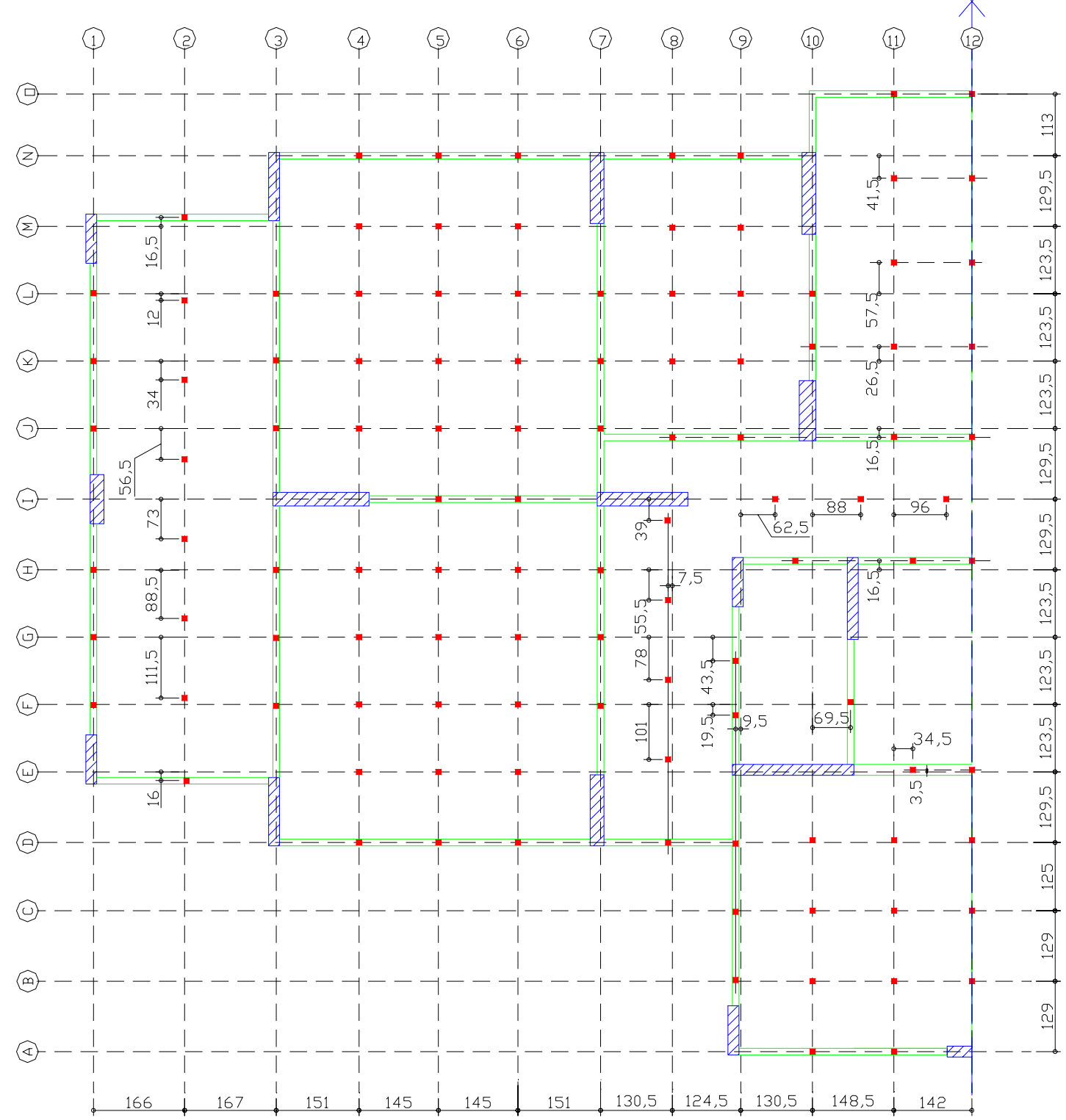

Figura 6.14 - Distribuição dos escoramentos para o processo construtivo convencional $(\mathrm{cm})$ - Laje/Viga/Pilar. 


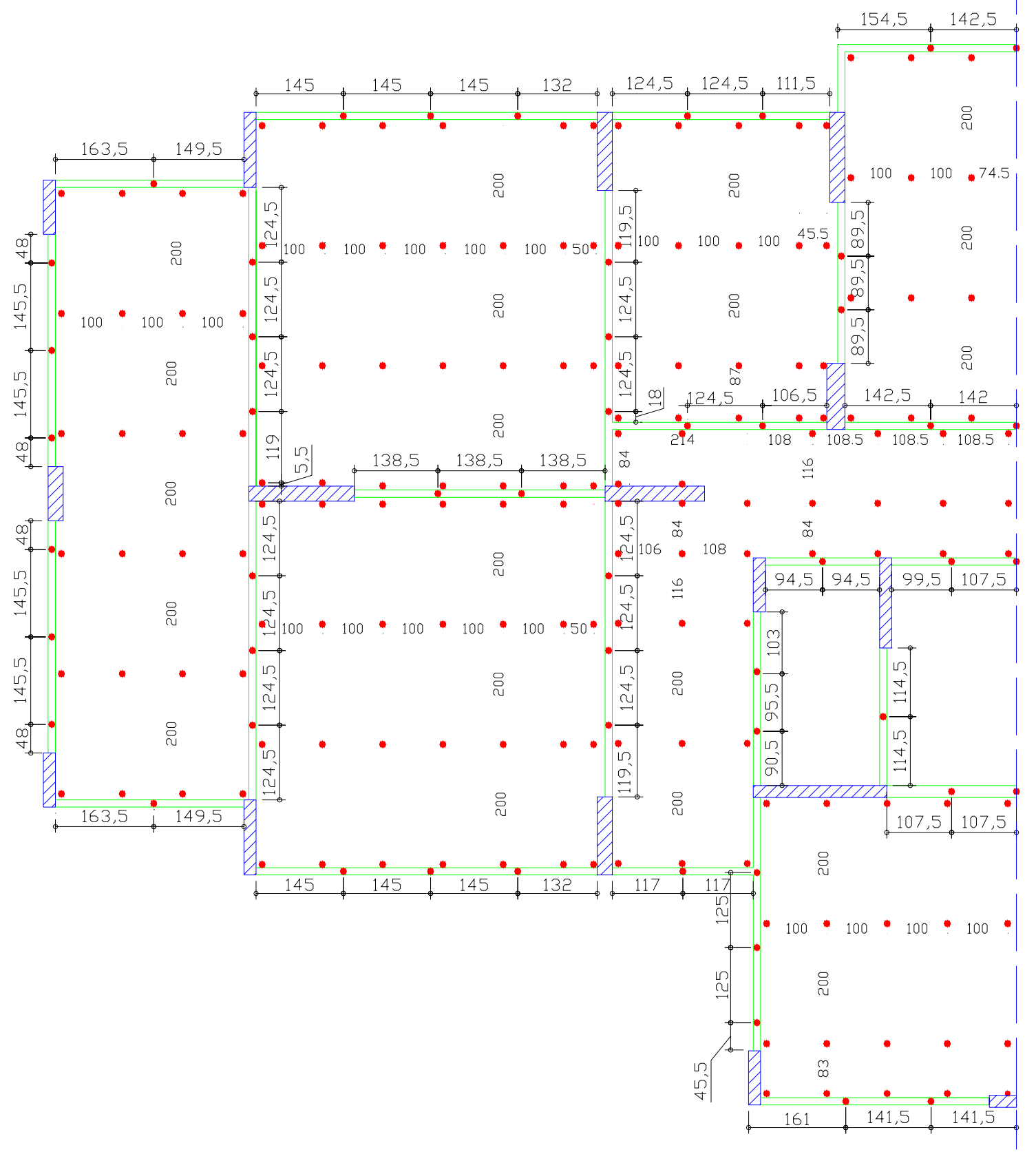

Figura 6.15 - Distribuição das escoras para o processo construtivo racionalizado $(\mathrm{cm})$ - Laje/Viga/Pilar. 


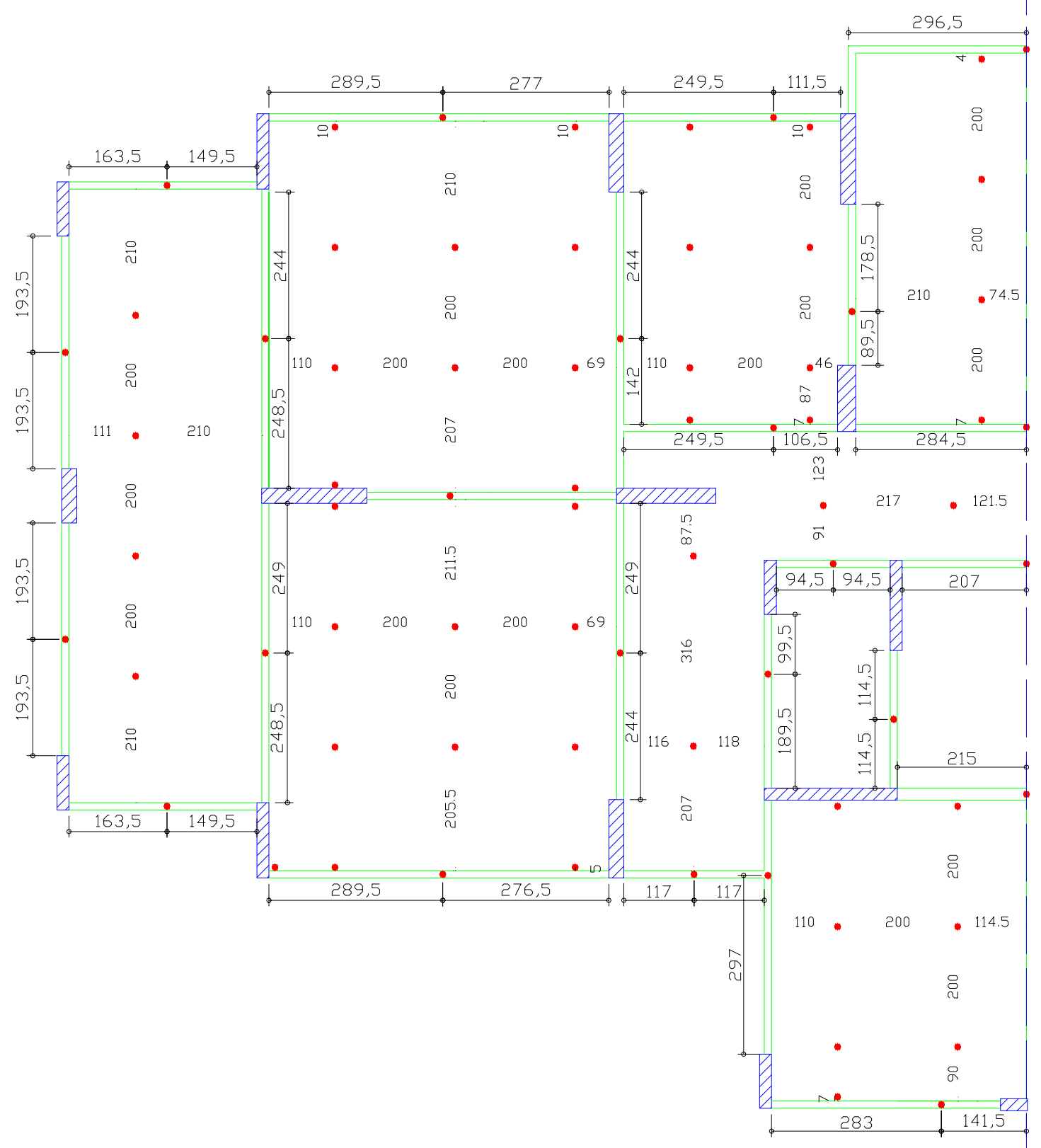

Figura 6.16 - Distribuição das reescoras com pré-carga para o processo construtivo racionalizado $(\mathrm{cm})$ - Laje/Viga/Pilar.

As tabelas 6.30 e 6.31 identificam as proporções de absorção de carga obtidas pelas modelagens das estruturas primárias. Com esses valores pode-se encontrar os fatores de carga que ocorrem no sistema temporário de apoio durante as etapas construtivas do pavimento adotado com sistema estrutural laje/viga/pilar. 
Tabela 6.30 - Proporções de absorção de carga - Laje/Viga/Pilar e $f_{c k}=20 M P a$.

\begin{tabular}{|c|c|c|c|c|}
\hline \multirow{2}{*}{$\begin{array}{l}\text { Processo } \\
\text { Construtivo }\end{array}$} & \multirow{2}{*}{$\begin{array}{c}\text { Material } \\
\text { das } \\
\text { Escoras }\end{array}$} & \multirow{2}{*}{$\begin{array}{c}\text { Estrutura } \\
\text { Primária }\end{array}$} & \multicolumn{2}{|c|}{$\begin{array}{c}\text { Proporção de Absorção } \\
\text { de Carga (\%) }\end{array}$} \\
\hline & & & Escoras & Pavimento \\
\hline \multirow{6}{*}{ Convencional } & \multirow{3}{*}{ Madeira } & EP1 & 44 & 56 \\
\hline & & EP2 & 25 & 75 \\
\hline & & EP3 & 28 & 72 \\
\hline & \multirow{3}{*}{ Aço } & EP1 & 56 & 44 \\
\hline & & EP2 & 30 & 70 \\
\hline & & EP3 & 33 & 67 \\
\hline \multirow{5}{*}{ Racionalizado } & \multirow{5}{*}{ Aço } & EP1 & 68 & 32 \\
\hline & & EP2 & 33 & 67 \\
\hline & & EP3 & 41 & 59 \\
\hline & & EP4 & 50 & 50 \\
\hline & & EP5 & 31 & 69 \\
\hline
\end{tabular}

Tabela 6.31 - Proporções de absorção de carga - Laje/Viga/Pilar e $f_{c k}=30 M P a$

\begin{tabular}{|c|c|c|c|c|}
\hline \multirow{2}{*}{$\begin{array}{l}\text { Processo } \\
\text { construtivo }\end{array}$} & \multirow{2}{*}{$\begin{array}{c}\text { Material } \\
\text { das } \\
\text { escoras }\end{array}$} & \multirow{2}{*}{$\begin{array}{c}\text { Estrutura } \\
\text { primária }\end{array}$} & \multicolumn{2}{|c|}{$\begin{array}{c}\text { Proporção de Absorção de } \\
\text { carga (\%) }\end{array}$} \\
\hline & & & Escoras & Pavimento \\
\hline \multirow{3}{*}{ Convencional } & \multirow{3}{*}{ Madeira } & EP1 & 41 & 59 \\
\hline & & EP2 & 24 & 76 \\
\hline & & EP3 & 26 & 74 \\
\hline \multirow{5}{*}{ Racionalizado } & \multirow{5}{*}{ Aço } & EP1 & 65 & 35 \\
\hline & & EP2 & 32 & 68 \\
\hline & & EP3 & 39 & 61 \\
\hline & & EP4 & 47 & 53 \\
\hline & & EP5 & 29 & 71 \\
\hline
\end{tabular}

Para as verificações de segurança e deformação excessiva são considerados os pontos mostrados na figura 6.17 . 


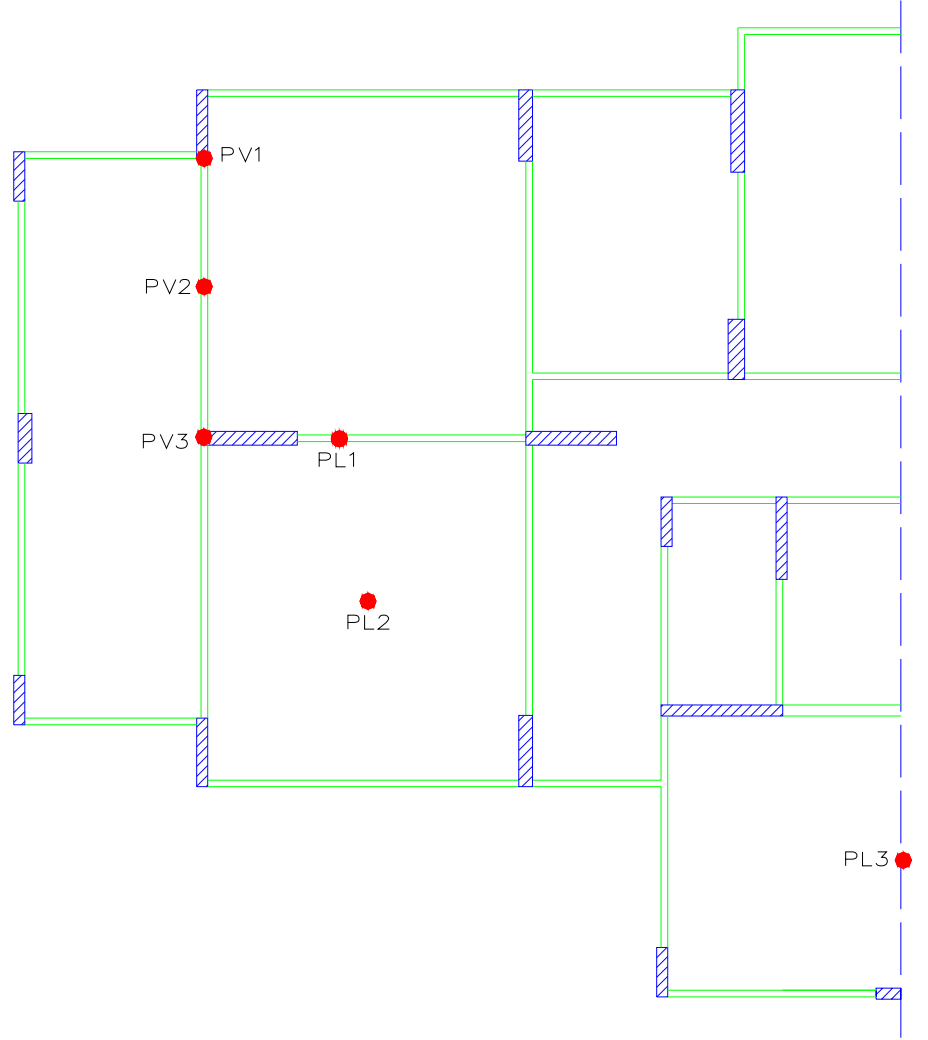

Figura 6.17 - Pontos do pavimento para verificação da segurança e da deformação excessiva - Laje/Viga/Pilar.

\subsubsection{VERIFICAÇÃO DO ESTADO LIMITE ÚLTIMO}

6.4.2.1 Pontos de laje (PL1 e PL3) e $f_{c k}=20 M P a$.

As armaduras longitudinais existentes $\left(A_{s e}\right)$ nos pontos PL1 e PL3 na situação usual de projeto podem ser vistas na tabela 6.32.

Tabela 6.32 - $A_{\text {se }}$ para pontos de laje - Laje/Viga/Pilar e $f_{c k}=20 M P a$.

\begin{tabular}{cc}
\hline \multicolumn{2}{c}{$\mathbf{A}_{\text {se }}\left(\mathrm{cm}^{2} / \mathrm{m}\right)$} \\
\hline PL1 & PL3 \\
\hline 6,19 & 3,58 \\
\hline
\end{tabular}

A tabela 6.33 identifica as armaduras longitudinais necessárias $\left(A_{\mathrm{sn}}\right)$ na situação construtiva de projeto. 
Tabela $6.33-\mathrm{A}_{\mathrm{sn}}$ para pontos de laje - Laje/Viga/Pilar e $\mathrm{f}_{\mathrm{ck}}=20 \mathrm{MPa}$.

\begin{tabular}{|c|c|c|c|c|c|c|c|c|c|}
\hline \multirow{2}{*}{$\begin{array}{l}\text { Sist. } \\
\text { Temp. }\end{array}$} & \multirow{2}{*}{$\begin{array}{l}\text { Proc. } \\
\text { Cons. }\end{array}$} & \multirow{2}{*}{ Mate. } & \multirow{2}{*}{$\begin{array}{l}\text { Ciclo } \\
\text { Cons. }\end{array}$} & \multirow{2}{*}{ k } & \multirow{2}{*}{$\begin{array}{l}\text { Idade } \\
\text { (dias) }\end{array}$} & \multicolumn{2}{|c|}{$A_{s n}\left(\mathrm{~cm}^{2} / \mathrm{m}\right)$} & \multirow{2}{*}{ Pav. } & \multirow{2}{*}{$\begin{array}{l}\text { Con } \\
\text { Pav. }\end{array}$} \\
\hline & & & & & & PL1 & PL3 & & \\
\hline \multirow{4}{*}{$(2+1)$} & \multirow{2}{*}{ Conv. } & Mad. & 7 & 1,57 & 7 & 2,38 & 1,71 & 4 & 5 \\
\hline & & Aço & 3 & 1,68 & 3 & 2,61 & 1,86 & 4 & 5 \\
\hline & \multirow{2}{*}{ Rac. } & Aço & 7 & 1,83 & 21 & 2,76 & 1,99 & 1 & 4 \\
\hline & & Aço & 3 & 1,83 & 9 & 2,78 & 2,00 & 1 & 4 \\
\hline \multirow{2}{*}{$(1+1)$} & Conv. & Aço & 3 & 1,87 & 3 & 2,92 & 2,08 & 2 & 3 \\
\hline & Rac. & Aço & 3 & 1,91 & 3 & 3,00 & 2,13 & 3 & 4 \\
\hline
\end{tabular}

A situação crítica corresponde ao sistema temporário de apoio (1+1), processo construtivo racionalizado, utilizando escoras/reescoras de aço e ciclo de construção de 3 dias. Essa situação ocorre no terceiro pavimento durante a concretagem do quarto piso. A tabela 6.34 mostra a porcentagem a que corresponde a armadura necessária da armadura existente para a situação crítica.

Tabela 6.34 - Comparação entre armaduras - Laje/Viga/Pilar e $f_{c k}=20 M P a$.

\begin{tabular}{cccc}
\hline Ponto & $\mathbf{A}_{\mathbf{s e}}\left(\mathbf{c m}^{2} / \mathbf{m}\right)$ & $\mathbf{A}_{\text {sn }}\left(\mathbf{c m}^{2} / \mathbf{m}\right)$ & $\begin{array}{c}\mathbf{A}_{\text {sn }} / \mathbf{A}_{\text {se }} \\
(\%)\end{array}$ \\
\hline PL1 & 6,19 & 3,00 & 48 \\
\hline PL3 & 3,58 & 2,13 & 59 \\
\hline
\end{tabular}

Como as armaduras necessárias da situação crítica estão abaixo das existentes conclui-se que nenhum perigo à segurança estrutural é oferecido.

\subsubsection{Pontos de laje (PL1 e PL3) e $f_{c k}=30 M P a$.}

As armaduras longitudinais existentes da situação usual de projeto para a resistência característica do concreto de 30MPa são apresentadas na tabela 6.35.

Tabela 6.35 - $A_{\text {se }}$ para pontos de laje - Laje/Viga/Pilar e $f_{c k}=30 M P a$.

\begin{tabular}{cc}
\hline \multicolumn{2}{c}{$\mathbf{A}_{\text {se }}\left(\mathbf{c m}^{2} / \mathbf{m}\right)$} \\
\hline PL1 & PL3 \\
\hline 5,93 & 3,50 \\
\hline
\end{tabular}

Na tabela 6.36 verificam-se as armaduras necessárias na situação construtiva de projeto. 
Tabela 6.36 - $A_{s n}$ para pontos de laje - Laje/Viga/Pilar e $\mathrm{f}_{\mathrm{ck}}=30 \mathrm{MPa}$.

\begin{tabular}{|c|c|c|c|c|c|c|c|c|c|}
\hline \multirow{2}{*}{$\begin{array}{l}\text { Sist. } \\
\text { Temp. }\end{array}$} & \multirow{2}{*}{$\begin{array}{l}\text { Proc. } \\
\text { Cons. }\end{array}$} & \multirow{2}{*}{ Mate. } & \multirow{2}{*}{$\begin{array}{l}\text { Ciclo } \\
\text { Cons. }\end{array}$} & \multirow{2}{*}{ k } & \multirow{2}{*}{$\begin{array}{l}\text { Idade } \\
\text { (dias) }\end{array}$} & \multicolumn{2}{|c|}{$A_{s n}\left(\mathrm{~cm}^{2} / \mathrm{m}\right)$} & \multirow{2}{*}{ Pav. } & \multirow{2}{*}{$\begin{array}{l}\text { Con. } \\
\text { Pav. }\end{array}$} \\
\hline & & & & & & PL1 & PL3 & & \\
\hline \multirow{2}{*}{$(2+1)$} & Conv. & Mad. & 28 & 1,53 & 28 & 2,26 & 1,64 & 4 & 5 \\
\hline & Rac. & Aço & 28 & 1,78 & 84 & 2,68 & 1,94 & 1 & 4 \\
\hline
\end{tabular}

Para $\circ \mathrm{f}_{\mathrm{ck}}=30 \mathrm{MPa}$, sistema temporário de apoio $(2+1)$ e ciclo de 28 dias a situação crítica corresponde ao processo construtivo racionalizado. Essa situação ocorre no primeiro pavimento durante a concretagem do quarto piso. A tabela 6.37 mostra a porcentagem a que corresponde a armadura necessária da armadura existente para a situação crítica.

Tabela 6.37 - Comparação entre armaduras - Laje/Viga/Pilar e $\mathrm{f}_{\mathrm{ck}}=30 \mathrm{MPa}$.

\begin{tabular}{cccc}
\hline Ponto & $\begin{array}{c}\mathbf{A}_{\text {se }} \\
\left(\mathbf{c m}^{2} / \mathbf{m}\right)\end{array}$ & $\begin{array}{c}\mathbf{A}_{\text {sn }} \\
\left(\mathbf{c m}^{2} / \mathbf{m}\right)\end{array}$ & $\begin{array}{c}\mathbf{A}_{\text {sn }} / \mathbf{A}_{\text {se }} \\
(\mathbf{\%})\end{array}$ \\
\hline PL1 & 5,93 & 2,68 & 45 \\
\hline PL3 & 3,50 & 1,94 & 55 \\
\hline
\end{tabular}

As armaduras da situação crítica para $\mathrm{f}_{\mathrm{ck}}=30 \mathrm{MPa}$ são menores do que as armaduras da situação crítica para $\mathrm{f}_{\mathrm{ck}}=20 \mathrm{MPa}$, como esperado.

6.4.2.3 Pontos de viga (PV1, PV2 e PV3) e $f_{c k}=20 M P a$.

Para essa análise considera-se a viga com os maiores momentos fletores (positivo e negativo) e maiores forças cortantes. Essa viga é a V12: 12x60 (tramo 2).

As armaduras longitudinais $\left(A_{s e}\right)$ e transversais $\left(A_{\text {swe }}\right)$ existentes na situação usual de projeto para os pontos da viga podem ser vistos na tabela 6.38.

Tabela 6.38 - $A_{\text {se }}$ e $A_{\text {swe }}$ para pontos de viga - Laje/Viga/Pilar e $f_{c k}=20 M P a$.

\begin{tabular}{ccc}
\hline \multicolumn{2}{c}{$\mathbf{A}_{\text {se }}\left(\mathrm{cm}^{2}\right)$} & $\mathbf{A}_{\text {swe }}\left(\mathbf{c m}^{2} / \mathbf{m}\right)$ \\
\cline { 1 - 2 } PV2 & PV3 & PV1 \\
\hline 2,27 & 4,69 & 4,31 \\
\hline
\end{tabular}

A tabela 6.39 mostra as armaduras longitudinais e transversais necessárias na situação construtiva de projeto. 
Tabela 6.39 - $A_{s n}$ e $A_{s w n}$ para pontos de viga - Laje/Viga/Pilar e $f_{c k}=20 M P a$.

\begin{tabular}{|c|c|c|c|c|c|c|c|c|c|c|}
\hline \multirow{2}{*}{$\begin{array}{l}\text { Sist. } \\
\text { Temp. }\end{array}$} & \multirow{2}{*}{$\begin{array}{l}\text { Proc. } \\
\text { Cons. }\end{array}$} & \multirow[t]{2}{*}{ Mate. } & \multirow{2}{*}{$\begin{array}{l}\text { Ciclo } \\
\text { Cons. }\end{array}$} & \multirow[t]{2}{*}{ k } & \multirow{2}{*}{$\begin{array}{l}\text { Idade } \\
\text { (dias) }\end{array}$} & \multicolumn{2}{|c|}{$\begin{array}{c}A_{\mathrm{sn}} \\
\left(\mathrm{cm}^{2}\right)\end{array}$} & \multirow{2}{*}{$\frac{\begin{array}{c}A_{\text {swn }} \\
\left(\mathrm{cm}^{2} / \mathrm{m}\right)\end{array}}{\mathrm{PV} 1}$} & \multirow[t]{2}{*}{ Pav. } & \multirow{2}{*}{$\begin{array}{l}\text { Con } \\
\text { Pav. }\end{array}$} \\
\hline & & & & & & PV2 & PV3 & & & \\
\hline \multirow{4}{*}{$(2+1)$} & \multirow{2}{*}{ Conv. } & Mad. & 7 & 1,57 & 7 & 0,91 & 1,61 & 1,06 & 4 & 5 \\
\hline & & Aço & 3 & 1,68 & 3 & 0,99 & 1,76 & 1,06 & 4 & 5 \\
\hline & \multirow{2}{*}{ Rac. } & Aço & 7 & 1,83 & 21 & 1,06 & 1,87 & 1,06 & 1 & 4 \\
\hline & & Aço & 3 & 1,83 & 9 & 1,06 & 1,89 & 1,12 & 1 & 4 \\
\hline \multirow{2}{*}{$(1+1)$} & Conv. & Aço & 3 & 1,87 & 3 & 1,10 & 1,98 & 1,59 & 2 & 3 \\
\hline & Rac. & Aço & 3 & 1,91 & 3 & 1,12 & 2,02 & 1,67 & 3 & 4 \\
\hline
\end{tabular}

A situação crítica corresponde ao sistema temporário de apoio (1+1) com processo construtivo racionalizado utilizando escoras/reescoras de aço e ciclo de construção de 3 dias. Essa situação ocorre no terceiro pavimento durante a concretagem do quarto piso. Os valores de $A_{\text {swn }}=1,06 \mathrm{~cm}^{2} / \mathrm{m}$ correspondem à armadura mínima. As tabelas 6.40 e 6.41 permitem a comparação respectivamente entre armaduras longitudinais e transversais (existentes e necessárias) para a situação crítica.

Tabela 6.40 - Comparação entre armaduras longitudinais - Laje/Viga/Pilar e $\mathrm{f}_{\mathrm{ck}}=20 \mathrm{MPa}$.

\begin{tabular}{cccc}
\hline Ponto & $\begin{array}{c}\mathbf{A}_{\text {se }} \\
\left(\mathbf{c m}^{2}\right)\end{array}$ & $\begin{array}{c}\mathbf{A}_{\text {sn }} \\
\left(\mathbf{c m}^{2}\right)\end{array}$ & $\begin{array}{c}\mathbf{A}_{\text {sn }} / \mathbf{A}_{\text {se }} \\
(\mathbf{\%})\end{array}$ \\
\hline PV2 & 2,27 & 1,12 & 49 \\
\hline PV3 & 4,69 & 2,02 & 43 \\
\hline
\end{tabular}

Tabela 6.41 - Comparação entre armaduras transversais - Laje/Viga/Pilar e $\mathrm{f}_{\mathrm{ck}}=20 \mathrm{MPa}$.

\begin{tabular}{cccc}
\hline Ponto & $\begin{array}{c}\mathbf{A}_{\text {swe }} \\
\left(\mathbf{c m}^{2} / \mathbf{m}\right)\end{array}$ & $\begin{array}{c}\mathbf{A}_{\text {swn }} \\
\left(\mathbf{c m}^{2} / \mathbf{m}\right)\end{array}$ & $\begin{array}{c}\mathbf{A}_{\text {swn }} / \mathbf{A}_{\text {swe }} \\
(\%)\end{array}$ \\
\hline PV1 & 4,31 & 1,67 & 39 \\
\hline
\end{tabular}

Para ambas análises as armaduras necessárias são menores que as existentes, garantindo a segurança estrutural durante as etapas construtivas.

6.4.2.4 Pontos de viga (PV1, PV2 e PV3) e $f_{c k}=30 M P a$.

As armaduras existentes na situação usual de projeto para a resistência 
característica do concreto de 30MPa são mostradas na tabela 6.42.

Tabela 6.42 - $A_{\text {se }}$ e $A_{\text {swe }}$ para pontos de viga - Laje/Viga/Pilar e $\mathrm{f}_{\mathrm{ck}}=30 \mathrm{MPa}$.

\begin{tabular}{ccc}
\hline \multicolumn{2}{c}{$\mathbf{A}_{\text {se }}\left(\mathrm{cm}^{2}\right)$} & $\mathbf{A}_{\text {swe }}\left(\mathrm{cm}^{2} / \mathbf{m}\right)$ \\
\cline { 1 - 1 } $\mathbf{P V 2}$ & $\mathbf{P V 3}$ & $\mathbf{P V 1}$ \\
\hline 2,22 & 4,47 & 3,68 \\
\hline
\end{tabular}

A tabela 6.43 mostra as armaduras longitudinais e transversais necessárias na situação construtiva de projeto para os pontos considerados.

Tabela 6.43 - $A_{s n}$ e $A_{s w n}$ para pontos de viga - Laje/Viga/Pilar e $f_{c k}=30 M P a$.

\begin{tabular}{|c|c|c|c|c|c|c|c|c|c|c|}
\hline \multirow{2}{*}{$\begin{array}{c}\text { Sist. } \\
\text { Temp. }\end{array}$} & \multirow[t]{2}{*}{$\begin{array}{l}\text { Proc. } \\
\text { Cons. }\end{array}$} & \multirow[t]{2}{*}{ Mate. } & \multirow[t]{2}{*}{$\begin{array}{l}\text { Ciclo } \\
\text { Cons. }\end{array}$} & \multirow[t]{2}{*}{ k } & \multirow[t]{2}{*}{$\begin{array}{l}\text { Idade } \\
\text { (dias) }\end{array}$} & \multicolumn{2}{|c|}{$\begin{array}{c}A_{\mathrm{sn}} \\
\left(\mathrm{cm}^{2}\right)\end{array}$} & \multirow{2}{*}{$\frac{\begin{array}{c}A_{\text {swn }} \\
\left(\mathrm{cm}^{2} / \mathrm{m}\right)\end{array}}{\text { PV1 }}$} & \multirow[t]{2}{*}{ Pav. } & \multirow{2}{*}{$\begin{array}{l}\text { Con. } \\
\text { Pav. }\end{array}$} \\
\hline & & & & & & PV2 & PV3 & & & \\
\hline \multirow{2}{*}{$(2+1)$} & Conv. & Mad & 28 & 1,53 & 28 & 0,88 & 1,54 & 1,39 & 4 & 5 \\
\hline & Rac. & Aço & 28 & 1,78 & 84 & 1,03 & 1,82 & 1,39 & 1 & 4 \\
\hline
\end{tabular}

Para o $\mathrm{f}_{\mathrm{ck}}=30 \mathrm{MPa}$, sistema temporário de apoio $(2+1)$ e ciclo de construção de 28 dias a situação crítica corresponde ao processo construtivo racionalizado utilizando escoras e reescoras de aço. Essa situação ocorre no primeiro pavimento durante a concretagem do quarto piso. Os valores de $A_{s w n}=1,39 \mathrm{~cm}^{2} / \mathrm{m}$ correspondem à armadura mínima. As tabelas 6.44 e 6.45 permitem a comparação respectivamente entre armaduras longitudinais e transversais (existentes e necessárias) para a situação crítica.

Tabela 6.44 - Comparação entre armaduras longitudinais - Laje/Viga/Pilar e $\mathrm{f}_{\mathrm{ck}}=30 \mathrm{MPa}$.

\begin{tabular}{cccc}
\hline Ponto & $\begin{array}{c}\mathbf{A}_{\text {se }} \\
\left(\mathbf{c m}^{2}\right)\end{array}$ & $\begin{array}{c}\mathbf{A}_{\text {sn }} \\
\left(\mathbf{c m}^{2}\right)\end{array}$ & $\begin{array}{c}\mathbf{A}_{\text {sn }} / \mathbf{A}_{\text {se }} \\
(\mathbf{\%})\end{array}$ \\
\hline PV2 & 2,22 & 1,03 & 46 \\
\hline PV3 & 4,47 & 1,82 & 41 \\
\hline
\end{tabular}

Tabela 6.45 - Comparação entre armaduras transversais - Laje/Viga/Pilar e $\mathrm{f}_{\mathrm{ck}}=30 \mathrm{MPa}$.

\begin{tabular}{cccc}
\hline Ponto & $\begin{array}{c}\mathbf{A}_{\text {swe }} \\
\left(\mathbf{c m}^{2} / \mathbf{m}\right)\end{array}$ & $\begin{array}{c}\mathbf{A}_{\text {swn }} \\
\left(\mathbf{c m}^{2} / \mathbf{m}\right)\end{array}$ & $\begin{array}{c}\mathbf{A}_{\text {swn }} / \mathbf{A}_{\text {swe }} \\
(\%)\end{array}$ \\
\hline PV1 & 3,68 & 1,39 & 38 \\
\hline
\end{tabular}


Para as situações construtivas com $\mathrm{f}_{\mathrm{ck}}=30 \mathrm{MPa}$ as armaduras necessárias longitudinais e transversais também são menores que as existentes, garantindo a segurança estrutural durante as etapas construtivas.

Foi feita a verificação à ruína das diagonais comprimidas de concreto no ponto PV1 e notou-se que, tanto na situação usual de projeto quanto na situação construtiva de projeto a força cortante solicitante de cálculo $\left(\mathrm{V}_{\mathrm{Sd}}\right)$ esteve a baixo da força cortante resistente de cálculo $\left(\mathrm{V}_{\mathrm{Rd} 2}\right)$, garantindo a segurança estrutural contra o esgotamento da capacideada resistente.

\subsubsection{VERIFICAÇÃO DO ESTADO LIMITE DE SERVIÇO}

\subsubsection{Deslocamento limite total para o ponto PL2.}

Este ponto é o menos solicitado por flexão entre os dois escolhidos de laje para essa análise. A tabela 6.46 apresenta o vão L entre apoios (vigas V12 e V13) e os limites normalizados para os deslocamentos em análise.

Tabela 6.46 - Deslocamento limite total no ponto PL2 - Laje/Viga/Pilar.

\begin{tabular}{cccc}
\hline $\mathbf{L}$ & $\mathbf{L} / 250$ & $\mathbf{L} / 350$ & $\Delta_{\mathbf{t}}$ \\
$(\mathbf{c m})$ & $(\mathbf{c m})$ & $(\mathbf{c m})$ & $\mathbf{( c m )}$ \\
\hline 591 & 2,36 & 1,69 & 4,00 \\
\hline
\end{tabular}

6.4.3.2 Ponto de laje (PL2) e $f_{c k}=20 M P a$

Os valores dos deslocamentos na situação usual de projeto são mostrados na tabela 6.47 .

Tabela 6.47 - Deslocamento usual no ponto PL2 - Laje/Viga/Pilar e $\mathrm{f}_{\mathrm{ck}}=20 \mathrm{MPa}$

\begin{tabular}{cccccc}
\hline $\begin{array}{c}\Delta_{\mathbf{e}} \\
\mathbf{( c m})\end{array}$ & $\mathbf{I g} / \mathbf{I e}$ & $\begin{array}{c}\Delta_{\mathbf{i}} \\
(\mathbf{c m})\end{array}$ & $\begin{array}{c}\Delta_{\mathbf{l}} \\
(\mathbf{c m})\end{array}$ & $\begin{array}{c}\Delta_{\mathbf{r}} \\
(\mathbf{c m})\end{array}$ & $\begin{array}{c}\Delta_{\mathbf{u}} \\
(\mathbf{c m})\end{array}$ \\
\hline 0,55 & 1,01 & 0,56 & 1,21 & 0,55 & 2,32 \\
\hline
\end{tabular}

A tabela 6.48 apresenta os deslocamentos finais do ponto PL2 na situação construtiva de projeto. 
Tabela 6.48 - Deslocamentos finais no ponto PL2 - Laje/Viga/Pilar e $\mathrm{f}_{\mathrm{ck}}=20 \mathrm{MPa}$.

\begin{tabular}{|c|c|c|c|c|c|c|c|c|c|c|}
\hline $\begin{array}{l}\text { Sist. } \\
\text { Temp. }\end{array}$ & $\begin{array}{l}\text { Proc. } \\
\text { Cons. }\end{array}$ & Mate. & $\begin{array}{l}\text { Ciclo } \\
\text { Cons. }\end{array}$ & $\begin{array}{c}\Delta_{e} \\
(\mathbf{c m})\end{array}$ & Ig/Ie & $\begin{array}{c}\Delta_{\mathrm{i}} \\
(\mathrm{cm})\end{array}$ & $\begin{array}{c}\Delta_{l} \\
(\mathbf{c m})\end{array}$ & $\begin{array}{c}\Delta_{\mathrm{r}} \\
(\mathbf{c m})\end{array}$ & $\begin{array}{c}\Delta_{\mathrm{f}} \\
(\mathbf{c m})\end{array}$ & Pav. \\
\hline \multirow{4}{*}{$(2+1)$} & \multirow{2}{*}{ Conv. } & Mad & 7 & 0,55 & 1,01 & 0,56 & 0,51 & 0,55 & 1,62 & 2 \\
\hline & & Aço & 3 & 0,55 & 1,01 & 0,56 & 0,51 & 0,55 & 1,62 & 2 \\
\hline & \multirow{2}{*}{ Rac. } & Aço & 7 & 0,55 & 1,01 & 0,56 & 0,51 & 0,55 & 1,62 & 1 \\
\hline & & Aço & 3 & 0,55 & 1,01 & 0,56 & 0,51 & 0,55 & 1,62 & 1 \\
\hline \multirow{2}{*}{$(1+1)$} & Conv. & Aço & 3 & 0,55 & 1,01 & 0,56 & 0,51 & 0,55 & 1,62 & 1 \\
\hline & Rac. & Aço & 3 & 0,55 & 1,01 & 0,56 & 0,51 & 0,55 & 1,62 & 1 \\
\hline
\end{tabular}

Pela comparação dos resultados dos deslocamentos finais com 0 deslocamento limite L/250 nota-se que não é necessário utilizar contra-flecha. A perda de rigidez por fissuração nas situações construtivas é pequena, como mostra a relação $\mathrm{Ig} / \mathrm{Ie}=1,01$. Esse valor é baixo porque a laje fissura apenas na entrada em serviço (365 dias), ou seja, as etapas construtivas não introduzem esforços capazes de superar o momento de fissuração considerado. Essa situação faz com que a relação que representa a perda de rigidez $(\mathrm{Ig} / \mathrm{Ie})$ seja igual tanto para a situação usual de projeto como para a situação construtiva.

O deslocamento usual corresponde a $58 \%$ do deslocamento limite total. Já os deslocamentos finais corresponderam a $40 \%$ desse mesmo valor. Esses valores garantem a verificação do estado limite de serviço relacionada às deformações excessivas.

\subsubsection{Ponto de laje (PL2) e $f_{c k}=30 M P a$.}

Para a resistência característica de $30 \mathrm{MPa}$ os valores de deslocamentos na situação usual de projeto são mostrados na tabela 6.49 .

Tabela 6.49 - Deslocamento usual no ponto PL2 - Laje/Viga/Pilar e $\mathrm{f}_{\mathrm{ck}}=30 \mathrm{MPa}$.

\begin{tabular}{cccccc}
\hline $\begin{array}{c}\Delta_{\mathbf{e}} \\
(\mathbf{c m})\end{array}$ & $\mathbf{I g} / \mathbf{I e}$ & $\begin{array}{c}\Delta_{\mathrm{i}} \\
(\mathbf{c m})\end{array}$ & $\begin{array}{c}\Delta_{\mathrm{l}} \\
(\mathbf{c m})\end{array}$ & $\begin{array}{c}\Delta_{\mathrm{r}} \\
(\mathbf{c m})\end{array}$ & $\begin{array}{c}\Delta_{\mathrm{u}} \\
(\mathbf{c m})\end{array}$ \\
\hline 0.45 & 1.00 & 0.45 & 0.97 & 0.55 & 1.97 \\
\hline
\end{tabular}

A tabela 6.50 apresenta os deslocamentos finais do ponto PL2 na situação construtiva de projeto. 
Tabela 6.50 - Deslocamentos finais no ponto PL2 - Laje/Viga/Pilar e $\mathrm{f}_{\mathrm{ck}}=30 \mathrm{MPa}$.

\begin{tabular}{|c|c|c|c|c|c|c|c|c|c|c|}
\hline $\begin{array}{l}\text { Sist. } \\
\text { Temp. }\end{array}$ & $\begin{array}{l}\text { Proc. } \\
\text { Cons. }\end{array}$ & Mate. & $\begin{array}{l}\text { Ciclo } \\
\text { Cons. }\end{array}$ & $\begin{array}{c}\Delta_{\mathrm{e}} \\
(\mathbf{c m})\end{array}$ & Ig/Ie & $\begin{array}{c}\Delta_{\mathrm{i}} \\
(\mathrm{cm})\end{array}$ & $\begin{array}{c}\Delta_{\mathrm{l}} \\
(\mathrm{cm})\end{array}$ & $\begin{array}{c}\Delta_{\mathrm{r}} \\
(\mathbf{c m})\end{array}$ & $\begin{array}{c}\Delta_{\mathrm{f}} \\
(\mathrm{cm})\end{array}$ & Pav. \\
\hline \multirow{2}{*}{$(2+1)$} & Conv. & Mad. & 28 & 0,45 & 1,00 & 0,45 & 0,41 & 0,55 & 1,42 & 2 \\
\hline & Rac. & Aço & 28 & 0,45 & 1,00 & 0,45 & 0,41 & 0,55 & 1,42 & 2 \\
\hline
\end{tabular}

Em ambas situações de projeto (usual e construtiva) para $f_{c k}=30 \mathrm{MPa}$ não ocorre fissuração na laje considerada. Verifica-se que não é necessária a utilização de contra flecha. O deslocamento usual corresponde a $49 \%$ do deslocamento limite total, e os deslocamentos finais correspondem a $35 \%$ desse valor. Os deslocamentos da situação usual e da situação construtiva estão abaixo dos limites normalizados.

\subsubsection{Deslocamento limite total para o ponto PL3.}

Este ponto é o de maior solicitação no pavimento. A tabela 6.51 apresenta o vão L entre apoios (viga V08 e pilar P16) e os limites normalizados para os deslocamentos no ponto PL3.

Tabela 6.51 - Deslocamento limite total no ponto PL3 - Laje/Viga/Pilar.

\begin{tabular}{cccc}
\hline $\mathbf{L}$ & $\mathbf{L} / 250$ & $\mathrm{~L} / 350$ & $\Delta_{\mathrm{t}}$ \\
$(\mathbf{c m})$ & $(\mathbf{c m})$ & $(\mathbf{c m})$ & $\mathbf{( c m )}$ \\
\hline 516 & 2,06 & 1,47 & 3,53 \\
\hline
\end{tabular}

6.4.3.5 Ponto de laje (PL3) e $f_{c k}=20 M P a$.

Para o $\mathrm{f}_{\mathrm{ck}}=20 \mathrm{MPa}$, os valores de deslocamentos na situação usual de projeto são mostrados na tabela 6.52 .

Tabela 6.52 - Deslocamento usual no ponto PL3 - Laje/Viga/Pilar e $f_{c k}=20 M P a$

\begin{tabular}{cccccc}
\hline $\begin{array}{c}\Delta_{\mathbf{e}} \\
\mathbf{( c m})\end{array}$ & $\mathbf{I g} / \mathbf{I e}$ & $\begin{array}{c}\Delta_{\mathbf{i}} \\
\mathbf{( c m )}\end{array}$ & $\begin{array}{c}\Delta_{\mathbf{l}} \\
\mathbf{( c m )}\end{array}$ & $\begin{array}{c}\Delta_{\mathbf{r}} \\
(\mathbf{c m})\end{array}$ & $\begin{array}{c}\Delta_{\mathrm{u}} \\
(\mathbf{c m})\end{array}$ \\
\hline 0,57 & 1,72 & 0,98 & 2,12 & 0,58 & 3,68 \\
\hline
\end{tabular}

A tabela 6.53 mostra os deslocamentos finais do ponto PL3 considerando as etapas construtivas. 
Tabela 6.53 - Deslocamentos finais no ponto PL3 - Laje/Viga/Pilar e $\mathrm{f}_{\mathrm{ck}}=20 \mathrm{MPa}$.

\begin{tabular}{|c|c|c|c|c|c|c|c|c|c|c|}
\hline $\begin{array}{l}\text { Sist. } \\
\text { Temp. }\end{array}$ & $\begin{array}{l}\text { Proc. } \\
\text { Cons. }\end{array}$ & Mate. & $\begin{array}{l}\text { Ciclo } \\
\text { Cons. }\end{array}$ & $\begin{array}{c}\Delta_{\mathrm{e}} \\
(\mathrm{cm})\end{array}$ & Ig/Ie & $\begin{array}{c}\Delta_{\mathrm{i}} \\
(\mathbf{c m})\end{array}$ & $\begin{array}{c}\Delta_{\mathrm{l}} \\
(\mathbf{c m})\end{array}$ & $\begin{array}{c}\Delta_{\mathrm{r}} \\
(\mathbf{c m})\end{array}$ & $\begin{array}{c}\Delta_{\mathrm{f}} \\
(\mathbf{c m})\end{array}$ & Pav. \\
\hline \multirow{4}{*}{$(2+1)$} & \multirow{2}{*}{ Conv. } & Mad. & 7 & 0,57 & 1,75 & 1,00 & 0,92 & 0,58 & 2,50 & 2 \\
\hline & & Aço & 3 & 0,57 & 1,81 & 1,03 & 0,95 & 0,58 & 2,56 & 2 \\
\hline & \multirow{2}{*}{ Rac. } & Aço & 7 & 0,57 & 1,73 & 0,99 & 0,91 & 0,58 & 2,47 & 1 \\
\hline & & Aço & 3 & 0,57 & 2,21 & 1,26 & 1,16 & 0,58 & 3,00 & 1 \\
\hline \multirow{2}{*}{$(1+1)$} & Conv. & Aço & 3 & 0,57 & 1,81 & 1,03 & 0,95 & 0,58 & 2,56 & 1 \\
\hline & Rac. & Aço & 3 & 0,57 & 1,78 & 1,01 & 0,93 & 0,58 & 2,53 & 1 \\
\hline
\end{tabular}

Uma análise comum para os deslocamentos finais exibidos pela tabela 6.53 se refere ao fato de todos estarem acima do limite $L / 250$, ou seja, necessita-se de contra-flecha para compensar os deslocamentos excessivos.

A situação crítica corresponde ao sistema temporário de apoio (2+1), processo construtivo racionalizado, escoras/reescoras de aço e ciclo de construção de 3 dias. Essa situação ocorre para a história de carregamento obtida durante as etapas construtivas do primeiro pavimento. Esse pavimento fica submetido ao maior fator de carga $(k=1,63)$ durante as etapas consideradas para essa análise e ocorre durante a retirada parcial do escoramento de sustentação do segundo pavimento. $A$ etapa de retirada parcial das escoras acrescenta carga no primeiro pavimento, o que torna esta situação a de maior solicitação.

Um dos passos das análises da situação crítica é calcular o deslocamento da etapa correspondente à idade de 9 dias $(3$ ciclos) com o carregamento correspondente ao peso próprio do pavimento majorado pelo fator de carga $\mathrm{k}=1,63$. É nessa situação que se verifica o início da formação das fissuras, levando a laje a uma relação entre as inércias ( $\mathrm{Ig} / \mathrm{Ie})$ de 2,21 aos 365 dias. Dessa forma, estima-se um aumento de $221 \%$ no valor do deslocamento elástico $\left(\Delta_{\mathrm{e}}\right)$ para se encontrar o deslocamento imediato em função da perda de rigidez por fissuração.

Para a situação crítica analisada anteriormente o deslocamento é de $3,00 \mathrm{~cm}$, ou $85 \%$ do deslocamento limite total, o que satisfaz a verificação do estado limite de serviço com relação às deformações excessivas. Porém, percebe-se a necessidade da utilização de contra flecha com valor mínimo de $0,94 \mathrm{~cm}$ no ponto considerado da laje para compensar a flecha excessiva.

Outra situação construtiva interessante a analisar é a menos crítica, constituída pela seguinte situação construtiva: sistema temporário de apoio $(2+1)$, 
processo construtivo racionalizado, utilizando escoras/reescoras de aço e ciclo de construção de 7 dias, ou seja, todas as variáveis da situação crítica porém com ciclo de construção de 7 dias. Para esta situação o deslocamento final do ponto PL3 é de $2,47 \mathrm{~cm}$ (localizado também no primeiro pavimento), ou seja, $70 \%$ do deslocamento limite total. Tal situação mostra a influência de uma única variável (ciclo de construção) nos deslocamentos finais do ponto considerado. A situação menos crítica apresenta decréscimo de $17 \%$ no deslocamento final e de $22 \%$ na razão de inércias bruta/equivalente em comparação com a situação crítica.

O deslocamento usual de $3,68 \mathrm{~cm}$ é $4 \%$ superior ao deslocamento limite total, o que inviabiliza a execução do projeto como é proposto. Dessa forma, modificações devem ser efetuadas para diminuir esse deslocamento, de acordo com esta verificação. No entanto, fato interessante corresponde ao acréscimo de $22 \%$ no deslocamento da situação usual em relação ao deslocamento da situação crítica. Essa diferença a mais de deslocamento indica que a situação usual de projeto, para esse sistema construtivo, está a favor da segurança.

\subsubsection{Ponto de laje (PL3) e $f_{c k}=30 M P a$.}

Para $f_{c k}=30 M P a$, os valores de deslocamentos encontrados na situação usual de projeto são mostrados na tabela 6.54 .

Tabela 6.54 - Deslocamento usual no ponto PL3 - Laje/Viga/Pilar e $f_{c k}=30 M P a$.

\begin{tabular}{cccccc}
\hline $\begin{array}{c}\Delta_{\mathbf{e}} \\
(\mathbf{c m})\end{array}$ & $\mathbf{I g} / \mathbf{I e}$ & $\begin{array}{c}\Delta_{\mathbf{i}} \\
(\mathbf{c m})\end{array}$ & $\begin{array}{c}\Delta_{\mathbf{l}} \\
\mathbf{( c m )}\end{array}$ & $\begin{array}{c}\Delta_{\mathbf{r}} \\
(\mathbf{c m})\end{array}$ & $\begin{array}{c}\Delta_{\mathrm{u}} \\
(\mathbf{c m})\end{array}$ \\
\hline 0,47 & 1,49 & 0,70 & 1,51 & 0,58 & 2,79 \\
\hline
\end{tabular}

A tabela 6.55 exibe os deslocamentos finais do ponto PL3 considerando a situação construtiva de projeto.

Tabela 6.55 - Deslocamentos finais no ponto PL3 - Laje/Viga/Pilar e $\mathrm{f}_{\mathrm{ck}}=30 \mathrm{MPa}$.

\begin{tabular}{|c|c|c|c|c|c|c|c|c|c|c|}
\hline $\begin{array}{l}\text { Sist. } \\
\text { Temp. }\end{array}$ & $\begin{array}{l}\text { Proc. } \\
\text { Cons. }\end{array}$ & Mate. & $\begin{array}{l}\text { Ciclo } \\
\text { Cons. }\end{array}$ & $\begin{array}{c}\Delta_{e} \\
(\mathbf{c m})\end{array}$ & $\mathrm{Ig} / \mathrm{Ie}$ & $\begin{array}{c}\Delta_{\mathrm{i}} \\
(\mathbf{c m})\end{array}$ & $\begin{array}{c}\Delta_{\mathrm{l}} \\
(\mathbf{c m})\end{array}$ & $\begin{array}{c}\Delta_{\mathrm{r}} \\
(\mathbf{c m})\end{array}$ & $\begin{array}{c}\Delta_{\mathrm{f}} \\
(\mathbf{c m})\end{array}$ & Pav. \\
\hline \multirow{2}{*}{$(2+1)$} & Conv. & Mad. & 28 & 0,47 & 1,49 & 0,70 & 0,64 & 0,58 & 1,92 & 2 \\
\hline & Rac. & Aço & 28 & 0,47 & 1,49 & 0,70 & 0,64 & 0,58 & 1,92 & 2 \\
\hline
\end{tabular}

Análise comum para os deslocamentos finais de $1,92 \mathrm{~cm}$ se refere ao fato de estarem abaixo do limite $\mathrm{L} / 250$ e corresponder a $54 \%$ do deslocamento limite total. 
Assim, não se necessita da utilização de contra flecha. Para o $\mathrm{f}_{\mathrm{ck}}=30 \mathrm{MPa}$ e ciclo de 28 dias os deslocamentos finais diminuem $36 \%$ comparados à situação crítica com $\mathrm{f}_{\mathrm{ck}}=20 \mathrm{MPa}$.

Ocorre um decréscimo de $32 \%$ na relação entre os momentos de inércia (Ig/Ie) para $\mathrm{f}_{\mathrm{ck}}=30 \mathrm{MPa}$ e ciclo de 28 dias comparada com a situação crítica com $f_{c k}=20 M P a$. Dessa forma, deslocamentos excessivos que ocorriam anteriormente para a situação crítica com $\mathrm{f}_{\mathrm{ck}}=20 \mathrm{MPa}$ não ocorrem para a situação com $\mathrm{f}_{\mathrm{ck}}=30 \mathrm{MPa}$ e ciclo de 28 dias.

$\mathrm{Na}$ situação usual de projeto o deslocamento é de $2,79 \mathrm{~cm}, 79 \%$ do deslocamento limite total. Como esse valor de deslocamento está acima do deslocamento limite L/250, deve-se utilizar contra flecha mínima de $0,73 \mathrm{~cm}$. O acréscimo de deslocamento na situação usual é de $45 \%$ em relação aos deslocamentos das situações construtivas. Esta diferença a mais de deslocamento indica que a situação usual de projeto para $\mathrm{f}_{\mathrm{ck}}=30 \mathrm{MPa}$ também está a favor da segurança.

6.4.3.7 Deslocamento limite total para o ponto PV2 - Viga V12: $12 \times 60$ (tramo 2).

A viga analisada é a que apresenta os maiores esforços entre todas do pavimento. Para o ponto PV2 pode-se verificar na tabela 6.56 o vão $L$ entre apoios (pilares P02 e P07) e os limites normalizados para o deslocamento em análise.

Tabela 6.56 - Deslocamento limite total no ponto PV2 - Laje/Viga/Pilar.

\begin{tabular}{cccc}
\hline $\mathbf{L}$ & $\mathbf{L} / 250$ & $\mathbf{L} / 350$ & $\Delta_{\mathbf{t}}$ \\
$(\mathbf{c m})$ & $(\mathbf{c m})$ & $(\mathbf{c m})$ & $\mathbf{( c m )}$ \\
\hline 572 & 2,28 & 1,63 & 3,91 \\
\hline
\end{tabular}

6.4.3.8 Ponto de viga (PV2) e $f_{c k}=20 M P a$.

Os valores de deslocamentos na situação usual de projeto estão indicados na tabela 6.57 .

Tabela 6.57 - Deslocamento usual no ponto PV2 - Laje/Viga/Pilar e $\mathrm{f}_{\mathrm{ck}}=20 \mathrm{Mpa}$.

\begin{tabular}{cccccc}
\hline $\begin{array}{c}\Delta_{\mathbf{e}} \\
(\mathbf{c m})\end{array}$ & $\mathbf{I g} / \mathbf{I e}$ & $\begin{array}{c}\Delta_{\mathbf{i}} \\
(\mathbf{c m})\end{array}$ & $\begin{array}{c}\Delta_{\mathbf{l}} \\
\mathbf{( c m )}\end{array}$ & $\begin{array}{c}\Delta_{\mathbf{r}} \\
(\mathbf{c m})\end{array}$ & $\begin{array}{c}\Delta_{\mathbf{u}} \\
(\mathbf{c m})\end{array}$ \\
\hline 0,15 & 2,33 & 0,35 & 0,71 & 0,13 & 1,19 \\
\hline
\end{tabular}


A tabela 6.58 mostra os deslocamentos finais do ponto PV2 considerando-se a situação construtiva de projeto.

Tabela 6.58 - Deslocamentos finais no ponto PV2 - Laje/Viga/Pilar e $f_{c k}=20 \mathrm{MPa}$.

\begin{tabular}{|c|c|c|c|c|c|c|c|c|c|c|}
\hline $\begin{array}{l}\text { Sist. } \\
\text { Temp. }\end{array}$ & $\begin{array}{l}\text { Proc. } \\
\text { Cons. }\end{array}$ & Mate. & $\begin{array}{l}\text { Ciclo } \\
\text { Cons. }\end{array}$ & $\begin{array}{c}\Delta_{e} \\
(\mathbf{c m})\end{array}$ & Ig/Ie & $\begin{array}{c}\Delta_{\mathrm{i}} \\
(\mathbf{c m})\end{array}$ & $\begin{array}{c}\Delta_{\mathrm{l}} \\
(\mathbf{c m})\end{array}$ & $\begin{array}{c}\Delta_{\mathrm{r}} \\
(\mathbf{c m})\end{array}$ & $\begin{array}{c}\Delta_{\mathbf{f}} \\
(\mathbf{c m})\end{array}$ & Pav. \\
\hline \multirow{4}{*}{$(2+1)$} & \multirow{2}{*}{ Conv. } & Mad. & 7 & 0,15 & 2,43 & 0,36 & 0,32 & 0,13 & 0,81 & 2 \\
\hline & & Aço & 3 & 0,15 & 2,55 & 0,38 & 0,33 & 0,130 & 0,85 & 2 \\
\hline & \multirow{2}{*}{ Rac. } & Aço & 7 & 0,15 & 2,37 & 0,36 & 0,31 & 0,13 & 0,79 & 1 \\
\hline & & Aço & 3 & 0,15 & 2,48 & 0,37 & 0,32 & 0,130 & 0,83 & 1 \\
\hline \multirow{2}{*}{$(1+1)$} & Conv. & Aço & 3 & 0,15 & 2,67 & 0,40 & 0,35 & 0,130 & 0,88 & 1 \\
\hline & Rac. & Aço & 3 & 0,15 & 2,54 & 0,38 & 0,33 & 0,130 & 0,84 & 1 \\
\hline
\end{tabular}

Os deslocamentos finais da tabela 6.58 estão abaixo do limite $L / 250$, ou seja, não é necessário especificar contra-flecha para compensar deslocamentos excessivos. A situação crítica corresponde ao sistema temporário de apoio $(1+1)$ com processo construtivo convencional utilizando escoras/reescoras de aço e ciclo de construção de 3 dias. Essa situação ocorre para a história de carregamento obtida durante as etapas construtivas do primeiro pavimento.

O deslocamento da situação crítica vale $0,88 \mathrm{~cm}$, ou $22 \%$ do deslocamento limite total, o que satisfaz a verificação do estado limite de serviço com relação às deformações excessivas.

$\mathrm{Na}$ situação usual de projeto o deslocamento é de $1,19 \mathrm{~cm}, 30 \%$ do deslocamento limite total. Ocorre um acréscimo de 35\% no deslocamento usual em relação ao deslocamento da situação crítica. Esta diferença a mais de deslocamento indica que a situação usual de projeto, para este sistema construtivo, está a favor da segurança.

Observa-se que os deslocamentos tanto usual como final estão relativamente longe do valor do deslocamento limite total. Isto ocorre devido à rigidez elevada do elemento viga que conduz a deslocamentos imediatos baixos, mesmo estando submetida a um estado de fissuração elevado.

Foram verificados os deslocamentos imediatos na entrada das paredes (aos 120 dias), porém em todas as situações construtivas analisadas os valores dos deslocamentos ficaram abaixo do limite normalizado que, para o vão $L=572 \mathrm{~cm}$ e limites $\mathrm{L} / 500$ ou $10 \mathrm{~mm}$, vale $10 \mathrm{~mm}$. 
6.4.3.9 Ponto de viga (PV2) e $f_{c k}=30 M P a$.

Para $\mathrm{f}_{\mathrm{ck}}=30 \mathrm{MPa}$ o deslocamento usual é mostrado na tabela 6.59 .

Tabela 6.59 - Deslocamento usual no ponto PV2 - Laje/Viga/Pilar e $\mathrm{f}_{\mathrm{ck}}=30 \mathrm{MPa}$

\begin{tabular}{cccccc}
\hline $\begin{array}{c}\Delta_{\mathbf{e}} \\
(\mathbf{c m})\end{array}$ & $\mathbf{I g} / \mathbf{I e}$ & $\begin{array}{c}\Delta_{\mathbf{i}} \\
(\mathbf{c m})\end{array}$ & $\begin{array}{c}\Delta_{\mathbf{l}} \\
\mathbf{( c m )}\end{array}$ & $\begin{array}{c}\Delta_{\mathbf{r}} \\
(\mathbf{c m})\end{array}$ & $\begin{array}{c}\Delta_{\mathrm{u}} \\
(\mathbf{c m})\end{array}$ \\
\hline 0,12 & 2,05 & 0,25 & 0,51 & 0,13 & 0,89 \\
\hline
\end{tabular}

A tabela 6.60 indica os deslocamentos finais do ponto PV2 considerando as etapas construtivas.

Tabela 6.60 - Deslocamentos finais no ponto PV2 - Laje/Viga/Pilar e $\mathrm{f}_{\mathrm{ck}}=30 \mathrm{MPa}$.

\begin{tabular}{ccccccccccc}
\hline $\begin{array}{c}\text { Sist. } \\
\text { Temp. }\end{array}$ & $\begin{array}{l}\text { Proc. } \\
\text { Cons. }\end{array}$ & Mate. & $\begin{array}{c}\text { Ciclo } \\
\text { Cons. }\end{array}$ & $\begin{array}{c}\Delta_{\mathbf{e}} \\
(\mathbf{c m})\end{array}$ & $\mathbf{I g} / \mathbf{I e}$ & $\begin{array}{c}\Delta_{\mathbf{i}} \\
(\mathbf{c m})\end{array}$ & $\begin{array}{c}\Delta_{\mathbf{l}} \\
(\mathbf{c m})\end{array}$ & $\begin{array}{c}\Delta_{\mathbf{r}} \\
(\mathbf{c m})\end{array}$ & $\begin{array}{c}\Delta_{\mathbf{f}} \\
(\mathbf{c m})\end{array}$ & Pav. \\
\hline \multirow{2}{*}{$(2+1)$} & Conv. & Mad. & 28 & 0,12 & 2,05 & 0,25 & 0,21 & 0,130 & 0,59 & 2 \\
\cline { 2 - 11 } & Rac. & Aço & 28 & 0,12 & 2,05 & 0,25 & 0,21 & 0,13 & 0,59 & 2 \\
\hline
\end{tabular}

Os deslocamentos finais estão abaixo do limite $L / 250$ e correspondem a $15 \%$ do deslocamento limite total. Assim, não se necessita da utilização de contra flecha. Para o $f_{c k}=30 M P a$ e ciclo de 28 dias os deslocamentos finais diminuem $33 \%$ comparado à situação crítica com $\mathrm{f}_{\mathrm{ck}}=20 \mathrm{MPa}$.

Ocorre um decréscimo de $23 \%$ no valor da relação $\mathrm{Ig} / \mathrm{Ie}$ para $\mathrm{f}_{\mathrm{ck}}=30 \mathrm{MPa}$ e ciclo de 28 dias comparado com a situação crítica com $\mathrm{f}_{\mathrm{ck}}=20 \mathrm{MPa}$.

$\mathrm{Na}$ situação usual de projeto o deslocamento é de $0,89 \mathrm{~cm}, 27 \%$ do deslocamento limite total. Neste caso também não se necessita usar contra-flecha. Há um acréscimo no deslocamento usual de $51 \%$ em relação aos deslocamentos das situações construtivas. Essa diferença a mais de deslocamento indica que a situação usual de projeto para $\mathrm{f}_{\mathrm{ck}}=30 \mathrm{MPa}$ também está a favor da segurança, como esperado 


\section{CAPÍTULO 7 - CONCLUSÕES}

A partir das análises dos resultados obtidos entre a situação construtiva de projeto e a situação usual de projeto conclui-se que essa última é mais conservadora no tocante às verificações da segurança dos elementos estruturais contra o esgotamento da capacidade resistente bem como nas verificações de utilização da estrutura relacionadas às deformações excessivas em todos os casos analisados. Ou seja, a situação usual de projeto, empregada nos escritórios de cálculo, está a favor da segurança para sistemas estruturais semelhantes aos apresentados e nas mesmas situações construtivas que as adotadas.

A segurança da situação usual de projeto pode ser comprovada com as comparações entre as situações construtivas mais críticas dentre todas encontradas e a situação usual.

A situação construtiva mais crítica na verificação de segurança dos elementos estruturais é para ao sistema estrutural em laje plana com sistema temporário de apoio (1+1), processo construtivo racionalizado, escoras e reescoras de aço, ciclo de construção de 3 dias e $\mathrm{f}_{\mathrm{ck}}=20 \mathrm{MPa}$. Nessa situação, a maior taxa de armadura necessária durante as etapas construtivas corresponde a $64 \%$ da armadura existente para um ponto de laje.

A situação construtiva mais crítica na verificação das deformações excessivas é para ao sistema estrutural laje/viga/pilar com sistema temporário de apoio $(2+1)$, processo construtivo racionalizado, escoras e reescoras de aço, ciclo de construção de 3 dias e $f_{c k}=20 \mathrm{MPa}$. Nessa situação, o deslocamento final de um dos pontos da laje vale $85 \%$ do deslocamento limite total e o deslocamento usual é $4 \%$ superior a esse valor limite. E ainda, o deslocamento usual é $23 \%$ maior que o deslocamento 
final.

A verificação do estado limite último é feita para uma única situação crítica de construção. Essa situação corresponde ao sistema temporário de apoio (1+1), processo construtivo racionalizado, escoras e reescoras de aço, ciclo de construção de 3 dias e $f_{c k}=20 M P a$, com exceção do sistema estrutural laje / paredes de alvenaria para o qual não se simulou o processo construtivo racionalizado. Porém, caso tivesse sido utilizado esse processo construtivo mostraria a mesma tendência dos resultados obtidos.

O fato dos deslocamentos usuais em todas as situações serem maiores que os finais se deve principalmente ao maior intervalo de tempo em dias considerado para o cálculo dos deslocamentos por fluência $\left(\Delta_{l}\right)$ no tempo infinito. Na situação usual de projeto o intervalo é de 28 - 10000 dias e na situação construtiva os intervalos considerados são menores e correspondem, nesse trabalho, a: 28 - 120, 120 - 365 e 365 - 10000 dias.

O pavimento que apresenta a maior deformação necessária à verificação do estado limite de serviço na situação construtiva de projeto depende do maior fator de carga previsto pelo MEP na história de carregamento do mesmo. Ao examinar os resultados de deformações para os pavimentos em cada sistema estrutural e situação construtiva, notou-se que o primeiro e o segundo pavimentos são os dois únicos na situação de maior deformação necessários à verificação proposta.

Com relação à perda de rigidez por fissuração, representada pelo inverso da razão entre os momentos de inércia (Ig/Ie), nota-se que a situação usual de projeto indica o menor valor possível para essa relação para cada sistema estrutural e cada $\mathrm{f}_{\mathrm{ck}}$. Essa situação ocorre porque se considera o momento de fissuração na idade de 28 dias. Na situação construtiva de projeto os valores dos momentos de fissuração se referem às idades corretas do concreto (inferiores a 28 dias). Nos casos em que a fissuração ocorre durante as etapas construtivas, a perda de rigidez considerada no cálculo dos deslocamentos finais (situação construtiva de projeto) é sempre maior comparada á perda de rigidez dos deslocamentos usuais (situação usual de projeto). Por exemplo, para o sistema estrutural em laje plana a relação Ig/Ie vale 1,73 para uma das lajes na situação usual de projeto e 2,36 na situação construtiva crítica, ou seja, ocorre um aumento na perda de rigidez de $36 \%$ na situação construtiva comparada com a usual. Assim, nota-se a importância dessa verificação para o cálculo dos deslocamentos. 
O sistema de escoramento ligado diretamente à laje a ser concretada fica submetido ao maior fator de carga durante a etapa de concretagem, independente da situação construtiva adotada.

A segurança está garantida durante e após as etapas construtivas para os casos estudados e as análises propostas. Porém, deve-se lembrar que a existência de sistemas estruturais de diferentes tipologias e o surgimento de novas técnicas na execução das estruturas requer uma análise mais cuidadosa das ações introduzidas pelas etapas construtivas e a verificação de segurança e utilização da estrutura. É nesse contexto que o método das estruturas primárias se torna uma ferramenta muito útil para a verificação das situações críticas no projeto de edifícios de concreto armado submetidos a ações de construção. 


\section{BIBLIOGRAFIA}

ACI COMMITEE 347 (1994). Manual of Concrete Pratice - Part-2, Detroit.

ACI COMMITTEE 347 (1988). Guide to formwork for concrete, Detroit.

ACI STANDARD 347-68, Recommended Practice for Concrete Formwork. American Concrete Institute, Detroit, Michigan, 1968.

ANSI A10.9-1970, Safety Requirements for Concrete Construction and Masonry Work. American National Standards Institute, New York, New York, 1970.

ASSOCIAÇÃO BRASILEIRA DE NORMAS TÉCNICAS (1980). NBR 6120:2003 Cargas para o cálculo de estruturas de edificações. Rio de Janeiro, ABNT.

ASSOCIAÇÃO BRASILEIRA DE NORMAS TÉCNICAS (2003). NBR 8681:2003 Ações e segurança nas Estruturas - Procedimento. Rio de Janeiro, ABNT.

ASSOCIAÇÃO BRASILEIRA DE NORMAS TÉCNICAS (2003). NBR 14931:2003. Execução de estruturas de concreto - Procedimento. Rio de Janeiro, ABNT.

ASSOCIAÇÃO BRASILEIRA DE NORMAS TÉCNICAS (2003). NBR 6118:2003. Projeto de estruturas de concreto - Procedimento. Rio de Janeiro, ABNT.

BAPTISTA, M. B. (1994). Análise de pavimentos de edifícios com a utilização do método dos elementos finitos. Dissertação (Mestrado) - Escola de Engenharia de São Carlos, Universidade de São Paulo, São Carlos. 1994.

BATISTA, A. M. (1998). Fôrmas de madeira e cimbramentos metálicos: Reflexões sobre a sua aplicação. In VI EMBRAMEM - ENCONTRO BRASILEIRO EM MADEIRAS E EM ESTRUTURAS DE MADEIRA, 1998, Florianópolis, p. 387-393. 
CHEN, W. F.; MOSALLAM, K. H. (1991). Concrete Buildings: Analysis for Safe Construction, CRC Pres Inc.

CHEN, W. F; MOSALLAM, K. H (1992). Construction Load Distributions for Laterally Braced Formwork. ACI Structural Journal, v. 89, n. 4, p. 415-424, julho - agosto.

CHEN, W. F.; ROSOWSKY, D. V.; EL-SHAHHAT, A. M. (1993). Construction Safety of Multistory Concrete Buildings. ACI Structural Journal, v. 90, n. 4, p. 335-341, Julho - Agosto.

CALIL JUNIOR, C.; OKIMOTO, F.; STAMATO G. C.; PFISTER, G. (2001). SET 613 Fôrmas de madeira para concreto armado.- Laboratório de Madeiras e de Estruturas de Madeira da Escola de Engenharia de São Carlos - Universidade de São Paulo. Gráfica ESSC.

CORRÊA, M. R. S. (1991). Aperfeiçoamento de modelos usualmente empregados no projeto de sistemas estruturais de edifícios. Tese (Doutorado) - Escola de Engenharia de São Carlos, Universidade de São Paulo, São Carlos. 1991.

CORRÊA, M. R. S.; RAMALHO, M. A. (1991). Considerações sobre a evolução dos esforços solicitantes nas estruturas de concreto armado. Seminário de dosagem e controle dos concretos estruturais. ENCOL S/A, p.22-50, julho- setembro.

CORRÊA, M. R. S.; RAMALHO, M. A. (2003). Projeto de edifícios - Alvenaria estrutural; $1^{\text {a }}$ ediçã; Editora Pini; 188p. (2003).

DESABAMENTO de prédio em construção fere dois operários (2003). Jornal Hoje. Cascavel - $\quad$ Paraná, 18 jan. Disponível em: <http://www.jhoje.com.br/180103/1901.htm>. Acesso em: 10 março 2003.

DIRETRIZES PARA ELABORAÇÃO DE DISSERTAÇÕES E TESES NA EESC USP. Universidade de São Paulo. Escola de Engenharia de São Carlos. $3^{a}$. Edição, São Carlos, 2002.

DUAN, M. Z.; CHEN, W. F. (1995). Improved Simplified Method for Slab and Shore Load Analysis during Construction. Project Report CE-STR-95-24, Purdue University, West Lafayette, Ind.

EL-SHAHHAT, A. M.; CHEN W. F. (1992). Improved Analysis for Shore-Slab Interaction. ACI Structural Journal, v. 89, n. 5, p. 528-537, setembro - outubro. 
ELLIS. Escoras de madeira com altura regulável. Disponível em: <http://www.ellisok.com> Acesso em: 10 março 2003.

EPAARACHCHI, D. E.; STEWART, M. G.; ROSOWSKY, D. V. (2002). Structural Reability of Multistory Buildings During Construction. Journal of Structural Engineering. v. 128, n. 2, p. 205-212, fevereiro.

FANG, D. P.; GENG, C. D.; ZHU,H. Y.; LIU, X. L. (2001). Floor Load Distribution in Reinforced Concrete Buildings During Construction. ACl Structural Journal. v. 98, n. 2, p.149-146, março - abril.

FATTAL, S. G (1983). Evaluation of construction loads in multistory concrete building. National Institute of Standards and Tecnology. NBS Building Science Series, n. 146, $139 \mathrm{p}$.

FRANÇA, R. L. (1985). Exemplo de cálculo do esforço de segunda ordem global em um edifício de concreto armado. In: Colóquio sobre estabilidade global das estruturas de concreto armado; IBRACON, São Paulo, 1985.

GARDNER, N. J. (1985). Shoring, reshoring and safety. Concrete International, v. 7, n.4, p.28-34, abril.

GARDNER, N. J. (1989). Formwork design and construction loads. In: CSCE/ CIDA WORKSHOP, Canadá, 1989, p.1-19.

GRUNDY, P.; KABAILA, A. (1963). Construction Loads on Slabs with Shored Formwork in Multistory Buildings. ACl Journal, Proceedings Vol.60, No. 12, Dezembro, pp. 1729-1738

HADIPRIONO, F. C. (1985). Analysis of Events in Recent Structural Failures. Journal of Structural Engineering , ASCE. v. 111, n. 7, p. 1468-1481, julho.

HADIPRIONO, F. C., WANG, H.K. (1986). Analysis of causes of Falsework Failures in Concrete Structures. Journal of Engineering and Management, ASCE. v. 112, n. 1, p. 112-121, março.

LEE, H. M.; LIU, X. L.; CHEN, W. F. (1988). Analysis of Construction Loads on Slabs and Shores by Personal Computer. Concrete International Design Construction, v. 10 , n. 6, p. 21-30, junho. 
LEE, H. M.; LIU, X. L.; CHEN, W. F. (1991). Analysis of Concrete Buildings During Construction. Journal of Structural Engineering. V. 117, n. 10, p. 3135-3148, outubro.

LIU, X. L.; CHEN, W. F.; BROWMAN, M.D. (1986). Shore-Slab Interaction in Concrete Buildings. Journal of Structural Engineering and Management, ASCE, V. 112., n. 2, pp. 227-244, junho.

OLIVEIRA, R. S. (1997). Análise de pavimentos de concreto armado com a consideração da não-linearidade física. Dissertação (Mestrado) - Escola de Engenharia de São Carlos, Universidade de São Paulo, São Carlos. 1997.

PERI FÔRMAS E ESCORAMENTOS (2003). Catálogos Técnicos de Escoramentos Metálicos. Março, 2003.

PFEIL, Walter (1987). Cimbramentos. Rio de Janeiro, Livros Técnicos e Científicos, Editora S.A., 431p. (1987).

PRADO, J. F. M. A. (1995). Estruturas de edifícios em concreto armado submetidas a ações verticais e horizontais. Dissertação (Mestrado) - Escola de Engenharia de São Carlos, Universidade de São Paulo, São Carlos. 1995.

PRADO, J. F. M. A. (1999). Estruturas de edifícios em concreto armado submetidas a ações de construção. Tese (Doutorado) - Escola de Engenharia de São Carlos, Universidade de São Paulo, São Carlos. 1999.

PEURIFOY, R. L.; OBERLENDER, G. D. (1996), Formwork for Concrete Structures,

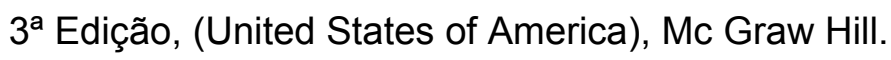

RODRIGUES JÚNIOR, S. J. (1996). Ações de construção em Lajes de Concreto Armado. Dissertação (Mestrado) - Pontifícia Universidade Católica - PUC, Rio de Janeiro. 1996

SAE INFORMÁTICA (2003). Sistemas de análise estrutural. Disponível em: < http://www.sae.eng.br >. Acesso em: 15 dezembro 2003.

SH FÔRMAS ANDAIMES E ESCORAMENTOS (2000). Catálogos Técnicos de Escoramentos Metálicos. Março, 2003.

STIVAROS, P. C.; HALVORSEN G. T. (1990). Shoring/Reshorig Operations for Multistory Buildings. ACl Structural Journal, v. 87, n. 5, p. 589-596, Setembro Outubro. 
SYMONS CORPORATION (2003). Catálogos Técnicos de Escoramentos Metálicos. Fevereiro, 2003.

VASCONCELLOS FILHO, A. (1981). Edifícios de andares múltiplos. Universidade Federal de Minas Gerais - Escola de Engenharia. Edições COTEC 06/85. 